\title{
The role of haptoglobin phenotype and 24-hour blood pressure characteristics in cerebral small vessel disease
}

Citation for published version (APA):

Staals, J. E. (2009). The role of haptoglobin phenotype and 24-hour blood pressure characteristics in cerebral small vessel disease. [Doctoral Thesis, Maastricht University]. Datawyse / Universitaire Pers Maastricht. https://doi.org/10.26481/dis.20091204js

Document status and date:

Published: 01/01/2009

DOI:

10.26481/dis.20091204js

Document Version:

Publisher's PDF, also known as Version of record

Please check the document version of this publication:

- A submitted manuscript is the version of the article upon submission and before peer-review. There can be important differences between the submitted version and the official published version of record.

People interested in the research are advised to contact the author for the final version of the publication, or visit the DOI to the publisher's website.

- The final author version and the galley proof are versions of the publication after peer review.

- The final published version features the final layout of the paper including the volume, issue and page numbers.

Link to publication

\footnotetext{
General rights rights.

- You may freely distribute the URL identifying the publication in the public portal. please follow below link for the End User Agreement:

www.umlib.nl/taverne-license

Take down policy

If you believe that this document breaches copyright please contact us at:

repository@maastrichtuniversity.nl

providing details and we will investigate your claim.
}

Copyright and moral rights for the publications made accessible in the public portal are retained by the authors and/or other copyright owners and it is a condition of accessing publications that users recognise and abide by the legal requirements associated with these

- Users may download and print one copy of any publication from the public portal for the purpose of private study or research.

- You may not further distribute the material or use it for any profit-making activity or commercial gain

If the publication is distributed under the terms of Article $25 \mathrm{fa}$ of the Dutch Copyright Act, indicated by the "Taverne" license above, 
The role of haptoglobin phenotype and 24-hour blood pressure characteristics in cerebral small vessel disease

Julie Staals 
Some of the studies in this thesis were financially supported by the 'Profileringsfonds', Maastricht UMC+.

Some of the studies in this thesis were materially supported by Boehringer Ingelheim BV.

Financial support by the Netherlands Heart Foundation and 'Stichting het Remmert Adriaan Laan Fonds' for the publication of this thesis is gratefully acknowledged.

Financial support for printing of this thesis was kindly provided by Boehringer Ingelheim BV.

(C) Julie Staals, Maastricht 2009

ISBN: 9789052788821

Cover design: Datawyse | Universitaire Pers Maastricht

Layout: Tiny Wouters

Production: Datawyse | Universitaire Pers Maastricht 


\title{
The role of haptoglobin phenotype and 24-hour blood pressure characteristics in cerebral small vessel disease
}

\author{
PROEFSCHRIFT \\ ter verkrijging van de graad van doctor \\ aan de Universiteit Maastricht, \\ op gezag van de Rector Magnificus, Prof. mr. G.P.M.F. Mols, \\ volgens het besluit van het College van Decanen, \\ in het openbaar te verdedigen \\ op vrijdag 4 december 2009 om 12.00 uur
}

door

Juliana Elisabeth Antonia Staals

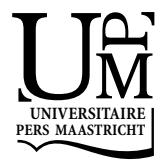




\section{Promotor}

Prof. dr. J. Lodder

Copromotor

Dr. R.J. van Oostenbrugge

\section{Beoordelingscommissie}

Prof. dr. H. ten Cate, voorzitter

Prof. dr. J.W. Cohen Tervaert

Prof. dr. P.W. de Leeuw

Dr. G.J. Luijckx, Universitair Medisch Centrum Groningen

Prof. dr. J. Wilmink 


\section{About the Cover}

The front cover illustration represents an artistic composition of inverted and enhanced radiography images of barium sulphate-injected medial and lateral lenticulostriate arteries and the recurrent artery of Heubner in the human striatum. The back cover presents part of a radiography image. These pictures of cerebral small deep perforating vessels were kindly provided by Prof. Martin D. Cassell, University of lowa, lowa City, USA.

The pictures were previously published in: J.A. Feekes and M.D. Cassell, The vascular supply of the functional compartments of the human striatum, Brain 2006;129:2189-2201. The pictures were used with permission of the authors and Oxford University Press. 



\section{Contents}

Abbreviations

Chapter 1 Introduction and outline of the thesis

Chapter 2 Differences in long-term survival in two lacunar stroke types:

a 15-year follow-up study in 782 cerebral infarct patients

Chapter 3 A SELDI-TOF-MS study in lacunar stroke with subsequent haptoglobin phenotyping

Chapter 4 Haptoglobin polymorphism and lacunar stroke

Chapter 5 Haptoglobin phenotype correlates with cerebral deep white matter lesions in hypertensive patients

Chapter 6 Are asymptomatic lacunar infarcts and white matter lesions associated with ambulatory blood pressure characteristics in lacunar stroke patients?

Chapter 7 Brain microbleeds relate to higher ambulatory blood pressure levels in first-ever lacunar stroke patients

Chapter 8 General discussion

Chapter 9 Summary / Samenvatting

Dankwoord

Publications

Curriculum vitae 



\section{Abbreviations}

\begin{tabular}{|c|c|}
\hline 1-DE & one-dimensional gel electrophoresis \\
\hline 2-DE & two-dimensional gel electrophoresis \\
\hline ABPM & ambulatory blood pressure monitoring \\
\hline aLACs & asymptomatic lacunar infarcts \\
\hline AT & atherothrombotic stroke \\
\hline BMBs & brain microbleeds \\
\hline $\mathrm{BP}$ & blood pressure \\
\hline CE & cardioembolic stroke \\
\hline $\mathrm{Cl}$ & confidence interval \\
\hline CT & computed tomography \\
\hline D & dipping \\
\hline DBP & diastolic blood pressure \\
\hline dWMLs & deep white matter lesions \\
\hline df & degrees of freedom \\
\hline E & extreme dipping \\
\hline FLAIR & fluid attenuated inversion recovery \\
\hline GE & gradient echo \\
\hline $\mathrm{Hp}$ & haptoglobin \\
\hline LAC & lacunar stroke \\
\hline $\mathrm{m} / \mathrm{z}$ & mass to charge \\
\hline MALDI-TOF-MS & $\begin{array}{l}\text { Matrix Assisted Laser Desorption / Ionization Time-Of-Flight } \\
\text { Mass Spectrometry }\end{array}$ \\
\hline MAP & mean arterial blood pressure \\
\hline MR & magnetic resonance \\
\hline MRI & magnetic resonance imaging \\
\hline MW & molecular weight \\
\hline $\mathrm{N}$ & non-dipping \\
\hline NS & not significant \\
\hline OR & odds ratio \\
\hline PP & pulse pressure \\
\hline pWMLs & periventricular white matter lesions \\
\hline SBP & systolic blood pressure \\
\hline SD & standard deviation \\
\hline SDS-PAGE & sodium dodecyl sulphate-polyacrylamide gel electrophoresis \\
\hline SELDI-TOF-MS & $\begin{array}{l}\text { Surface-Enhanced Laser Desorption / Ionization Time-Of-Flight } \\
\text { Mass Spectrometry }\end{array}$ \\
\hline SVD & small vessel disease \\
\hline VMLs & white matter lesions \\
\hline
\end{tabular}





\section{Chapter 1}

\section{Introduction and outline of the thesis}

Adapted from:

JEA Staals

J Lodder

Hypertension and lacunar stroke

Chapter 18 in: Mohler E, Townsend R, ed. Advanced therapy in hypertension and vascular disease. Hamilton: B.C.Decker, 2006:152-160. 
Chapter 1 


\section{Lacunar stroke}

Stroke is a worldwide occurring disease and puts a major burden on the healthcare system. Stroke can be divided into ischemic ( $\pm 80 \%)$ and hemorrhagic $( \pm 20 \%)$. The latter can be divided into intracerebral hemorrhage (about three-quarters of all hemorrhages) and subarachnoidal hemorrhage. In ischemic stroke we distinguish cardioembolic strokes $( \pm 25 \%$ of all ischemic strokes), large vessel atheromatosis $( \pm 40 \%)$, lacunar strokes $( \pm 25 \%)$ and strokes with a rare cause $( \pm 5 \%)$, whereas in about $5 \%$ a definite cause remains obscure. ${ }^{1}$ Lacunar infarcts are small infarcts, located deep in the brain or in the brain stem (pons), and range in diameter from 0.5 to $20 \mathrm{~mm}$ on neuro-imaging. ${ }^{2}$ They are usually caused by occlusion of a single small deep perforating artery or one of its branches. ${ }^{3}$

Lacunar infarcts can clinically be identified by their rather specific clinical manifestations, the so-called lacunar syndromes, of which pure motor stroke, pure sensory stroke, and sensorimotor stroke are the most frequent. ${ }^{3}$ These syndromes consist of sudden development of paresis and/or sensory deficits involving at least two out of three domains of the ipsilateral face, arm or leg, not attended by visual field deficit or higher cortical dysfunction. Other important lacunar syndromes are ataxic hemiparesis, in which hemiparesis is combined with ataxia, and dysarthriaclumsy hand syndrome, in which facial weakness and dysarthria are combined with slight weakness and clumsiness of the hand. ${ }^{3}$ Prediction of a clinical stroke syndrome being the result of a lacunar infarct can be done rather accurately by dedicated clinicians; clinicians who are less well-trained or interested in cerebrovascular disease perform less well. ${ }^{4}$ Apart from causing neurological symptoms, lacunar infarcts can also remain "silent", which means they occur without acute focal neurological deficit.

In the absence of cortical involvement, and the lesion being small, prognosis on short-term seems to be more favorable in lacunar infarct patients than in patients with an infarct involving the cortex: in a series of almost 1000 ischemic strokes, 339 being lacunar, we found a 30-day case fatality rate of $\pm 2 \%$ in lacunar stroke and $\pm 14 \%$ in cortical infarcts. ${ }^{5}$ One year mortality was $\pm 14 \%$ and $\pm 29 \%$, respectively. In another stroke cohort we found that after approximately six months $83 \%$ of the lacunar stroke survivors were functionally independent, which was higher than the $46 \%$ in the cortical group. ${ }^{6}$ However, data on long-term prognosis in lacunar stroke are scarce. Furthermore, the annual risk of stroke recurrence of about $7 \%$ is similar among different stroke subtypes. ${ }^{7}$ Thus, lacunar infarcts cannot definitely be considered a benign stroke type, and secondary preventive measures are strongly warranted. 


\section{Two types of vascular pathology}

It was Fisher who by autopsy studies in the 1960s distinguished two causes of small vessel obstruction. ${ }^{2,3} \mathrm{He}$ described so-called lipohyalinosis mainly in brains with small, multiple and usually asymptomatic lacunar infarcts. This vasculopathy,

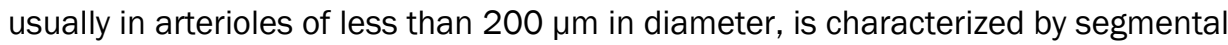
disorganization of the vessel wall. The second type of small vessel pathology Fisher distinguished was microatheromatosis, since he found microatheromatous plaques which narrowed or occluded a small perforating artery (mostly $>400 \mu \mathrm{m}$ in diameter) mainly in brains with larger, usually single symptomatic lacunar infarcts.

Fisher suggested that lacunar infarcts in general are caused by hypertension, as he found elevated blood pressure in almost $90 \%$ of his cases. ${ }^{3}$ Lipohyalinosis, he supposed, was associated with more severe hypertension. Since hypertension is better controlled nowadays, the supposed key role of hypertension in the pathogenesis of lacunar infarction may be less obvious. The general stroke incidence decline of recent decades may relate to better blood pressure control, but no time trend studies have been performed for lacunar stroke.

In the 1990s, we hypothesized that the two different types of cerebral small vessel pathology can be appreciated during life: lacunar stroke patients with a single, symptomatic lesion on CT-scan have small vessel atheromatosis, whereas lacunar stroke patients with one or more "silent" lacunar lesions have lipohyalinosis. ${ }^{8}$ Patients with multiple lacunar infarcts differ in vascular risk profile: they have more often hypertension and diabetes mellitus than patients with a single symptomatic lacunar infarct. ${ }^{8-10}$ We also found that prognosis for short-term mortality, recurrent stroke and eventual functional outcome are more unfavorable in those with silent lacunar lesions. ${ }^{11}$ Differences in long-term outcome have not been studied.

In recent years, MR imaging in lacunar stroke patients has shown that silent lacunar lesions are more prevalent than was seen in the CT age. (Figures 1.1-1.3) This could mean that lipohyalinosis is more prevalent than was thought, and that CT studies have underestimated the differences between patients with and without silent lesions. However, because of the absence of further pathology studies, it remains subject of debate whether the two types that can be distinguished by imaging really represent two pathogenetically different entities, or are just mild and severe ends of one pathogenetic small vessel disease spectrum. 


\section{Outline of thesis - Chapter 2}

Lacunar stroke is generally considered a rather 'benign' stroke but data on long-term prognosis are scarce. Most mortality studies in lacunar stroke are characterized by short follow-up time, small patient groups, and absence of a nonlacunar stroke group for comparison. Furthermore, there are no long-term prognostic data on lacunar stroke subtypes.

The aim of this chapter is to describe long-term prognosis for mortality in lacunar stroke patients, additionally distinguishing two lacunar stroke subtypes.

\section{White matter lesions}

Periventricular and subcortical (deep) white matter lesions, which appear as diffuse hypodensities on CT or increased intensity lesions on a T2-weighted MR-image, were originally named leukoaraiosis, which literally means rarefaction of the white matter. (Figure 1.4)

White matter lesions are frequently found in asymptomatic elderly persons, but also in symptomatic patients with stroke or cognitive decline. The presence of white matter lesions on MRI in asymptomatic elderly varies up to $100 \%$, depending on the criteria used, and the subjects' age.12 Many studies have shown an association between white matter lesions and cerebrovascular risk factors, especially hypertension and co-existent silent lacunar infarcts. ${ }^{12}$ White matter lesions are a risk factor for subsequent stroke, especially lacunar stroke. ${ }^{13,14}$ In symptomatic stroke patients, white matter abnormalities are more prevalent in patients with lacunar than in those with cortical infarcts. ${ }^{15}$ In particular, patients with multiple lacunar infarcts have leukoaraiosis more often than patients with a single symptomatic lacunar infarct.8,9

All these observations suggest an ischemic cause of white matter abnormalities. The cerebral white matter is not supplied by the small deep perforating arterioles in whose areas lacunar infarcts are located, but by the distal branches of the long medullary arteries which arise from cerebral surface branches of the large cerebral arteries.16 Pathology studies have shown arteriolosclerosis within areas of leukoaraiosis, which consists of hyaline wall thickening with consequent narrowing of the arteriolar lumen. This vasculopathy may lead to chronic and diffuse hypoperfusion of the white matter area. ${ }^{17}$ The periventricular white matter seems most vulnerable as this area is at the end of the territory of the medullary vessels where the perfusion pressure will be lowest. Recent studies documented differences in genetic predisposition, vascular risk factors, clinical consequences in terms of cognitive impairment and progression rate between periventricular and deep subcortical white matter lesions. ${ }^{18-22}$ These studies suggest that a distinction between these two subtypes could, at least clinically, be relevant. 
One of the most debated issues in research on white matter lesions is whether they influence cognitive function. Binswanger described in the late 1890 s a clinical syndrome of dementia with pseudobulbar symptoms and a gait disorder, in which he found "arteriosclerosis" and extensive atrophy of the white matter without involvement of the cortex (subcortical arteriosclerotic encephalopathy). ${ }^{12,23}$ After the introduction of CT it was suggested that the combination of dementia and leukoaraiosis on CT was diagnostic of Binswanger's disease. However, it soon became clear that leukoaraiosis could also be found in non-demented persons. Although leukoaraiosis is frequently found in normal subjects, numerous studies show an association with dementia, both Alzheimer disease and vascular-type dementia. There is also evidence that leukoaraiosis is related to mild cognitive abnormalities, particularly memory and mental speed, in otherwise healthy people; a relationship that is also found in stroke patients. ${ }^{12,24,25}$ Obviously, the clinical accompaniments of leukoaraiosis range from apparently normal to severe dementia. Apart from differences in study characteristics such as imaging modality, various neuropsychological tests, and definition and methods of measurement of white matter lesions, such variation may be explained by strategic lesion location, degree of brain atrophy, prior education level, age, and genetic factors.

\section{Endothelial dysfunction}

The cerebrovascular endothelium serves a variety of physiological functions, such as maintenance of adequate vessel tone, expression of adhesion molecules, and hemostasis. It is believed that dysfunction of endothelium plays an important initiating role in cerebral small vessel disease. ${ }^{26}$ This is supported by evidence from several studies. ${ }^{27}$

Regulation of cerebral blood flow occurs by vasodilatation or vasoconstriction in the arterioles. The endothelial layer plays an important role in the regulation of vascular tone adjustments. Cerebrovascular reactivity, which reflects the reserve dilatory capacity of the cerebral arterioles, is reduced in small vessel disease.28-30 In lacunar stroke patients with multiple silent lacunar lesions, cerebrovascular reactivity is even lower than in patients with a single symptomatic lacune. ${ }^{29}$ Indirect evidence comes from studies that show that statin treatment, which not only has lipid-lowering effects but also improves endothelial function, improved cerebrovascular reactivity in patients with small vessel disease. ${ }^{31,32}$

Endothelium presents an anticoagulant and antiinflammatory phenotype to blood. Activation of the endothelium induces the endothelial cells to express several prothrombotic factors, regulatory proteins and adhesion molecules. Hassan et al. found that markers of endothelial dysfunction were higher in patients with lacunar infarcts than in controls. ${ }^{33}$ They also found a different endothelial marker profile between lacunar infarct patients with and without white matter lesions, suggesting 
a different role of endothelial dysfunction in the pathogenesis of the broad clinical spectrum of small vessel disease.

Endothelium constitutes the blood-brain barrier. It is postulated that endothelial dysfunction leads to leakage of plasma components into the vessel wall and surrounding brain tissue, which might be the start of a cascade leading to the different forms of small vessel disease. ${ }^{26,34} \mathrm{~A}$ recent preliminary study by Wardlaw et al. showed that MRI postcontrast enhancement in cerebrospinal fluid was higher in lacunar than in cortical stroke patients, suggesting that the blood-brain barrier may be dysfunctional in patients with lacunar stroke. ${ }^{35}$ Kwa et al. reported that retinal arterial pathology, in particular arterial narrowing, sclerosis, and retinal exudates, correlates with cerebral small vessel disease, providing evidence that vascular leakage plays a role in small vessel vasculopathy. ${ }^{36}$

It is unknown whether endothelial dysfunction plays a similar role in the two distinct types of cerebral small vessel disease. Endothelial dysfunction, leading to inflammatory and oxidative reactions, is supposed to be the precipitating factor in the atherosclerotic process in large vessels, and may play a similar role in its analogue in small vessels, which is microatheromatosis. ${ }^{37}$ The blood-brain barrier function of the endothelium may be a more important factor in the pathogenesis of lipohyalinosis/arteriolosclerosis. ${ }^{26}$

Increased blood pressure may be one of the factors that induces injury to the endothelial layer. However, hypertension is not a unique factor in small vessel disease, so other factors that influence endothelial function must play a role. Family studies have shown that genetic factors influence the risk of lacunar stroke. ${ }^{38}$ Any genetic contribution is likely to be polygenetic. The genes from the renin-angiotensin-system are the most extensively investigated genes in stroke. This is probably because the effector hormone of this system, angiotensin II, has many different effects on blood pressure, vascular structure and vascular function which all may influence stroke risk. Angiotensin II also plays an important role in the regulation of endothelial function. ${ }^{39,} 40$ However, studies on the genes of the renin-angiotensin-system have yielded many conflicting results. ${ }^{41}$

Thus far, research into the underlying pathogenetic mechanisms of small vessel disease focused on known factors that are thought to be involved in vascular pathogenesis. Especially proteins that are acknowledged to play a role in large vessel atherosclerosis, such as coagulation and inflammation factors and their genetic determinants, are studied. Surface-Enhanced Laser Desorption / Ionization Time-of-Flight Mass Spectrometry (SELDI-TOF-MS) is a new technique that may be used to obtain new insight in the pathogenesis of small vessel disease by looking for possible differences in protein expression profile. This technology provides a rapid method to detect expressed proteins in a biological sample. It uses chip surfaces which bind a subset of proteins from a sample. An energy-absorbing matrix is added so that when laser energy is applied to the chip the proteins become ionized, enabling their mass to charge $(\mathrm{m} / \mathrm{z})$ ratio to be measured by time- 
of-flight mass spectrometry. Protein profiles of different patient groups can be compared to find distinctive patterns.

\section{Outline of thesis - Chapter 3}

The aim of this chapter is to explore whether it is possible with the SELDI-TOFMS technique to detect differences in protein expression profile between serum samples of two lacunar stroke subtypes, and subsequently whether differently expressed proteins can be identified. In this way we aim to get new ideas about the underlying pathogenetic process of small vessel disease.

\section{Haptoglobin phenotypes}

Haptoglobin is a hemoglobin-binding plasma glycoprotein. Two different coding alleles, $\mathrm{Hp} 1$ and $\mathrm{Hp} 2$, determine the presence of $\alpha-1$ and/or $\alpha$-2-chains in the haptoglobin-molecule. Consequently, three haptoglobin protein phenotypes occur: Hp1-1 [structural formula $\left.\left(\alpha^{1} \beta\right)_{2}\right]$, Hp2-1 $\left[\left(\alpha^{1} \beta\right)_{2}+\left(\alpha^{2} \beta\right)_{n}\right]$ and Hp2-2 $\left[\left(\alpha^{2} \beta\right)_{n}\right] .42$ These phenotypes show several functional differences that may be important in vascular disease: Hp1-1 has more antioxidant and immunomodulatory capacities, less angiogenic potential, and has been related to higher blood pressures than Hp2-2. ${ }^{43}$

Haptoglobin phenotype has extensively been studied as risk factor for developing atherosclerotic large vessel disease. The Hp2-2 phenotype has been associated with an increased risk of peripheral and coronary artery disease and the risk of vascular complications in patients with diabetes mellitus. ${ }^{44-47}$ However, its role in lacunar stroke and other signs of cerebral small vessel disease has never been studied.

\section{Outline of thesis - Chapter 4 and 5}

The study in chapter 3 suggested a role for haptoglobin phenotype in cerebral small vessel disease.

In chapter 4 and 5 we further explore the possible role of haptoglobin phenotype in cerebral small vessel disease. In chapter 4 we study differences in haptoglobin phenotype frequencies between lacunar stroke patients and a healthy control group. We also distinguish patients with and without additional silent lacunar lesions or white matter lesions. In chapter 5 we examine the relationship between haptoglobin phenotypes and early silent signs of cerebral small vessel disease (in terms of asymptomatic lacunar lesions and white matter lesions) in stroke-free hypertensive patients. 


\section{Hypertension}

Hypertension is an important risk factor for every stroke type, although it is often regarded a specific risk factor for lacunar stroke. However, hypertension is not a unique risk factor for lacunar stroke. Most studies showed no or only marginally significant differences in the frequency of hypertension between lacunar and nonlacunar stroke patients. ${ }^{1,48}$ (Table 1.1) In interpreting studies that report risk factor profiles of lacunar stroke, it is important to evaluate whether they used a risk factor-free stroke classification. Some commonly used stroke classifications, such as the TOAST classification, include hypertension in the criteria of lacunar stroke, which may lead to bias when assessing the prevalence of hypertension in lacunar stroke. ${ }^{48,49}$ A systematic review confined to studies using risk factor-free stroke subtype definitions reported a minor excess of hypertension in lacunar versus nonlacunar stroke (OR 1.11, 95\% Cl 1.04-1.19). Other vascular risk factors do not differ between lacunar and nonlacunar infarct patients. ${ }^{1,48}$ What determines the development of small or large vessel disease of the brain in the presence of similar risk factor profiles remains unclear, but at least suggests a role of genetic factors. The prevalence of hypertension in patients with lacunar stroke varies between 44 and 89\%.5,10,50-57 (Table 1.1) These divergent figures may be explained by differences in study design, in definition of lacunar stroke, in the use of imaging technique and in definition of hypertension. In the absence of a clear blood pressure cut off point above which the risk of stroke starts to increase, it may be better to consider blood pressure as a continuous variable affecting stroke risk, and to consider "elevated blood pressure" rather than the fixed definition of "hypertension" in this regard. Another explanation for the divergent hypertension frequencies in lacunar stroke may be that most studies did not distinguish the two lacunar infarct entities. The relative frequency of each may determine the overall frequency of hypertension in a lacunar stroke series, patients with multiple lacunar infarcts or white matter lesions being more often hypertensive than those with a single symptomatic lacunar infarct.8-10,56

Hypertension is a treatable risk factor and yet few studies examined the effects of hypertension treatment on the risk of lacunar stroke, neither in primary nor secondary prevention studies. Most primary prevention trials that included nonstroke hypertensive patients and used stroke as an outcome measure did not consider stroke subtypes, whereas most secondary prevention trials did neither. The SHEP study was a placebo-controlled trial that tested whether antihypertensive drug therapy reduced the frequency of stroke in an elderly population with isolated systolic hypertension. ${ }^{58}$ It was the only trial that examined the various subtypes of stroke in a primary prevention setting. It concluded that the incidence of lacunar infarction was reduced almost by half with active antihypertensive treatment. The PROGRESS study was a placebo-controlled trial that tested whether blood pressure-lowering treatment, independent of the level of baseline blood pressure, 
reduced the frequency of recurrent stroke in patients with prior stroke. ${ }^{59}$ This was the only trial that examined the various subtypes of the outcome stroke in a secondary prevention setting, although the baseline strokes were not classified into subtype. It showed that the risk of lacunar stroke was reduced almost by a quarter (although not statistically significant) with active blood pressure lowering treatment. The PRoFESS study was a placebo-controlled secondary prevention trial that tested whether blood pressure-lowering treatment, initiated soon after stroke, could reduce the frequency of recurrent stroke. 60 About half of included patients had suffered a lacunar stroke at baseline. The rate of recurrent stroke was not lowered significantly, but the mean duration of follow-up was rather short (2.5 years).

Although the evidence is thin, it seems reasonable to treat at least elevated blood pressure in patients who suffered a lacunar stroke. Future secondary stroke prevention trials should not only consider lacunar stroke at baseline, but should also account for the two lacunar stroke subtypes, to enable estimates of stroke reduction separately in these subtypes. The presence of microbleeds and white matter lesions should also be considered. Theoretically, efficacy of antihypertensive treatment may differ between the small vessel disease subtypes, depending on differences in circadian blood pressure regulation.

Table 1.1 Frequency of hypertension in studies of lacunar stroke.

\begin{tabular}{lccccccc}
\hline Study & \multicolumn{2}{c}{ Lacunar stroke } & \multicolumn{2}{c}{ Non-lacunar stroke } & \multicolumn{2}{c}{ OR (95 \% Cl) } \\
& $\%(\mathrm{n} / \mathrm{N})$ & hypertension & \multicolumn{2}{c}{$\%(\mathrm{n} / \mathrm{N})$ hypertension } & & \\
\hline Norrving et al. (1989) & 53 & $(32 / 61)$ & 44 & $(27 / 61)$ & 1.39 & $(0.68-2.83)$ \\
Lodder et al. (1990) & 44 & $(45 / 102)$ & 47 & $(95 / 202)$ & 0.89 & $(0.55-1.43)$ \\
Boiten et al. (1991) & 50 & $(51 / 103)$ & 37 & $(35 / 94)$ & 1.65 & $(0.94-2.91)$ \\
Tegeler et al. (1991) & 60 & $(33 / 55)$ & 56 & $(30 / 54)$ & 1.20 & $(0.56-2.57)$ \\
Mast et al. (1995) & 73 & $(134 / 184)$ & 64 & $(290 / 453)$ & 1.54 & $(1.04-2.29)$ \\
Boiten et al. (1996) & 48 & $(138 / 287)$ & 45 & $(260 / 582)$ & 1.24 & $(0.93-1.65)$ \\
Schmal et al. (1998) & 59 & $(142 / 241)$ & 58 & $(88 / 151)$ & 1.03 & $(0.68-1.55)$ \\
Grau et al. (2001) & 78 & $(806 / 1028)$ & 62 & $(2481 / 3989)$ & 2.21 & $(1.88-2.59)$ \\
De Jong et al. (2003) & 47 & $(160 / 339)$ & 44 & $(289 / 659)$ & 1.14 & $(0.88-1.52)$ \\
Khan et al. (2007) & 89 & $(367 / 414)$ & 71 & $(334 / 471)$ & 3.16 & $(2.19-4.54)$ \\
\hline
\end{tabular}




\section{Circadian blood pressure profile}

As stated before, not all lacunar stroke patients are hypertensive. Not the qualitative label "hypertension", but quantitative blood pressure characteristics of the 24-hour blood pressure profile may be more important. In general practice, hypertension is mostly established by several repeated casual blood pressure measurements. However, blood pressure shows a circadian pattern, with lower values at night (nocturnal dipping). This 24-hour pattern can be easily measured by using a noninvasive ambulatory blood pressure monitoring (ABPM) device. It has been shown that hypertensive target organ damage, including cerebral damage, correlates more closely with 24-hour average blood pressure than with casual blood pressure readings. ${ }^{61-64}$

Most studies on the role of circadian blood pressure in cerebral small vessel disease have been performed in stroke-free healthy or hypertensive patients. Overall, these studies have shown that higher daytime blood pressure as well as nighttime blood pressure predict asymptomatic lacunar infarcts and white matter lesions. ${ }^{61,65-71}$ However, studies in lacunar stroke patients are few and results were varying. ${ }^{72-76}$ Moreover, these studies consisted of small or highly selected patient groups, used dichotomised instead of continuous blood pressure levels, or, in case of longitudinal studies, had very divergent follow-up times within the study group. In addition to absolute blood pressure levels during day and night, the degree of nocturnal dipping has been studied in relation to small vessel disease. Patients with decreased nocturnal dipping, so-called nondippers, have more advanced target organ damage such as cardiac left ventricular hypertrophy, and also higher cardiovascular morbidity, including stroke. ${ }^{62,77,78}$ As the presence of lacunar lesions and white matter lesions may be considered reflecting cerebral end organ damage, one would expect to find a relationship between such cerebral damage and a nondipping state. However, the role of dipping in cerebral target organ damage is controversial. Several studies in healthy people, asymptomatic hypertensive patients, or lacunar stroke patients demonstrated an association between reduced nighttime dipping and the prevalence of silent lacunar infarcts and white matter lesions. ${ }^{65,68-70,74,79}$ Reduced nocturnal dipping also had an adverse effect on the development of new silent ischemic lesions and recurrent symptomatic stroke in patients with symptomatic lacunar infarction. ${ }^{75}$ This might simply be explained by the fact that the brain is exposed to a sustained elevated blood pressure over 24 hours. However, others failed to show an association between the degree of dipping and silent lesions. ${ }^{67,71-73}$ Some studies in asymptomatic (hypertensive) patients even reported the opposite or found that both nondipping and extreme dipping are associated with silent cerebral ischemic damage, reflecting the socalled J-curve phenomenon.80-82 Nakamura et al. observed that, during follow-up after stroke, patients had an increase in symptomatic (recurrence) and asymptomatic (silent) brain lesions more often when they were nocturnal dippers 
rather than nondippers, but they made no distinction between large vessel and small vessel strokes. ${ }^{83}$

Marked nocturnal blood pressure fall might lead to an excessive reduction of cerebral perfusion, and thus to ischemic lesions. This might especially be true in hypertensive patients with a disturbed cerebral autoregulation. Cerebral autoregulation is the ability of the brain to maintain the cerebral blood flow within certain limits despite fluctuations in perfusion pressure, which depends for a large part on the systemic blood pressure. The physiological limits of autoregulation normally lie between 60 and $150 \mathrm{mmHg}$ mean arterial pressure. ${ }^{84}$ In chronic hypertension these limits are shifted to higher values, to protect the brain against hyperperfusion at high blood pressures. ${ }^{84}$ Autoregulation results from vasomotor adjustments in the arteriolar vessels. The endothelium, in interaction with the media (= smooth muscle cell layer), probably plays an important role. ${ }^{84}$ Several studies indicate that cerebral small vessel disease is accompanied by an impaired cerebral autoregulation. ${ }^{29,85,86}$ An impaired autoregulation means that cerebral blood flow more passively follows blood pressure changes, thereby increasing the risk of hypoperfusion during circumstances of lowered systemic blood pressure, such as nocturnal dipping. Would this mechanism play a role, one may wonder whether diligent anti-hypertensive treatment aggravates rather than ameliorates prognosis in such lacunar stroke subgroup. Cerebral autoregulation has been shown to be more impaired in lacunar infarct patients with multiple silent lacunes ${ }^{29}$, and it would be interesting to know whether in lacunar infarct patients with silent lacunes and white matter lesions, antihypertensive treatment in combination with nocturnal dipping may accelerate small vessel disease progression. This issue certainly requires more study in the future. Another issue of importance in this respect is the different effects on nocturnal dipping between various types of blood pressure lowering drugs.

\section{Outline of thesis - Chapter 6}

Most studies on the role of ambulatory blood pressure in cerebral small vessel disease have been performed in stroke-free healthy or hypertensive patients. In this chapter, we study the effect of ambulatory blood pressure on the presence of silent lacunar lesions, deep and periventricular white matter lesions in lacunar stroke patients. The use of ABPM allows us to explore several quantitative circadian blood pressure characteristics such as daytime and nighttime blood pressure levels and nocturnal dipping. 


\section{Microbleeds}

Brain microbleeds have become increasingly recognized with the use of newer sensitive MR imaging techniques. They can be seen at T2*-weighted gradient echo MR images as hypointens small round spots. (Figure 1.5) They consist of deposits of hemosiderin and represent small old hemorrhages.

The prevalence in healthy adults is about $5 \%$, but is much higher among people with cerebrovascular disease. $.87,88$ Highest prevalence, about $60 \%$, is found among people with symptomatic intracrebral hemorrhage. ${ }^{87}$ Hypertension is the most consistent predictor of brain microbleeds, with odds ratios of 3.9 averaged across studies in healthy adults and 2.3 in stroke patients. ${ }^{87,89}$ Age also is an important risk factor. 89

In ischemic stroke, microbleeds are more often seen in patients with lacunar stroke than in patients with atherothrombotic or cardioembolic stroke. ${ }^{87}$ Both in stroke patients and in healthy people, microbleeds are strongly associated to the presence of silent lacunar infarcts and white matter lesions. ${ }^{87}$ These data suggest that microbleeds are caused by the same small vessel pathology as lacunes and white matter lesions. Pathology studies are scarce but indeed found evidence of lipohyalinosis and arteriolosclerosis in the small vessels supplying the areas of the brain harboring microbleeds. ${ }^{90-92}$ The same vascular pathology also underlies the majority of hypertension-related symptomatic deep intracerebral hemorrhages.

In some cases with microbleeds, evidence of amyloid-angiopathy has been found. ${ }^{90}$ It is therefore suggested that, analogous to large symptomatic lobar and deep intracerebral hemorrhages, two types of microbleeds with probably different etiologies should be distinguished: those located in deep brain structures, caused by hypertension-related small vessel disease, and those located in (sub)cortical areas, caused by amyloid-angiopathy. Clinical evidence for this distinction is still limited. 93

In patients with symptomatic cerebral hemorrhage as well as in lacunar stroke, microbleeds are a risk factor for recurrent stroke. ${ }^{94,95}$ An important, yet unanswered question, is whether microbleeds should be a reason not to start anticoagulation or thrombolytic therapy because they might be involved with increased bleeding risk. The clinical relevance of microbleeds has been further emphasized by their association with cognitive dysfunction. ${ }^{96}$ Although microbleeds are often labeled as "silent" sign of small vessel disease, they should not be considered benign and deserve increasing attention in clinical research. 


\section{Outline of thesis - Chapter 7}

Hypertension is an important risk factor for brain microbleeds in lacunar stroke patients. However, beyond the qualitative label "hypertension", little is known about the association with ambulatory blood pressure levels. In this chapter we study the relationship between brain microbleeds and several quantitative blood pressure characteristics as measured by ABPM in lacunar stroke patients. Furthermore, we distinguish between microbleeds in deep and lobar locations and examine whether the association with blood pressure differs between these two types.

\section{Aim of this thesis}

The general aim of the present thesis is to try to further dissolve the underlying processes that lead to different forms of cerebral small vessel disease. We explore several differences between lacunar stroke patients with and without silent signs of small vessel disease, in particular silent lacunar lesions and white matter lesions. Brain microbleeds are more recently recognized as another silent sign of small vessel disease.

In concrete terms, in this thesis we address differences in long-term mortality, in protein expression profile, in haptoglobin phenotypes, and in 24-hour blood pressure characteristics. The present chapter described the background from which these research objectives were deducted.

\section{Outline of thesis - Chapter 8 and 9}

Chapter 8 presents a general discussion of our findings with implications for future research. Chapter 9 presents a summary of this thesis in English, followed by a Dutch version. 

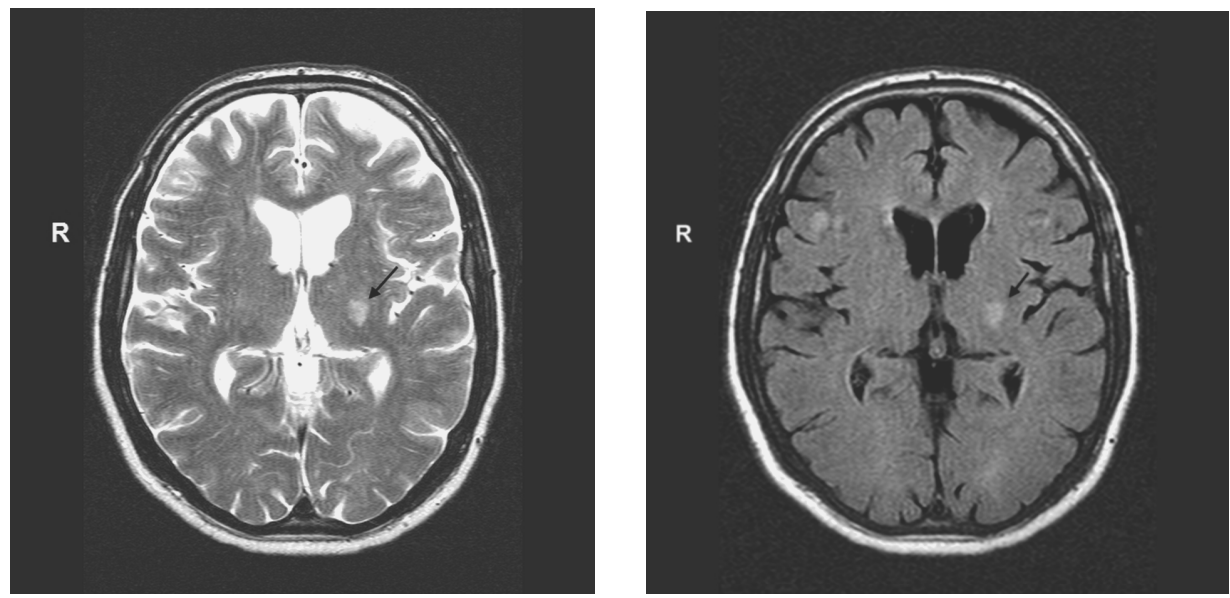

Figure 1.1 Symptomatic lacunar infarct in posterior leg of left internal capsula [MR images, T2 and FLAIR].
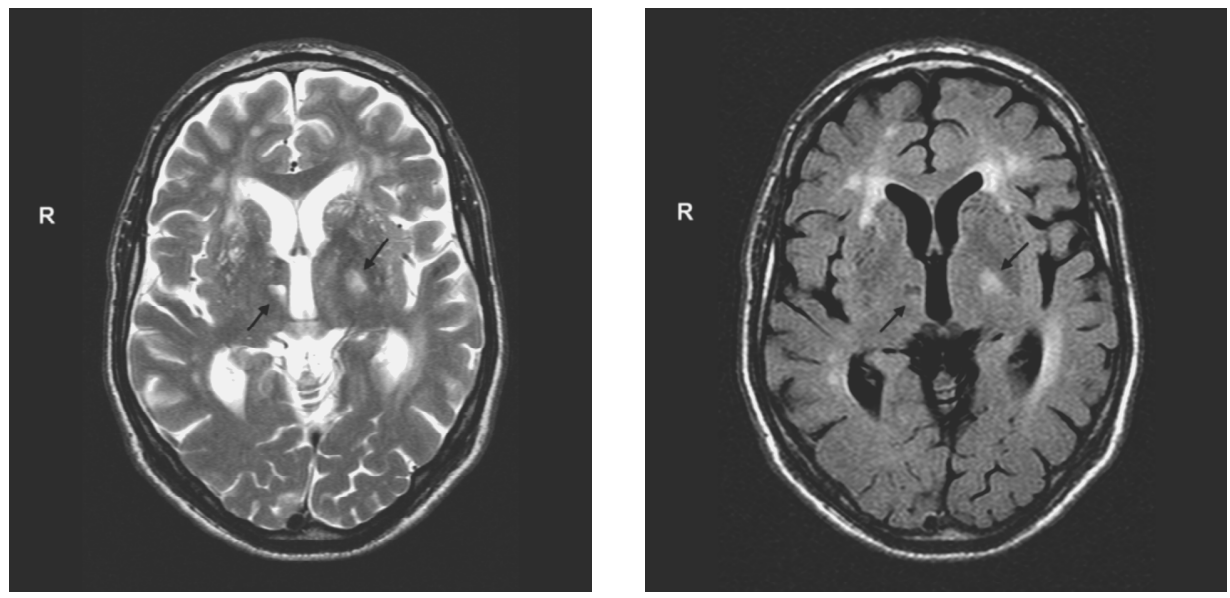

Figure 1.2 Symptomatic lacunar infarct in posterior leg of left internal capsula and old asymptomatic lacunar infarct in right thalamus [MR images, T2 and FLAIR]. 
A

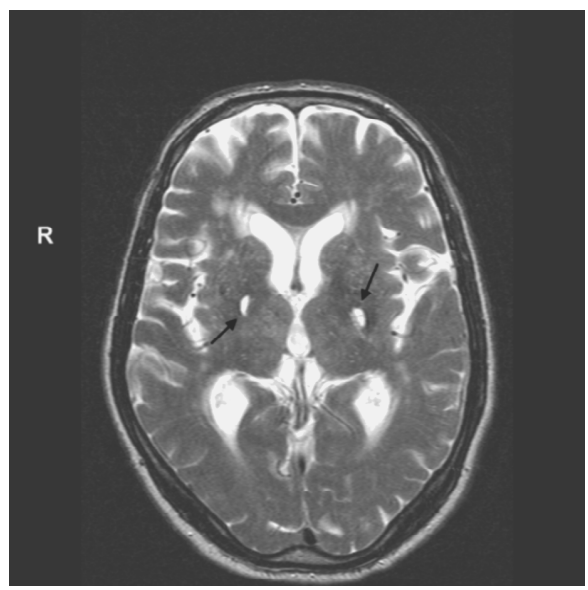

C

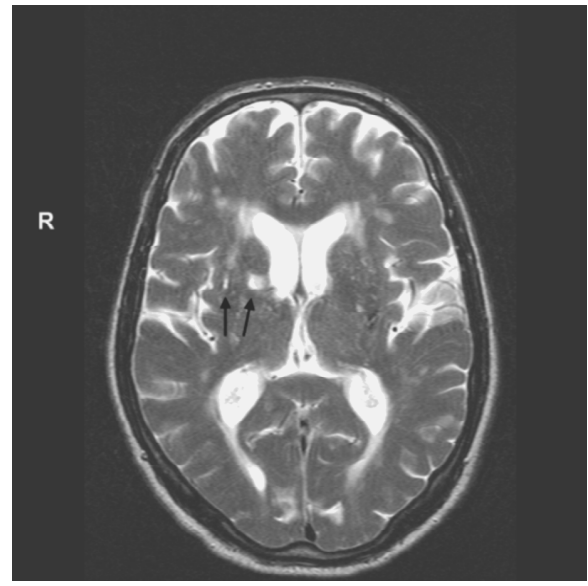

B

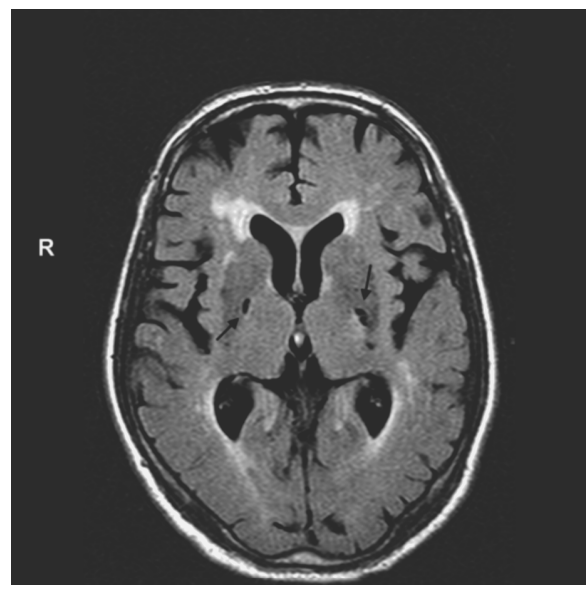

D

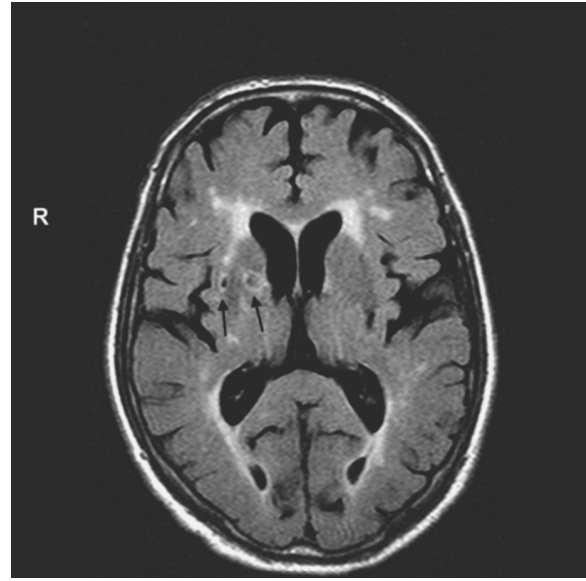

Figure 1.3 Multiple old asymptomatic lacunar infarcts in the posterior leg of the internal capsula at both sides $(A, B)$, in the anterior leg of the right internal capsula, and on the outer edge of the right lenticular nucleus (C,D) [MR images, T2 and FLAIR at two levels]. 
A

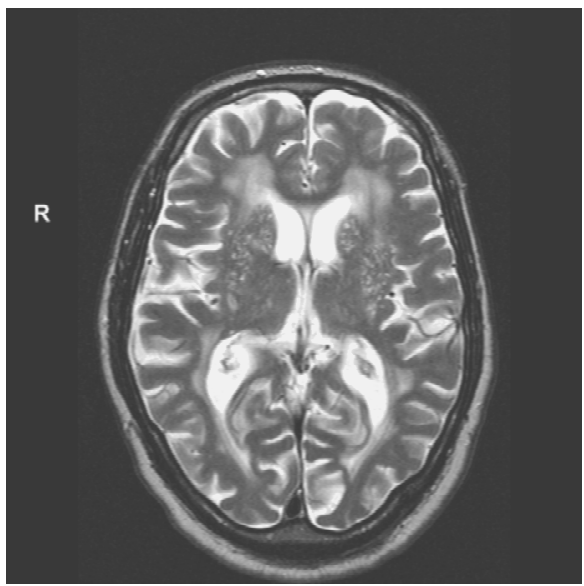

B

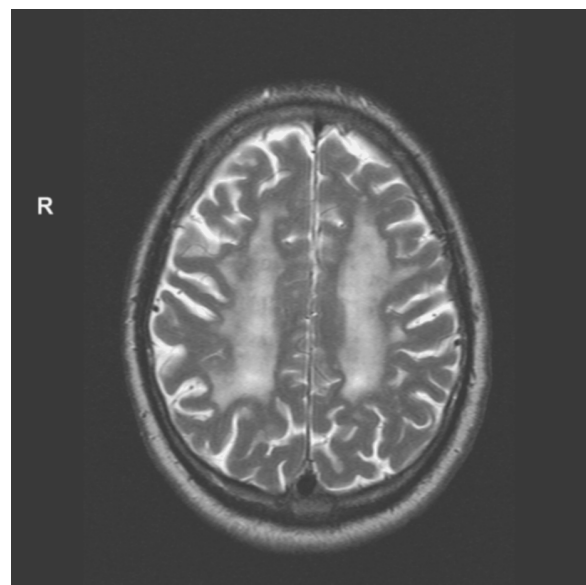

Figure 1.4 Extensive periventricular (A) and deep (B) white matter lesions [MR images, T2 at two levels].

A

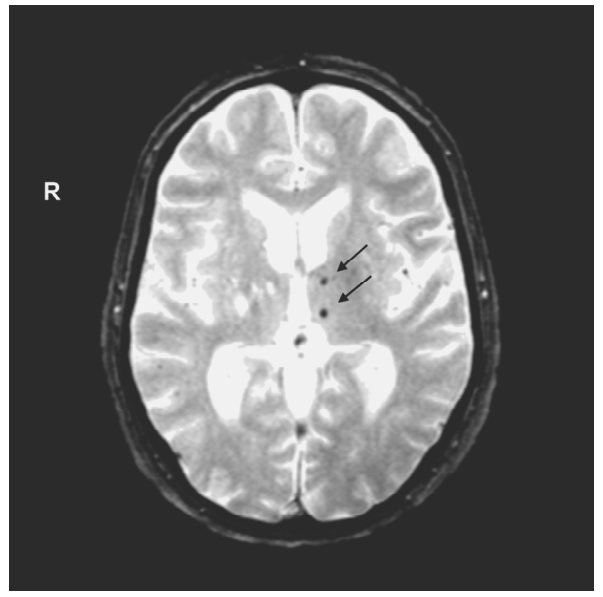

B

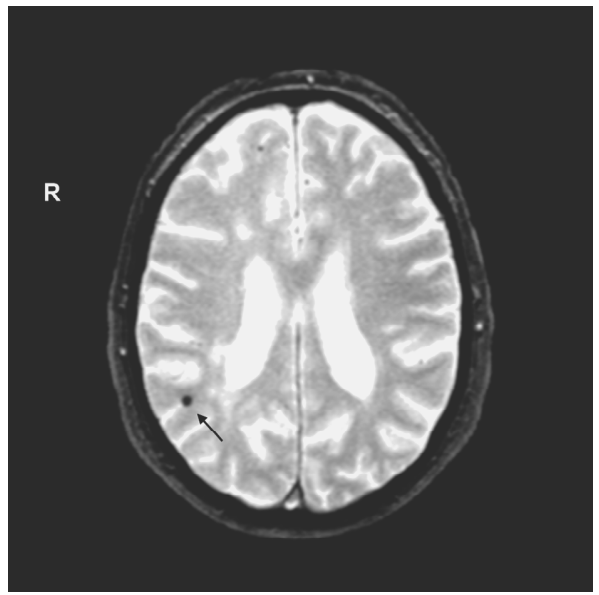

Figure 1.5 Two deep microbleeds in the left thalamus (A) and one lobar microbleed (B) [MR images, T2* GE at two levels]. 


\section{References}

1. Lodder J, Boiten J. Incidence, natural history, and risk factors in lacunar infarction. Adv Neurol. 1993;62:213-226.

2. Fisher CM. The arterial lesions underlying lacunes. Acta neuropath (Berl). 1969;12:1-15.

3. Fisher CM. Lacunar strokes and infarcts: a review. Neurology. 1982;32:871-876.

4. Lodder J, Bamford JM, Kappelle J, Boiten J. What causes false clinical prediction of small, deep infarcts. Stroke. 1994;25:86-91.

5. de Jong G, van Raak L, Kessels F, Lodder J. Stroke subtype and mortality: a follow-up study in 998 patients with a first cerebral infarct. J Clin Epidemiol. 2003;56:262-268.

6. Boiten J, Lodder J. Prognosis for survival, handicap and recurrence of stroke in lacunar and superficial infarction. Cerebrovasc Dis. 1993;3:221-226.

7. de Jong G, Lodder J, Kessels F, van Raak L. Homogeneity of large and small vessel disease over time: arguments from a study on recurrent stroke in 998 patients with first cerebral infarct. J Stroke Cerebrovasc Dis. 2004;13:141-147.

8. Boiten J, Lodder J, Kessels F. Two clinically distinct lacunar infarct entities? A hypothesis. Stroke. 1993;24:652-656.

9. Spolveri S, Baruffi MC, Cappelletti C, Semerano F, Rossi S, Pracucci G, Inzitari D. Vascular risk factors linked to multiple lacunar infarcts. Cerebrovasc Dis. 1998;8:152-157.

10. Mast H, Thompson JLP, Lee S-H, Mohr JP, Sacco RL. Hypertension and diabetes mellitus as determinants of multiple lacunar infarcts. Stroke. 1995;26:30-33.

11. de Jong G, Kessels F, Lodder J. Two types of lacunar infarcts, further arguments from a study on prognosis. Stroke. 2002;33:2072-2076.

12. Pantoni L, Garcia JH. The significance of cerebral white matter abnormalities 100 years after Binswanger's report. Stroke. 1995;26:1293-1301.

13. Kuller LH, Longstreth WT, Arnold AM, Bernick C, Bryan RN, Beauchamp NJ. White matter hyperintensity on cranial magnetic resonance imaging: a predictor of stroke. Stroke. 2004;35: 1821-1825.

14. Yamauchi H, Fukuda H, Oyanagi C. Significance of white matter high intensity lesions as a predictor of stroke from arteriolosclerosis. JNNP. 2002;72:576-582.

15. Mantyla R, Aronen HJ, Salonen O, Pohjasvaara T, Korpelainen M, Peltonen T, StandertskjoldNordenstam C-G, Kaste M, Erkinjuntti T. Magnetic resonance imaging white matter hyperintensities and mechanism of ischemic stroke. Stroke. 1999;30:2053-2058.

16. Pantoni L, Garcia JH. Pathogenesis of leukoaraiosis, a review. Stroke. 1997;28:652-659.

17. van Swieten JC, van den Hout JHW, van Ketel BA, Hijdra A, Wokke JHJ, van Gijn J. Periventricular lesions in the white matter on magnetic resonance imaging in the elderly: a morphometric correlation with arteriolosclerosis and dilated perivascular spaces. Brain. 1991;114:761-774.

18. Henskens LH, Kroon AA, van Boxtel MP, Hofman PA, de Leeuw PW. Associations of the angiotensin II type 1 receptor A1166C and the endothelial nitric oxide synthase G894T gene polymorphisms with silent subcortical white matter lesions in essential hypertension. Stroke. 2005;36: 1869-1873.

19. Delano-Wood L, Abeles N, Sacco JM, Wierenga CE, Horne NR, Bozoki A. Regional white matter pathology in mild cognitive impairment. Stroke. 2008;39:794-799.

20. Sachdev P, Wen W. Should we distinguish between periventricular and deep white matter hyperintensities? Stroke. 2005;36:2342-2343.

21. Gouw AA, van der Flier WM, Fazekas F, van Straaten ECW, Pantoni L, Poggesi A, Inzitari D, Erkinjuntti T, Wahlund LO, Waldemar G, Schmidt R, Scheltens P, Barkhof F. Progression of white matter hyperintensities and incidence of new lacunes over a 3-year period. Stroke. 2008;39: 1414-1420.

22. Lazarus R, Prettyman R, Cherryman G. White matter lesions on magnetic resonance imaging and their relationship with vascular risk factors in memory clinic attenders. Int J Geriatr Psychiatry. 2005;20:274-279.

23. Ward NS, Brown MM. Leukoaraiosis. In: Donnan G, Norrving B, Bamford JM , Bogousslavsky J, eds. Subcortical stroke. Oxford University Press; 2002:47-66. 
24. de Groot JC, de Leeuw F-E, Oudkerk M, van Gijn J, Hofman A, Jolles J, Breteler MMB. Cerebral white matter lesions and cognitive function: the Rotterdam Scan Study. Ann Neurol. 2000;47: 145-151.

25. Rasquin SMC, Verhey FRJ, van Oostenbrugge RJ, Lodder J. Demographic and CT-scan features related to cognitive impairment in the first year after stroke. JNNP. 2004;75:1562-1567.

26. Wardlaw JM, Sandercock PAG, Dennis MS, Starr J. Is breakdown of the blood-brain barrier responsible for lacunar stroke, leukoaraiosis, and dementia? Stroke. 2003;34:806-812.

27. Knottnerus ILH, Ten Cate H, Lodder J, Kessels F, van Oostenbrugge RJ. Endothelial dysfunction in lacunar stroke. A systematic review. Cerebrovasc Dis. 2009;27:519-526.

28. Pretnar-Oblak J, Zaletel M, Zvan B, Sabovic M, Pogacnik T. Cerebrovascular reactivity to L-Arginine in patients with lacunar infarctions. Cerebrovasc Dis. 2006;21:180-186.

29. Molina C, Sabin JA, Montaner J, Rovira A, Abilleira S, Codina A. Impaired cerebrovascular reactivity as a risk marker for first-ever lacunar infarction. Stroke. 1999;30:2296-2301.

30. Maeda H, Matsumoto M, Handa N, Hougaku H, Ogawa S, Itoh T, Tsukamoto Y, Kamada T. Reactivity of cerebral blood flow to carbon dioxide in various types of ischemic cerebrovascular disease: evaluation by the transcranial Doppler method. Stroke. 1993;24:670-675.

31. Sterzer P, Meintzschel F, Rosler A, Lanfermann H, Steinmetz H, Sitzer M. Pravastatin improves cerebral vasomotor reactivity in patients with subcortical small-vessel disease. Stroke. 2001;32: 2817-2820.

32. Pretnar-Oblak J, Sabovic M, Sebestjen M, Pogacnik T, Zaletel M. Influence of atorvastatin treatment on L-Arginine cerebrovascular reactivity and flow-mediated dilatation in patients with lacunar infarctions. Stroke. 2006;37:2540-2545.

33. Hassan A, Hunt BJ, O'Sullivan M, Parmar K, Bamford JM, Briley D, Brown MM, Thomas DJ, Markus HS. Markers of endothelial dysfunction in lacunar infarction and ischaemic leukoaraiosis. Brain. 2003;126:424-432.

34. Farrall AJ, Wardlaw JM. Blood-brain barrier: ageing and microvascular disease - systematic review and meta-analysis. Neurobiol Aging. 2009;30:337-352.

35. Wardlaw JM, Farrall A, Armitage PA, Carpenter T, Chappell F, Doubal F, Chowdhury D, Cvoro V, Dennis MS. Changes in background blood-brain barrier integrity between lacunar and cortical ischemic stroke subtypes. Stroke. 2008;39:1327-1332.

36. Kwa VIH, van der Sande JJ, Stam J, Tijmes N, Vrooland JL. Retinal arterial changes correlate with cerebral small-vessel disease. Neurology. 2002;59:1536-1540.

37. Ross R. Atherosclerosis-an inflammatory disease. NEJM. 1999;340:115-126.

38. Jerrard-Dunne P, Cloud G, Hassan A, Markus HS. Evaluating the genetic component in ischemic stroke subtypes. A family history study. Stroke. 2003;34:1364-1369.

39. ladecola C, Gorelick PB. Hypertension, angiotensin, and stroke: beyond blood pressure. Stroke. 2004;35:348-350.

40. Sokol SI, Portnay EL, Curtis JP, Nelson MA, Hebert PR, Setaro JF, Foody JM. Modulation of the renin-angiotensin-aldosterone system for the secondary prevention of stroke. Neurology. 2004;63: 208-213.

41. Elbaz A, Amarenco P. Genetic susceptibility and lacunar stroke. In: Donnan G, Norrving B, Bamford J, Bogousslavsky J, eds. Subcortical stroke. Oxford University Press; 2002:99-110.

42. Van Vlierberghe $\mathrm{H}$, Langlois $\mathrm{M}$, Delanghe J. Haptoglobin polymorphisms and iron homeostasis in health and in disease. Clin Chim Acta. 2004;345:35-42.

43. Langlois MR, Delanghe JR. Biological and clinical significance of haptoglobin polymorphism in humans. Clin Chem. 1996;42:1589-1600.

44. Delanghe J, Langlois M, Duprez D, de Buyzere M, Clement D. Haptoglobin polymorphism and peripheral arterial occlusive disease. Atherosclerosis. 1999;145:287-292.

45. Delanghe J, Cambier B, Langlois $M$, de Buyzere $M$, Neels $H$, de Bacquer D, van Cauwelaert $P$. Haptoglobin polymorphism, a genetic risk factor on coronary artery bypass surgery. Atherosclerosis. 1997;132:215-219.

46. Nakhoul F, Zoabi R, Kanter Y, Zoabi M, Skorecki K, Hochberg I, Leibu R, Miller B, Levy A. Haptoglobin phenotype and diabetic nephropathy. Diabetologia. 2001;44:602-604. 
47. Levy AP, Hochberg I, Jablonski K, Resnick HE, Lee ET, Best L, Howard BV. Haptoglobin phenotype is an independent risk factor for cardiovascular disease in individuals with diabetes: the Strong Heart Study. J Am Coll Cardiol. 2002;40:1984-1990.

48. Jackson C, Sudlow C. Are lacunar strokes really different? A systematic review of differences in risk factor profiles between lacunar and nonlacunar infarcts. Stroke. 2005;36:891-904.

49. Adams Jr HP, Bendixen BH, Kapelle $\sqcup$, Biller J, Love BB, Gordon DL, Marsh EE. Classification of subtype of acute ischemic stroke: definitions for use in a multicenter clinical trial. TOAST. Stroke. 1993;24:35-41.

50. Lodder J, Bamford JM, Sandercock PAG, Jones LN, Warlow CP. Are hypertension or cardiac embolism likely causes of lacunar infarction? Stroke. 1990;21:375-381.

51. Grau AJ, Weimar C, Buggle F, Heinrich A, Goertler M, Neumaier S, Glahn J, Brandt T, Hacke W, Diener H-C. Risk factors, outcome, and treatment in subtypes of ischemic stroke. Stroke. 2001; 32:2559-2566.

52. Norrving B, Crenqvist S. Clinical and radiological features of lacunar versus nonlacunar minor stroke. Stroke. 1989;20:59-64.

53. Boiten J, Lodder J. Lacunar infarcts, pathogenesis and validity of the clinical syndromes. Stroke. 1991;22:1374-1378.

54. Tegeler CH, Shi F, Morgan T. Carotid stenosis in lacunar stroke. Stroke. 1991;22:1124-1128.

55. Boiten J, Luijckx GJ, Kessels F, Lodder J. Risk factors for lacunes. Neurology. 1996;47:1109.

56. Khan U, Porteous L, Hassan A, Markus HS. Risk factor profile of cerebral small vessel disease and its subtypes. J Neurol Neurosurg Psychiatry. 2007;78:702-706.

57. Schmal M, Marini C, Carolei A, di Napoli M, Kessels F, Lodder J. Different vascular risk profiles among cortical infarcts, small deep infarcts, and primary intracerebral haemorrhage point to different types of underlying vasculopathy. Cerebrovasc Dis. 1998;8:14-19.

58. Perry HM, Davis BR, Price TR, Applegate WB, Fields WS, Guralnik JM, Kuller L, Pressel S, Stamler J, Probstfield J. Effect of treating isolated systolic hypertension on the risk of developing various types and subtypes of stroke. JAMA. 2000;284:465-471.

59. Chapman N, Huxley R, Anderson C, Bousser MG, Chalmers J, Colman S, Davis S, Donnan G, MacMahon S, Neal B, Warlow C, Woodward M. Effects of perindopril-based blood pressurelowering regimen on the risk of recurrent stroke according to stroke subtype and medical history. Stroke. 2004;35:116-121.

60. Yusuf S, Diener HC, Sacco RL, Cotton D, Ounpuu S, Lawton WA, Palesch Y, Martin RH, Albers GW, Bath P, Bornstein N, Chan BP, Chen ST, Cunha L, Dahlöf B, De Keyser J, Donnan GA, Estol C, Gorelick P, Gu V, Hermansson K, Hilbrich L, Kaste M, Lu C, Machnig T, Pais P, Roberts R, Skvortsova V, Teal P, Toni D, VanderMaelen C, Voigt T, Weber M, Yoon BW; PRoFESS Study Group. Telmisartan to prevent recurrent stroke and cardiovascular events. N Eng J Med. 2008;359: 1225-1237.

61. Shimada K, Kawamoto A, Matsubayashi K, Ozawa T. Silent cerebrovascular disease in the elderly, correlation with ambulatory pressure. Hypertension. 1990;16:692-699.

62. Verdecchia P, Schillaci G, Guerrieri M, Gatteschi C, Benemio G, Boldrini F, Porcellati C. Circadian blood pressure changes and left ventricular hypertrophy in essential hypertension. Circulation. 1990;81:528-536.

63. Ohkubo T, Hozawa A, Nagai K, Kikuya M, Tsuji I, Ito S, Satoh H, Hisamichi S, Imai Y. Prediction of stroke by ambulatory blood pressure monitoring versus screening blood pressure measurements in a general population: the Ohasama study. J Hypertens. 2000;18:847-854.

64. Staessen JA, Thijs L, Fagard R, O'Brien ET, Clement D, de Leeuw PW, Mancia G, Nachev C, Palatini P, Parati G, Tuomilehto J, Webster J. Predicting cardiovascular risk using conventional vs ambulatory blood pressure in older patients with systolic hypertension. JAMA. 1999;282:539-546.

65. Shimada K, Kawamoto A, Matsubayashi K, Nishinaga M, Kimura S, Ozawa T. Diurnal blood pressure variations and silent cerebrovascular damage in elderly patients with hypertension. J Hypertens. 1992;10:875-878.

66. O'Sullivan M, Duggan J, Lyons S, Thornton J, Lee M, O'Brien E. Hypertensive target-organ damage in the very elderly. Hypertension. 2003;42:130-135. 
67. Sierra C, de la Sierra A, Mercader J, Gomez-Angelats E, Urbano-Marquez A, Coca A. Silent cerebral white matter lesions in middle-aged essential hypertensive patients. J Hypertens. 2002;20: 519-524.

68. Goldstein IB, Bartzokis G, Hance DB, Shapiro D. Relationship between blood pressure and subcortical lesions in healthy elderly people. Stroke. 1998;29:765-772.

69. Sander D, Winbeck K, klingelhofer J, Conrad B. Extent of cerebral white matter lesions is related to changes of circadian blood pressure rhythmicity. Arch Neurol. 2000;57:1302-1307.

70. Schwartz GL, Bailey KR, Mosley T, Knopman DS, Jack CR, Canzanello VJ, Turner ST. Association of ambulatory blood pressure with ischemic brain injury. Hypertension. 2007;49:1228-1234.

71. van Boxtel MP, Henskens LH, Kroon AA, Hofman PA, Gronenschild EH, Jolles J, de Leeuw PW. Ambulatory blood pressure, asymptomatic cerebrovascular damage and cognitive function in essential hypertension. J Hum Hypertens. 2006;20:5-13.

72. Chamorro A, Saiz A, Vila N, Ascaso C, Blanc R, Alday M, Pujol J. Contribution of arterial blood pressure to the clinical expression of lacunar infarction. Stroke. 1996;27:388-392.

73. Chamorro A, Pujol J, Saiz A, Vila N, Vilanova JC, Alday M, Blanc R. Periventricular white matter lucencies in patients with lacunar stroke. A marker of too high or too low blood pressure? Arch Neurol. 1997;54:1284-1288.

74. Yamamoto Y, Akiguchi I, Oiwa K, Hayashi M, Ohara T, Ozasa K. The relationship between 24-hour blood pressure readings, subcortical ischemic lesions and vascular dementia. Cerebrovasc Dis. 2005;19:301-308.

75. Yamamoto Y, Akiguchi I, Oiwa K, Hayashi M, Kimura J. Adverse effect of nighttime blood pressure on the outcome of lacunar infarct patients. Stroke. 1998;29:570-576.

76. Yamamoto Y, Akiguchi I, Oiwa K, Hayashi M, Imai K. Twenty-four-hour blood pressure changes in the course of lacunar disease. Cerebrovasc Dis. 2001;11:100-106.

77. Verdecchia P, Schillaci G, Gatteschi C, Zampi I, Battistelli M, Bartoccini C, Porcellati C. Blunted nocturnal fall in blood pressure in hypertensive women with future cardiovascular morbid events. Circulation. 1993;88:986-992.

78. Pickering T, Schwartz J, Verdecchia P, Imai Y, Kario K, Eguchi K, Pierdomenico S, Ohkubo T, Wing L. Prediction of strokes versus cardiac events by ambulatory monitoring of blood pressure: results from an international database. Blood Press Monit. 2007;12:397-399.

79. Kukla C, Sander D, Schwarze J, Wittich I, Klingelhofer J. Changes of circadian blood pressure patterns are associated with the occurence of lacunar infarction. Arch Neurol. 1998;55:683-688.

80. Kario K, Matsuo T, Kobayashi H, Imiya M, Matsuo M, Shimada K. Nocturnal fall of blood pressure and silent cerebrovascular damage in elderly hypertensive patients. Hypertension. 1996;27: 130-135.

81. Watanabe N, Imai Y, Nagai K, Tsuji I, Satoh H, Sakuma M, Sakuma H, Kato J, Onodera-Kikuchi N, Yamada M, Abe F, Hisamichi S, Abe K. Nocturnal blood pressure and silent cerebrovascular lesions in elderly Japanese. Stroke. 1996;27:1319-1327.

82. Kohara K, Igase M, Yinong J, Fukuoka T, Maguchi M, Okura T, Kitami Y, Hiwada K. Asymptomatic cerebrovascular damages in essential hypertension in the elderly. Am J Hypertens. 1997;10: 829-835.

83. Nakamura K, Oita J, Yamaguchi T. Nocturnal blood pressure dip in stroke survivors. Stroke. 1995;26:1373-1378.

84. Paulson OB, Strandgaard S, Edvinsson L. Cerebral autoregulation. Cerebrovasc Brain Metab Rev. 1990;2:161-192.

85. Matsushita K, Kuriyama Y, Nagatsuka K, Nakamura M, Sawada T, Omae T. Periventricular white matter lucency and cerebral blood flow autoregulation in hypertensive patients. Hypertension. 1994;23:565-568.

86. Terborg C, Gora F, Weiller C, Rother J. Reduced vasomotor reactivity in cerebral microangiopathy. Stroke. 2000;31:924-929.

87. Cordonnier C, Salman RA, Wardlaw J. Spontaneous brain microbleeds: systematic review, subgroup analyses and standards for study design and reporting. Brain. 2007;130:1988-2003.

88. Koennecke H-C. Cerebral microbleeds on MRI: prevalence, associations, and potential clinical implications. Neurology. 2006;66:165-171. 
89. van Es ACGM, van der Grond J, de Craen AJM, Admiraal-Behloul F, Blauw GJ, van Buchem MA. Risk factors for cerebral microbleeds in the elderly. Cerebrovasc Dis. 2008;26:397-403.

90. Fazekas F, Kleinert R, Roob G, Kleinert G, Kapeller P, Schmidt R, Hartung H-P. Histopathologic analysis of foci of signal loss on gradient-echo T2*-weighted MR images in patients with spontaneous intracerebral hemorrhage: evidence of microangiopathy-related microbleeds. AJNR Am J Neuroradiol. 1999;20:637-642.

91. Tatsumi S, Shinohara M, Yamamoto T. Direct comparison of microbleeds with postmortem MR images. Cerebrovasc Dis. 2008;26:142-146.

92. Tanaka A, Ueno Y, Nakayama Y, Takano K, Takebayashi S. Small chronic hemorrhages and ischemic lesions in association with spontaneous intracerebral hematomas. Stroke. 1999; 30:1637-1642.

93. Vernooij MW, van der Lugt A, Ikram MA, Wielopolski PA, Niessen WJ, Hofman A, Krestin GP, Breteler MM. Prevalence and risk factors of cerebral microbleeds: the Rotterdam Scan Study. Neurology. 2008;70:1208-1214.

94. Imaizumi T, Horita Y, Hashimoto Y, Niwa J. Dotlike hemosiderin spots on T2*-weighted magnetic resonance imaging as a predictor of stroke recurrence: a prospective study. J Neurosurg. 2004; 101:915-920.

95. Greenberg SM, Eng JA, Ning M, Smith EE, Rosand J. Hemorrhage burden predicts recurrent intracerebral hemorrhage after lobar hemorrhage. Stroke. 2004;35:1415-1420.

96. Werring DJ, Frazer DW, Coward LJ, Losseff NA, Watt H, Cipolotti L, Brown MM, Jager HR. Cognitive dysfunction in patients with cerebral microbleeds on T2*-weighted gradient-echo MRI. Brain. 2004;127:2265-2275. 


\section{Chapter}

\section{Differences in long-term survival in two lacunar stroke types: a 15-year follow-up study in 782 cerebral infarct patients}

J Staals

L van Raak

A Hilton

J Lodder

Cerebrovasc Dis 2008;25:26-31 


\section{Abstract}

\section{Background}

Mortality studies in lacunar stroke are scarce and often characterized by short follow-up time, small patient groups and absence of a nonlacunar stroke group for comparison. Besides, there are no separate long-term prognostic data on lacunar stroke subtypes. We performed a long-term mortality study in lacunar stroke, subtyping two distinct phenotypes and including nonlacunar ischemic stroke for comparison.

\section{Methods}

We performed cross-sectional follow-up, determining survival status, after a median of 15.0 years, in 333 first-ever atherothrombotic (AT), 184 cardioembolic (CE) and 265 lacunar (LAC) strokes, distinguishing LAC with (type 2) or without (type 1) asymptomatic lacunar lesions on CT.

\section{Results}

End of follow-up mortality (in 30-day survivors) in LAC (76.2\%) was significantly lower than in CE (87.1\%; OR 0.48, 95\% Cl 0.27-0.84), but not AT (79.0\%; OR 0.85, 95\% Cl 0.57-1.26); and was significantly lower in LAC type 1 than type 2 (70.9\% vs. $87.5 \%$; OR 0.35, 95\% $\mathrm{Cl} 0.17-0.73$ ). Kaplan-Meier analysis showed most favorable survival in LAC type 1 . In the Cox regression analyses LAC type 1 appeared as an independent predictor of better survival vs. type 2 , vs. AT and vs. CE.

\section{Conclusions}

Lacunar stroke in general cannot be considered a "benign" stroke type: only long-term survival in patients without concomitant asymptomatic lacunar lesions is better than in large vessel stroke. This difference in long-term survival between the two lacunar stroke subtypes should be taken into account in prognostic counselling of individual lacunar stroke patients. 


\section{Introduction}

Knowledge about long-term prognosis for mortality in ischemic stroke is not only important for counselling individual patients, but also for improvement of primary and secondary prevention. Although lacunar stroke accounts for about a quarter of ischemic stroke, mortality studies are less abundant compared to the other types of ischemic stroke. ${ }^{1}$ Lacunar stroke is generally considered a rather "benign" stroke but data on long-term prognosis are scarce. Few mortality studies in lacunar stroke had a follow-up over five years, patient numbers were rather small, and few included comparison with other stroke types. ${ }^{2-6}$

Lacunar infarcts are small, deeply in the brain located infarcts, mostly caused by local pathology in a small perforating artery. Earlier, we distinguished two types of lacunar stroke patients: those with a single symptomatic lesion on cerebral imaging and those with multiple additional "silent" lacunar lesions. ${ }^{7}$ We found that prognosis for short-term functional outcome, recurrent stroke and survival is more unfavorable in the second type. ${ }^{8}$ However, there are no long-term prognostic data on these lacunar subtypes.

We performed a long-term follow-up study on mortality in lacunar stroke, subtyping two distinct phenotypes. Nonlacunar ischemic stroke was included for comparison.

\section{Methods}

Between July 1987 and July 1992 all inpatients and outpatients with a first-ever supratentorial brain infarct were registered in the Maastricht Stroke Registry, University Hospital Maastricht, the Netherlands. ${ }^{8}$ All patients underwent standard stroke investigations as described previously.8,9 Brain CTscan was performed in 96\% of the patients. In the absence of CT we used the Allen score to determine the probability that the stroke was due to infarction. ${ }^{10,11}$ Patients with a score of less than 4 , i.e. with a probability of more than $90 \%$ that their stroke was of ischemic origin, were included in the register. Vascular risk factors, i.e. hypertension, diabetes mellitus and ischemic heart disease, defined according to previously published criteria, were listed. 8,9

\section{Stroke types}

We distinguished atherothrombotic (AT), cardioembolic (CE) and lacunar (LAC) strokes. These were defined as described previously.8,9 Patients with a rare, specific stroke cause, such as cerebral vasculitis, carotid artery dissection, or venous occlusion, were not included.

Besides for a symptomatic infarct, CT scans were also reviewed for the presence of leukoaraiosis and asymptomatic lacunar infarcts. 
Leukoaraiosis: focal or diffuse hypodensities in the periventricular or deep white matter, not involving the cortex, and with ill-defined margins to distinguish them from infarction. No effort was made to quantify the degree of white matter density, as this might depend on the tuning of the CT scan.

Asymptomatic lacunar infarcts: a subcortical small sharply demarcated hypodense lesion with a diameter of less than $15 \mathrm{~mm}$, but not compatible with the presenting stroke syndrome and stroke lesion site. We distinguished lacunar stroke patients with one or more asymptomatic lacunar infarcts (LAC type 2) from those without (LAC type 1).

Two neurologists reviewed CT scans independently, and in case of disagreement tried to reach consensus by argument; otherwise CT was regarded as negative.

\section{Cross-sectional follow-up}

We collected survival status of every patient recorded on May 1, 2005. If the patient had died, we collected the date of death through the hospital registry, the national or municipal population registry, family doctor's registry or nursing home registry.

\section{Statistical analysis}

We used SPSS 11.0.1 software package for Windows. Baseline characteristics were compared using $\chi^{2}$ tests for proportions or t-tests for group means. We calculated 30-day case fatality and end of follow-up mortality in 30-day survivors. Mortality rates between stroke types were compared by $\chi^{2}$ testing, with results expressed as odds ratio (OR) with 95\% confidence interval $(\mathrm{Cl})$ and $\mathrm{p}$-value. We constructed Kaplan-Meier survival curves with log rank tests for significance. Cox proportional hazards regression analysis was used to look for independent contribution of age, sex and other known risk factors for long-term mortality in stroke: diabetes mellitus, ischemic heart disease and hypertension. ${ }^{12-14}$ Results are expressed as OR with $95 \% \mathrm{Cl}$ and $\mathrm{p}$-value.

\section{Results}

Of 790 patients with a first-ever supratentorial brain infarct eight (four AT, four LAC) who could not be traced and of whom we were unable to determine whether they had died or not, were excluded. Thus, 782 patients remained: 333 (42.6\%) AT, 184 (23.5\%) CE, 265 (33.9\%) LAC. Table 2.1 presents baseline characteristics. Median follow-up time was 15.0 (12.8-17.8) years. During follow-up 638 (81.6\%) patients had died. 


\section{Mortality in stroke types}

Table 2.1 shows 30-day case fatality and end of follow-up mortality (in 30-day survivors) in the different stroke types, and compares mortality figures between stroke types. Thirty-day case fatality was significantly lower in LAC than in the two other stroke types. There was no significant difference in mortality at the end of follow-up between LAC and AT. Figure 2.1 shows Kaplan-Meier survival curves of the three different stroke types. Log rank testing revealed a significant difference between the three survival lines with LAC having the highest survival rate.

Cox regression analysis (Table 2.2) identified age, male sex, diabetes mellitus, and stroke type (only CE vs. LAC) as independent predictors of poorer long-term survival.

Table 2.1 Baseline characteristics and mortality in three ischemic stroke types.

\section{a Baseline characteristics}

\begin{tabular}{lcccc}
\hline & AT & CE & LAC & All \\
\hline Number of patients $^{*}$ & 333 & 184 & 265 & 782 \\
Age (years) $^{*}$ & 70.5 & 74.7 & 68.1 & 70.7 \\
Male $^{\dagger}$ & $186(55.9 \%)$ & $75(40.8 \%)$ & $148(55.8 \%)$ & $409(52.3 \%)$ \\
Hypertension $^{\text {Diabetes mellitus }}$ & $145(43.5 \%)$ & $89(48.4 \%)$ & $129(48.7 \%)$ & $363(46.4 \%)$ \\
Ischemic heart disease $^{\dagger}$ & $62(18.6 \%)$ & $40(21.7 \%)$ & $54(20.4 \%)$ & $156(19.9 \%)$ \\
Leukoaraiosis $^{\dagger}$ & $90(27.0 \%)$ & $63(34.2 \%)$ & $55(20.8 \%)$ & $208(26.6 \%)$ \\
30-day case fatality $^{\dagger}$ & $65(19.5 \%)$ & $42(22.8 \%)$ & $77(29.1 \%)$ & $184(23.5 \%)$ \\
End of follow-up mortality & $28(8.4 \%)$ & $45(24.5 \%)$ & $5(1.9 \%)$ & $78(10.0 \%)$ \\
(in 30-day survivors) ${ }^{\dagger}$ & $241(79.0 \%)$ & $121(87.1 \%)$ & $198(76.2 \%)$ & $560(79.5 \%)$ \\
\hline
\end{tabular}

b Thirty-day case fatality

\begin{tabular}{lccr}
\hline & OR & $95 \% \mathrm{Cl}$ & p-value \\
\hline AT vs. CE & 0.28 & $0.17-0.47$ & $<0.001$ \\
LAC vs. CE & 0.06 & $0.02-0.15$ & $<0.001$ \\
LAC vs. AT & 0.21 & $0.08-0.55$ & 0.001 \\
\hline
\end{tabular}

c End of follow-up mortality (in 30-day survivors)

\begin{tabular}{lccc}
\hline & OR & $95 \%$ Cl & p-value \\
\hline AT vs. CE & 0.56 & $0.32-0.99$ & 0.04 \\
LAC vs. CE & 0.48 & $0.27-0.84$ & 0.01 \\
LAC vs. AT & 0.85 & $0.57-1.26$ & 0.42 \\
\hline
\end{tabular}

${ }^{*}$ t-test, $p<0.001 ;{ }^{\dagger} \chi^{2}$ test, $p<0.05$

Table 2.2 Mortality (of 30-day survivors) in ischemic stroke (associations by Cox regression analysis).

\begin{tabular}{lccc}
\hline & OR & $95 \%$ Cl & p-value \\
\hline Age & 1.10 & $1.09-1.11$ & $<0.001$ \\
Male & 1.41 & $1.18-1.69$ & $<0.001$ \\
Diabetes mellitus & 1.37 & $1.11-1.70$ & 0.004 \\
Ischemic heart disease & 1.12 & $0.93-1.36$ & 0.24 \\
Hypertension & 1.18 & $0.99-1.40$ & 0.06 \\
Stroke type & & & 0.04 \\
$\quad$ AT vs. CE & 0.84 & $0.68-1.05$ & 0.13 \\
$\quad$ LAC vs. CE & 0.74 & $0.59-0.93$ & 0.01 \\
$\quad$ LAC vs. AT & 0.88 & $0.73-1.06$ & 0.19 \\
\hline
\end{tabular}




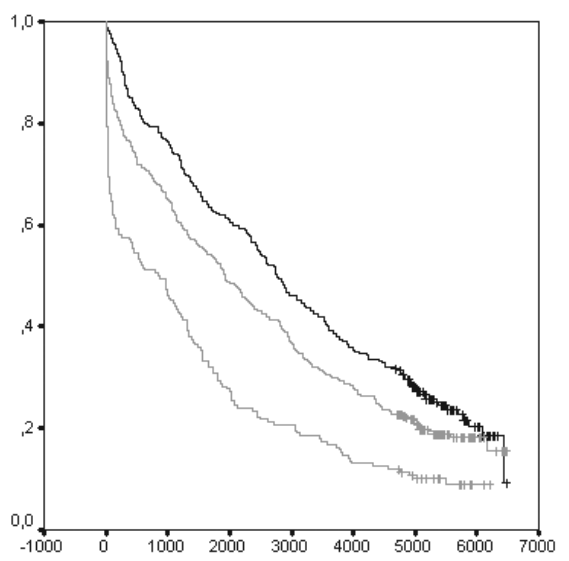

Figure 2.1 Kaplan-Meier survival curve in three ischemic stroke types. Top line=LAC; middle line=AT; bottom line $=C E$. Log rank: $54.88 ; p<0.001$. $X$-axis in days.

\section{Two lacunar stroke subtypes}

Six of the 265 LAC patients of whom CT was not available were excluded, leaving 259 patients. We distinguished 80 (30.9\%) patients with one or more asymptomatic lacunar infarcts on CTscan (type 2), and 179 (69.1\%) without (type 1). Table 2.3 shows baseline characteristics.

\section{Mortality in lacunar stroke subtypes}

At the end of follow-up $197(76.1 \%)$ of the lacunar stroke patients had died: 127 (70.9\%) of type 1 , and 70 (87.5\%) of type 2 (OR 0.35; 95\% Cl 0.17-0.73; $p=0.004$ ). Only five of these patients had died within the first 30 days. As shown in the Kaplan-Meier survival curve (Figure 2.2), type 2 had a lower survival rate than type 1 ( $p=0.001$ ). Cox regression analysis (in 30-day survivors) showed that LAC subtype was independently associated with survival (Table 2.4 ).

Cox regression analysis (in 30-day survivors) of LAC subtypes, together with the other stroke types, revealed LAC type 1 as a predictor of lower mortality versus LAC type 2 (OR 0.72; 95\% Cl 0.54-0.97; $p=0.033$ ), versus AT (OR 0.78; 95\% Cl 0.63$0.97 ; p=0.027$ ), and versus CE (OR 0.66; 95\% Cl 0.51-0.85; $p=0.001)$. Comparing LAC type 2 versus AT and versus CE, and AT versus CE yielded no statistically significant differences, whereas the other factors did not change significantly (results not shown but similar to Table 2.2). 
Table 2.3 Baseline characteristics of patients with lacunar stroke.

\begin{tabular}{|c|c|c|}
\hline & LAC type 1 & LAC type 2 \\
\hline Number of patients & 179 & 80 \\
\hline Age (years) * & 66.8 & 70.0 \\
\hline Male & $97 \quad(54.2 \%)$ & $46 \quad(57.5 \%)$ \\
\hline Hypertension & 81 (45.3\%) & $46 \quad(57.5 \%)$ \\
\hline Diabetes mellitus & 38 (21.2\%) & $16 \quad(20.0 \%)$ \\
\hline Ischemic heart disease & $40 \quad(22.3 \%)$ & $12(15.0 \%)$ \\
\hline Leukoaraiosis ${ }^{\dagger}$ & $27 \quad(15.1 \%)$ & $50 \quad(62.5 \%)$ \\
\hline
\end{tabular}

${ }^{*}$ t-test, $p=0.03 ;{ }^{\dagger} \chi^{2}$ test, $p<0.001$

Table 2.4 Mortality (of 30-day survivors) in lacunar stroke (associations by Cox regression analysis).

\begin{tabular}{lccc}
\hline & OR & $95 \% \mathrm{Cl}$ & p-value \\
\hline Age & 1.09 & $1.07-1.11$ & $<0.001$ \\
Male & 1.56 & $1.16-2.10$ & 0.004 \\
Diabetes mellitus & 1.91 & $1.34-2.71$ & $<0.001$ \\
Ischemic heart disease & 1.44 & $1.01-2.03$ & 0.04 \\
Hypertension & 1.22 & $0.90-1.64$ & 0.20 \\
Presence of silent lacunar lesions (LAC type 2 vs. type 1) & 1.41 & $1.04-1.91$ & 0.03 \\
\hline
\end{tabular}

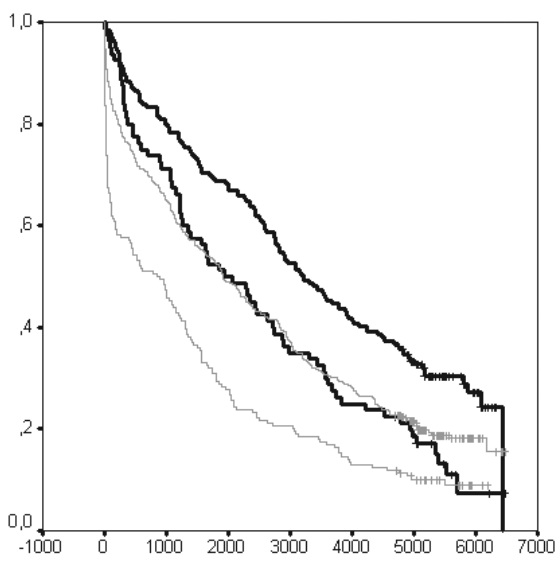

Figure 2.2 Kaplan-Meier survival curve in two LAC stroke subtypes, CE and AT stroke. Top black line=LAC type 1; bottom black line=LAC type 2; top grey line=AT; bottom grey line=CE. Log rank: 63.94; $p<0.001$. $X$-axis in days.

\section{Leukoaraiosis}

Cox regression analysis (in 30-day survivors) including leukoaraiosis in addition to age, sex, diabetes mellitus, ischemic heart disease and hypertension showed leukoaraiosis to be an independent predictor of mortality only in LAC (OR 1.45; 95\% Cl 1.05-2.00; $p=0.025$ ), but not in AT or CE (results not shown). 


\section{Discussion}

The most important finding of our study is that long-term survival in small vessel stroke is not significantly different from that in large vessel stroke. It supports our earlier findings on short-term (two year) prognosis which also indicated that lacunar stroke cannot be considered as a more "benign" stroke subtype. ${ }^{9}$ Only early case fatality rate is lower than in large vessel stroke. Sacco et al. have recently found better 5-year survival in lacunar stroke, which also largely depended on a low early mortality, whereas from the third year onward annual mortality did not differ from nonlacunar stroke. ${ }^{15}$

However, when the two lacunar subtypes are considered, it is clear from our analysis that this conclusion should be mitigated: the lacunar type without multiple lacunar lesions has a significantly better prognosis for long-term survival, whereas the other type catches up with the large vessel stroke type over time. This distinction should be kept in mind when considering prognosis in individual lacunar stroke patients.

Because early mortality in lacunar stroke is low, studies on pathology are scarce. As pointed out by the work of Fisher in the 1960s, and more recently that of Lammie, two vascular pathologies of small vessel disease seem to exist: lipohyalinosis, or also called arteriolosclerosis, was found mainly in brains with multiple lacunar lesions and leukoaraiosis, and microatheromatosis, in cases with a single lacunar lesion. ${ }^{16,17}$ Earlier we hypothesized that the two lacunar stroke subgroups that can be distinguished on neuro-imaging and clinical grounds represent these distinct vascular pathologies. ${ }^{7,8}$ The currently found difference in long-term mortality is in line with our former findings of differences in vascular risk factor profile, association with leukoaraiosis, asymptomatic lesion progression and short-term prognosis for functional outcome, recurrent stroke and mortality. $7,8,18$ Leukoaraiosis, which presence and degree is related to lacunar infarcts, may be used to further purify lacunar subtypes. ${ }^{19}$ Pathology studies show arteriolosclerosis to be the underlying vascular pathology in leukoaraiosis. ${ }^{20,21}$ Leukoaraiosis and multiple asymptomatic lacunar lesions are strongly associated, which argues in favor of similar vascular pathology. ${ }^{7}$ Previously it was shown that leukoaraiosis is a predictor of (short-term) mortality in lacunar stroke and elderly neurological patients, and in our analysis leukoaraiosis was also a predictor of long-term mortality in lacunar stroke. ${ }^{22,23}$ It is obvious that the distinction between different small vessel pathologies on clinical grounds can never be made with $100 \%$ certainty, but it may be valid enough to facilitate future research into differences in pathogenesis at cell-biological and genetic level.

Our study has some drawbacks. It was hospital-based but we registered both inpatients and outpatients. Our hospital is the only hospital in the adherent referral area, and we registered over $90 \%$ of all strokes in our community. ${ }^{24}$ Therefore, major bias seems unlikely. When we started the study almost 20 years ago, we 
used CT. In particular CT-negative lacunar cases may have been wrongly classified. However, earlier we found that the judgement of trained clinicians is rather reliable. ${ }^{25,26}$ We included only supratentorial ischemic strokes because cerebellar and brainstem stroke may be more heterogeneous in cause. Mortality studies in lacunar stroke are often characterized by methodological concerns such as short follow-up time, small patient groups and absence of a nonlacunar stroke group for comparison. ${ }^{2,3,27}$ The unique point of our study is that it had a long median followup time of 15 years and included a large group of 782 patients, which made it possible to analyze different stroke subtypes.

In summary, lacunar stroke cannot merely be considered a rather "benign" stroke type, as only long-term survival in patients with a single lacunar lesion, unlike those with multiple lacunar lesions, is better than in large vessel stroke. The difference in long-term survival between the two lacunar stroke subtypes should be taken into account in prognostic counselling of individual lacunar stroke patients. Prognostically validated distinction of stroke subtypes may facilitate future research into differences in stroke cause on cell-biological and genetic level. 


\section{References}

1. Bamford J, Sandercock P, Jones L, Warlow C. The natural history of lacunar infarction: the Oxfordshire community stroke project. Stroke. 1987;18:545-551.

2. $\quad$ Norrving B. Long-term prognosis after lacunar infarction. Lancet Neurol. 2003;2:238-245.

3. Jackson C, Sudlow C. Comparing risks of death and recurrent vascular events between lacunar and non-lacunar infarction. Brain. 2005;128:2507-2517.

4. Eriksson S-E, Olsson J-E. Survival and recurrent strokes in patients with different subtypes of stroke: a fourteen-year follow-up study. Cerebrovasc Dis. 2001;12:171-180.

5. Appelros P, Samuelsson M, Lindell D. Lacunar infarcts: functional and cognitive outcomes at five years in relation to MRI findings. Cerebrovasc Dis. 2005;20:34-40.

6. Liu X, Xu G, Wu W, Zhang R, Yin Q, Zhu W. Subtypes and one-year survival of first-ever stroke in Chinese patients: the Nanjing Stroke Registry. Cerebrovasc Dis. 2006;22:130-136.

7. Boiten J, Lodder J, Kessels F. Two clinically distinct lacunar infarct entities? A hypothesis. Stroke. 1993;24:652-656.

8. de Jong G, Kessels F, Lodder J. Two types of lacunar infarcts, further arguments from a study on prognosis. Stroke. 2002;33:2072-2076.

9. de Jong G, van Raak L, Kessels F, Lodder J. Stroke subtype and mortality: a follow-up study in 998 patients with a first cerebral infarct. J Clin Epidemiol. 2003;56:262-268.

10. Allen CM. Clinical diagnosis of the acute stroke syndrome. Q J Med. 1983;208:515-523.

11. Celani MG, Ceravolo MG, Duca E, Minciotti P, Caputo N, Orlandini M, Ricci S, Provinciali L. Was it infarction or haemorrhage? A clinical diagnosis by means of the Allen score. J Neurol. 1992; 239:411-413.

12. Sacco RL, Wolf PA, Kannel WB, McNamara PM. Survival and recurrence following stroke. The Framingham study. Stroke. 1982;13:1982.

13. Viitanen M, Eriksson S, Asplund K, Wester PO, Winblad B. Determinants of long-term mortality after stroke. Acta Med Scand. 1987;221:349-356.

14. Kammersgaard LP, Olsen TS. Cardiovascular risk factors and 5-year mortality in the Copenhagen Stroke Study. Cerebrovasc Dis. 2006;21:187-193.

15. Sacco S, Marini C, Totaro R, Russo T, Cerone D, Carolei A. A population-based study of the incidence and prognosis of lacunar stroke. Neurology. 2006;66:1335-1338.

16. Fisher CM. The arterial lesions underlying lacunes. Acta neuropath (Berl). 1969;12:1-15.

17. Lammie GA, Brannan F, Slattery J, Warlow CP. Nonhypertensive cerebral small-vessel disease. An autopsy study. Stroke. 1997;28:2222-2229.

18. van Zagten M, Boiten J, Kessels F, Lodder J. Significant progression of white matter lesions and small deep (lacunar) infarcts in patients with stroke. Arch Neurol. 1996;53:650-655.

19. Basile AM, Pantoni L, Pracucci G, Asplund K, Chabriat H, Erkinjuntti T, Fazekas F, Ferro JM, Hennerici M, O'Brien J, Scheltens P, Visser MC, Wahlund LO, Waldemar G, Wallin A, Inzitari D. Age, hypertension, and lacunar stroke are the major determinants of the severity of age-related white matter changes. The LADIS (Leukoaraiosis and Disability in the Elderly) Study. Cerebrovasc Dis. 2006;21:315-322.

20. van Swieten JC, van den Hout JHW, van Ketel BA, Hijdra A, Wokke JHJ, van Gijn J. Periventricular lesions in the white matter on magnetic resonance imaging in the elderly: a morphometric correlation with arteriolosclerosis and dilated perivascular spaces. Brain. 1991;114:761-774.

21. Fazekas F, Kleinert R, Offenbacher H, Schmidt R, Kleinert G, Payer F, Radner H, Lechner H. Pathologic correlates of incidental MRI white matter signal hyperintensities. Neurology. 1993; 43:1683-1689.

22. Miyao S, Takano A, Teramoto J, Takahashi A. Leukoaraiosis in relation to prognosis for patients with lacunar infarction. Stroke. 1992;23:1434-1438.

23. Inzitari D, Cadelo M, Marranci ML, Pracucci G, Pantoni L. Vascular deaths in elderly neurological patients with leukoaraiosis. J Neurol Neurosurg Psychiatry. 1997;62:177-181.

24. Heuts-van Raak L. Seizures following a first cerebral infarct. Risk factors and prognosis. Dissertation, University Maastricht; 1996. 
25. Boiten J, Lodder J. Lacunar infarcts, pathogenesis and validity of the clinical syndromes. Stroke. 1991;22:1374-1378.

26. Lodder J, Bamford JM, Kappelle J, Boiten J. What causes false clinical prediction of small, deep infarcts. Stroke. 1994;25:86-91.

27. Staaf G, Lindgren A, Norrving B. Pure motor stroke from presumed lacunar infarct: long-term prognosis for survival and risk of recurrent stroke. Stroke. 2001;32:2592-2596. 



\section{A SELDI-TOF-MS study in lacunar stroke with subsequent haptoglobin phenotyping}

J Staals

JAP Bons

RJ van Oostenbrugge

ILH Knottnerus

MP van Dieijen-Visser

FG Bouwman

EC Mariman

JR Delanghe

J Lodder

WKWH Wodzig

Curr Neurovasc Res 2008;5:93-98 


\section{Abstract}

Using Surface-Enhanced Laser Desorption / Ionization Time-of-Flight Mass Spectrometry (SELDI-TOFMS), we aimed to detect differences in protein profile in serum samples of two lacunar stroke subtypes. SELDI-TOF-MS, followed by protein identification, was performed in samples of 8 first-ever lacunar stroke patients with MR imaging showing a single symptomatic lacunar lesion (type 1), and 8 with multiple additional "silent" lacunar lesions and extensive white matter lesions (type 2). A 16 kDa protein, identified as alpha-2-chain of haptoglobin $(\mathrm{Hp})$, was found to be overrepresented in type 1 compared to type 2 (peak intensity 12.5 vs. 5.0; $p=0.02$ ). As a polymorphism with two alleles, Hp1 and $\mathrm{Hp} 2$, determines the presence of alpha-1 and/or alpha-2-chains in the Hp-molecule, Hp phenotypic analysis was performed. $\mathrm{Hp} 1: \mathrm{Hp} 2$ allele frequency was $0.562: 0.438$ in type 1 and $0.812: 0.188$ in type 2 (population reference $0.4: 0.6$ ).

We conclude that the overrepresentation of the alpha-2-chain in lacunar stroke type 1 compared to type 2 relates to a higher $\mathrm{Hp} 2$ allele frequency in the former. Yet, compared to population reference, the phenotype distribution in both patient groups deviates towards a high $\mathrm{Hp} 1$ allele frequency. Our findings suggest a role for the Hp gene in the etiology of cerebral small vessel disease. Larger studies are now needed to explore this new candidate gene. 


\section{Introduction}

Lacunar infarcts are small, deeply in the brain located infarcts, mostly caused by occlusion of a small perforating artery. ${ }^{1}$ They can present with an acute lacunar stroke syndrome, but can also remain asymptomatic. Lacunar strokes account for about $25 \%$ of all ischemic strokes. Lacunar stroke patients with concomitant "silent" lacunar lesions differ from those patients with only a single symptomatic lesion in having more cerebral white matter lesions (WMLs) on neuro-imaging, having more often hypertension, and having worse prognosis on functional outcome, a higher stroke recurrence rate and higher short- and long-term mortality. ${ }^{2-5}$ Whether the underlying two types of small vessel disease (SVD) are ends of one pathogenetic spectrum or represent two pathogenetically different entities, remains subject of debate. Research into the underlying pathogenetic mechanisms thus far focused on known proteins that are thought to be involved in vascular pathogenesis, such as coagulation and inflammation factors ${ }^{6-9}$, and their genetic determinants. ${ }^{10-12}$

To obtain new insight in the underlying pathogenesis of lacunar stroke, we set out to look for possible differences in protein expression profile in patients with or without extensive concomitant silent cerebral SVD using SELDI-TOF-MS (SurfaceEnhanced Laser Desorption / Ionization Time-of-Flight Mass Spectrometry) in serum samples. This technology provides a rapid method to detect expressed proteins in a biological sample. It uses chip surfaces which bind a subset of proteins from a sample. An energy-absorbing matrix is added so that when laser energy is applied to the chip the proteins become ionized, enabling their mass to charge $(\mathrm{m} / \mathrm{z})$ ratio to be measured by time-of-flight mass spectrometry. Protein profiles of different patient groups can be compared to find distinctive patterns.

This approach led us to the finding of a difference between the two lacunar stroke types in the expression of a $16 \mathrm{kDa}$ protein, which was identified as alpha-2-chain of haptoglobin (Hp). These results brought us to the analysis of $\mathrm{Hp}$ polymorphism.

\section{Methods}

\section{Study population}

From May 2003 on, all patients who present with a first-ever stroke are registered in the Maastricht Stroke Registry, a prospective stroke database at University Hospital Maastricht, the Netherlands. Lacunar stroke is defined as an acute stroke syndrome with an MRI finding compatible with the clinical findings and consisting of a T2-weighted hyperintense subcortical small lesion of less than $20 \mathrm{~mm}$ in diameter. ${ }^{13}$ With informed consent, these patients participate in an ongoing lacunar stroke research project for which the local Medical Ethical Committee gave 
approval. From this cohort we selected two groups of each eight patients, according to pre-defined criteria. Eight patients had only one single symptomatic lacunar lesion (type 1). In the eight type 2 patients MRI additionally showed multiple (four or more) asymptomatic lacunar lesions as well as extensive WMLs. Extensive WMLs was defined as confluent deep white matter hyperintensities together with irregular periventricular hyperintensities extending into the deep white matter. ${ }^{14}$ Patients had no potential source of cardiac embolism, diabetes mellitus, ischemic heart disease, peripheral arterial vessel disease or carotid stenosis. Table 3.1 shows patient characteristics. Fasting blood samples were taken at least three months after stroke. Collection of serum samples was standardized by using a clotting time of 30 minutes at room temperature, spinning for 10 minutes at 4000 RPM (3000 g), and storage in aliquots within one hour after blood collection at $-80^{\circ} \mathrm{C}$.

Table 3.1 Patient baseline characteristics.

\begin{tabular}{lll}
\hline Lacunar stroke patients & type 1 & type 2 \\
\hline Number & 8 & 8 \\
Age (median in years) & $57(46-80)$ & $67(44-79)$ \\
Male & 4 & 4 \\
Hypertension & 6 & 6 \\
Smoking & 2 & 1 \\
Number of lacunes (median) & 1 & $5.5(5-11)$ \\
\hline
\end{tabular}

\section{SELDI analysis}

Anion exchange fractionation (Figure 3.1): Serum samples were pre-treated using an anion exchange procedure, which allowed high-throughput fractionation of all 16 serum samples based on the biophysical properties of proteins, as described by Solassol et al. ${ }^{15}$ Serum was separated into six different fractions $(\mathrm{pH} 9, \mathrm{pH} 7, \mathrm{pH}$, $\mathrm{pH} 4, \mathrm{pH} 3$, and organic wash). The procedure was standardized according to Ciphergen protocols. All fractionated serum samples had only two thaw steps from collection to analyzing. After this fractionation the samples were applied on ProteinChips.

ProteinChip arrays: In the screening experiment, denatured serum and six fractions of all 16 patients were applied to two different array surfaces (Ciphergen Biosystems Inc., Fremont, CA, USA) to find out the optimal array and fraction. The weak cation exchange (CM10) and the immobilized metal affinity capture coupled

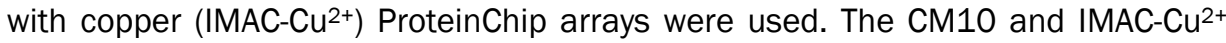
experiments were performed according to Ciphergen protocols. The ProteinChip arrays were read on a Protein Biosystem IIc (Ciphergen Biosystems Inc.) instrument. A well defined protocol for calibration of the PBS IIc, implementation of quality control samples and acceptance criteria for quality control were used. ${ }^{16}$ 


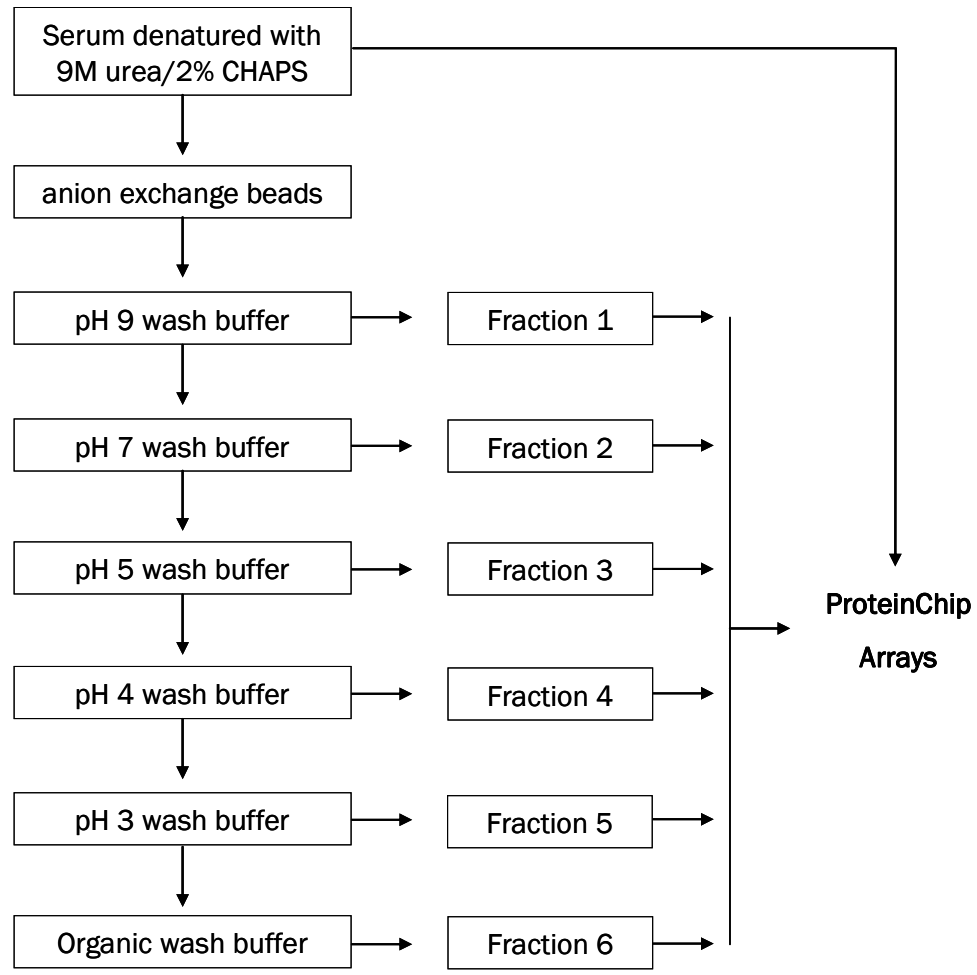

Figure 3.1 Schematic view of the anion exchange fractionation procedure. Samples were added to a filtration plate, and eluted in a stepwise manner, by altering the $\mathrm{pH}$ of the wash buffer.

\section{Data Analysis}

Serum protein profiles of both lacunar stroke groups were compared. Peaks were identified after mass calibration, background subtraction, and normalization using Ciphergen Express Data manager 3.0.6. Cluster analysis was performed using the Biomarker Wizard in the Ciphergen Express Software. The biomarker Wizard parameters were as follows: signal-to-noise ratio for the first pass: 5.0 (peak height) and 3.0 (valley depth) and for the second pass: 3.0 (peak height) and 1.0 (valley depth). The minimal peak threshold was 50\% of all spectra. The cluster mass window was set at 1.0 peak width and the specified $m / z$ range was 2000 to 30,000 for the low range, 5000 to 100,000 for the mid range, and 10,000 to 200,000 for the high range. The Mann-Whitney Wilcoxon test (U-test) was used to detect significant differences in the intensities of the $m / z$ values between both groups. 


\section{Identification}

Protein identification was performed by one-dimensional gel electrophoresis (1-DE) and two-dimensional gel electrophoresis (2-DE) followed by Matrix Assisted Laser Desorption / Ionization Time-of-Flight Mass Spectrometry (MALDI-TOF-MS) as described in the studies of Bouwman et al. with minor modifications. ${ }^{17,18}$ Two patient samples of each group were chosen which presented a clear up- or downregulation in the protein spectra. To identify the $16.1 \mathrm{kDa}$ marker, $10 \mu \mathrm{l}$ of denatured serum sample was diluted in $90 \mu \mathrm{l}$ Milli-Q. Ten $\mu \mathrm{l}$ of this diluted serum sample was subsequently diluted with $2 \mu \mathrm{l} 6 \mathrm{x}$ sample buffer (10\% SDS, 0.6 M DTT, $30 \%$ glycerol, $0.012 \%$ bromophenol blue, $0.35 \mathrm{M}$ Tris) and loaded on 12.5\% sodium dodecyl sulphate-polyacrylamide gel electrophoresis (SDS-PAGE) gels. For the 2-DE, $10 \mu \mathrm{l}$ of the denatured serum sample was diluted in $190 \mu \mathrm{l}$ 2-DE buffer (6 M urea, 30\% glycerol, 2\% SDS and $50 \mathrm{mM}$ Tris-HCL) and was loaded for the first dimension.

\section{Total Hp concentration and Hp phenotyping}

Because of the results of SELDI analysis and protein identification, we measured total $\mathrm{Hp}$ concentration, using particle-enhanced immunonephelometry on the BN Prospec (Dade Behring Inc., Deerfield, IL, USA). Hp phenotyping was carried out using starch gel electrophoresis according to Smithies et al. ${ }^{19}$

\section{Results}

\section{SELDI analysis}

Although the anion exchange fractionating procedure was performed, the best distinctive pattern was found with denatured serum on the IMAC-Cu${ }^{2+}$ ProteinChip array. Three peaks were significantly different between both groups. The peak at $\mathrm{m} / \mathrm{z} 16,122$ was the most prominent discriminating peak, which was up-regulated in lacunar stroke type 1 versus type 2 with mean intensities of 12.5 and 5.0, respectively $(p=0.02)$. The clusterplot and protein spectra are illustrated in Figure 3.2 and Figure 3.3A. 


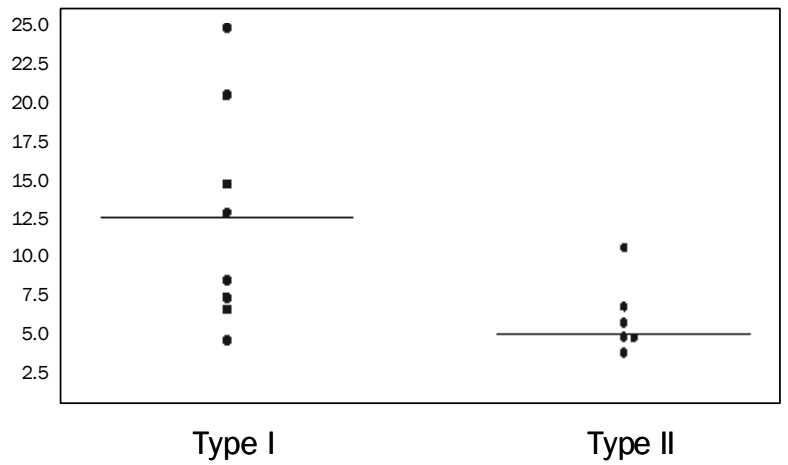

Figure 3.2 The cluster plot of the peak at $m / z$ 16,122. The lacunar groups type 1 and type 2 are indicated on the $x$-axis and the normalized intensities are indicated on the $y$-axis. The horizontal bars present the mean intensities.

A
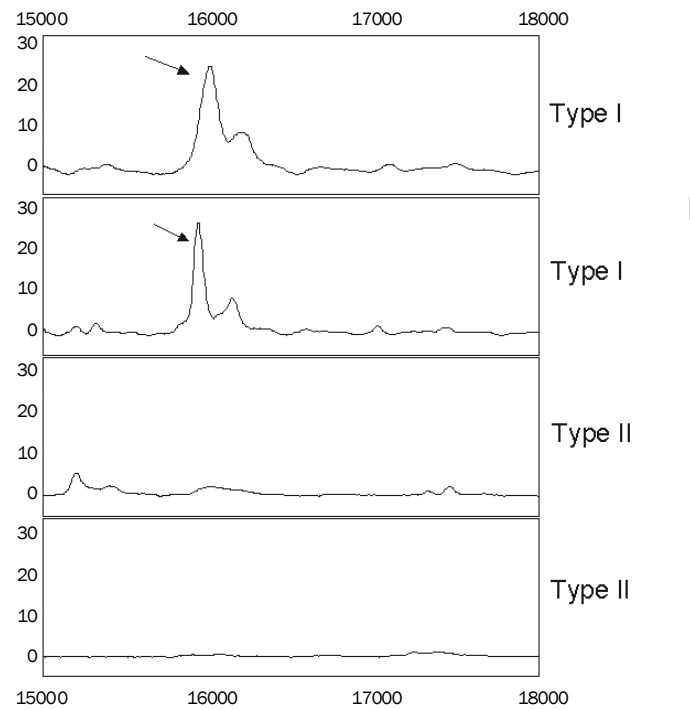

B

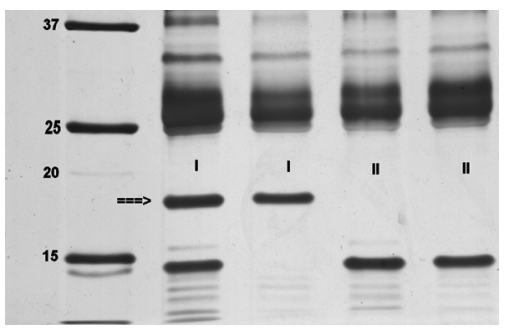

Figure 3.3 A. SELDI protein mass spectra of two type 1 and two type 2 patient samples are illustrated. The marker at $m / z 16.122$ is indicated with an arrow. The mass is given as $m / z$ values on the $x$-axis and the intensity is displayed along the $y$-axis. B. Silver stained band pattern of the same samples separated by SDS-PAGE. There was one band at $16 \mathrm{kDa}$ present for the type 1 samples (indicated with an arrow), which was absent in the type 2 samples. 


\section{Identification}

1-DE and 2-DE were used for isolation and purification of the $m / z$ 16,122 marker, followed by MALDI-TOF-MS analysis, which was used for identification. Denatured serum samples of two type 1 patients which showed a high peak intensity at $m / z$ 16,122 on the IMAC-Cu${ }^{2+}$ ProteinChip arrays, and denatured serum samples of two type 2 patients which showed a low peak intensity were used.

Figure 3.3B illustrates that the band at a molecular weight (MW) of $16 \mathrm{kDa}$, which represents the peak at $m / z 16,122$, is clearly visible in the two type 1 patient samples and absent in the two type 2 samples. This agrees with the SELDI-TOF-MS results. After excising the $16.1 \mathrm{kDa}$ peak out of the SDS-PAGE gel, identification with the Mascot search engine against the Swiss-Prot database revealed the following protein as the best candidate of database searches: alpha-chain of $\mathrm{Hp}$ (P00738) with a probability Mascot score (probability based mowse score) of 68 . Protein scores $>67$ are significant $(p<0.05)$. The alpha-chain of $\mathrm{Hp}$ exists in two variants, alpha-1 $(8.9 \mathrm{kDa})$ and alpha-2 $(16 \mathrm{kDa})$, the latter being compatible with the marker at $m / z 16,122$.

There were three protein spots on 2-DE gels horizontally surrounding the $16 \mathrm{kDa}$ spot which were clearly present in the type 1 patient samples and absent in the type 2 patient samples. All spots were successfully identified as alpha-chain of $\mathrm{Hp}$ (Probability Mascot scores: 69-75). These spots are probably isoforms of the alphachain, with the same MW, but different pl value ( $\mathrm{pl} 4-7$ ).

\section{Haptoglobin}

Because the peak of the marker at $m / z 16,122$ was identified as the alpha-2-chain of $\mathrm{Hp}$, total $\mathrm{Hp}$ concentration and phenotype distribution were measured. Results are presented in Table 3.2. Mean Hp concentration in type 1 was not significantly different from that in type 2 ( $\mathrm{t}$-test; $\mathrm{p}=0.62$ ). $\mathrm{Hp}$ phenotype distribution and $\mathrm{Hp} 1: \mathrm{Hp} 2$ allele frequency are presented with a western European reference population. ${ }^{20}$

Table 3.2 Results

\begin{tabular}{lccc}
\hline & type 1 & type 2 & reference population ${ }^{20}$ \\
\hline 16 kDa peak intensity & 12.5 & 5.0 & \\
Mean Hp (g/l) & $1.69 \pm 0.47$ & $1.81 \pm 0.51$ & \\
Hp phenotype $(1-1: 2-1: 2-2)^{*}$ & $2: 5: 1$ & $5: 3: 0$ & $15: 50: 35 \%$ \\
Hp1 : Hp2 allele frequency ${ }^{\dagger}$ & $0.562: 0.438$ & $0.812: 0.188$ & $0.40: 0.60$ \\
\hline
\end{tabular}

* absolute numbers in type 1 and 2 , percentages in reference population; ${ }^{\dagger} \chi^{2}$ test : $p=0.13$ in type 1 vs. type $2 ; p<0.05$ in lacunar stroke (type 1 and 2 combined) vs. reference population 


\section{Discussion}

The first important finding of our study is that using SELDI-TOF-MS we detected differences in protein profile between lacunar stroke patients with or without concomitant signs of silent cerebral SVD. A protein at $m / z 16,122$, which was successfully identified as alpha-2-chain of $\mathrm{Hp}$, was found overexpressed in patients without silent lacunar lesions (type 1 ) in comparison with those with such lesions (type 2).

$\mathrm{Hp}$ is a plasma protein which is synthesized in the liver. It has hemoglobin-binding capacity, and can be regarded as a major antioxidant. It also plays a role in inflammatory reactions, being an inflammation-sensitive protein. Its production is induced by cytokines. ${ }^{20}$ There is a plausible role for $\mathrm{Hp}$ in vascular disease as both oxidative and inflammatory factors are important in the pathogenesis of atherosclerosis, and its presence has been shown in atherosclerotic coronary lesions. ${ }^{21,22}$ High levels of $\mathrm{Hp}$ have been associated with the incidence of stroke. ${ }^{23,24}$

$\mathrm{Hp}$ consists of alpha- and beta-polypeptide chains, linked by disulfide bonds. ${ }^{20}$ Three Hp phenotypes, Hp1-1 [structural formula $\left.\left(\alpha^{1} \beta\right)_{2}\right], \operatorname{Hp} 2-1\left[\left(\alpha^{1} \beta\right)_{2}+\left(\alpha^{2} \beta\right)_{n}\right]$ and Hp2-2 $\left[\left(\alpha^{2} \beta\right)_{n}\right]$, are genetically determined by a polymorphism with two alleles: $\mathrm{Hp} 1$ and $\mathrm{Hp} 2$. This polymorphism results in variants in alpha-chains: alpha-1 (8.9 kDa) and alpha-2 (16 kDa). ${ }^{20}$ One explanation for an overrepresentation of the alpha-2-chain would be a higher total $\mathrm{Hp}$ concentration, but we found no such difference between our two lacunar groups. Another explanation could be that the multimeric Hp2 proteins are larger sized in type 1. This was not further explored. Thirdly, it could represent a higher Hp2 allele frequency, which was the case as resulted from phenotypic analysis. We conclude that the overrepresentation of the alpha-2-chain in type 1 compared to type 2 relates to a higher $\mathrm{Hp} 2$ allele frequency in the former. Yet, in contrast to a reference population, in both lacunar stroke groups Hp1 outweighed Hp2 allele frequency. ${ }^{20}$

This brings in the second important finding of our study: the deviation of the phenotype distribution in both lacunar patient groups taken together towards a high Hp1 allele frequency compared to a general population reference group. Although our group is small this may signify the $\mathrm{Hp}$ gene as a new candidate gene involved in cerebral SVD.

The mechanism underlying a possible association between $\mathrm{Hp}$ phenotype and SVD is speculative but could be related to blood pressure regulation. Hypertension is an important risk factor for both lacunar stroke and WMLs. ${ }^{25} \mathrm{Hp}$ levels have been associated with systolic blood pressure. ${ }^{23}$ A study by Depypere et al. associated Hp1 with more severe hypertension in preeclampsia, an affliction that, like lacunar stroke, involves the cerebral small calibre vessels. ${ }^{26}$ The frequency of Hp1 allele varies depending on racial origin and is higher in black populations compared to whites. ${ }^{27}$ Weinberger et al. reported a relationship between $\mathrm{Hp} 1$ and sodium- 
sensitive hypertension and sodium-sensitive hypertension is considered more common in black populations. ${ }^{28}$ Black populations show a higher incidence of lacunar stroke than whites, although this excess risk in blacks for lacunar stroke seems to be independent of hypertension. ${ }^{29,} 30$ Multiple silent lacunar lesions are more often associated with hypertension than single lacunar lesions. ${ }^{2}$ In both our patient groups though, hypertension was equally present. However, there are indications that other characteristics of the 24-hour blood pressure profile, such as nocturnal dipping, may be more important in small vessel pathogenesis than just the label "hypertension", which is defined at an arbitrarily fixed value. ${ }^{31}$ Associations between $\mathrm{Hp}$ phenotype and blood pressure profile have not been investigated.

In addition to a role in blood pressure regulation, there may be other, yet unknown mechanisms for $\mathrm{Hp}$ phenotype to be involved in the pathogenesis of cerebral small vessel disease. It was suggested that blood-brain barrier failure with leakage of plasma components into brain tissue might be an early stage of the process that ultimately leads to lacunar infarcts and WMLs. ${ }^{32}$ Hp1-1 passes the blood-brain barrier, while Hp2-2 may pass to a far less extent due to its larger size. In barrier dysfunction the passage is increased. ${ }^{33} \mathrm{Hp}$ phenotype may play a role in determining the severity of SVD once a barrier defect has developed.

Our results differ from findings on $\mathrm{Hp}$ polymorphism in extracerebral large vessel atherosclerotic disease, which showed $\mathrm{Hp} 2$ to be a risk factor in development, severity and outcome of peripheral vascular and coronary artery disease. ${ }^{34-36}$ In the Strong Heart Study Hp2 was a strong predictor for cardiovascular disease, including stroke, in diabetic patients. ${ }^{37}$ However, lacunar strokes were not separately distinguished and small and large vessel ischemic stroke may differ in this respect. Studies on Hp phenotype in cardiovascular disease considered only extracerebral atherosclerostic disease, mainly in diabetic patients. They emphasize the differences in antioxidant and immunomodulatory properties of the $\mathrm{Hp}$ proteins. However, cerebral SVD constitutes a quite different vascular pathology, in which these properties may play a less important role. Hemorrhage and rupture of instable atherosclerotic plaques, in which $\mathrm{Hp} 2$ may play a critical role, is probably not involved in lacunar stroke, in which occlusive thrombosis of a microatheroma or lipohyalinosis are the underlying vessel lesions. ${ }^{38,39}$

A major drawback of our study is the small sample size of 16 patients. However, the study was not primarily designed to study polymorphisms; haptoglobin phenotypic analysis arose from the results of the SELDI-TOF-MS analysis. The small sample size followed from the strictly chosen predefined inclusion criteria to enhance any contrast in protein profile difference. Therefore, larger studies should clarify the relative role of $\mathrm{Hp}$ polymorphism in cerebral SVD, and for comparison also in cerebral large vessel disease.

In conclusion, SELDI-TOF-MS technique allowed us to detect differences in protein expression between two lacunar stroke types which leads to new ideas about a 
genetic contribution to cerebral small vessel pathogenesis. If a larger study would confirm our results, the association between $\mathrm{Hp} 1$ and lacunar stroke signifies a new candidate gene involved in cerebral SVD. 


\section{References}

1. Fisher CM. The arterial lesions underlying lacunes. Acta neuropath (Berl). 1969;12:1-15.

2. Boiten J, Lodder J, Kessels F. Two clinically distinct lacunar infarct entities? A hypothesis. Stroke. 1993;24:652-656.

3. de Jong G, Kessels F, Lodder J. Two types of lacunar infarcts, further arguments from a study on prognosis. Stroke. 2002;33:2072-2076.

4. Spolveri S, Baruffi MC, Cappelletti C, Semerano F, Rossi S, Pracucci G, Inzitari D. Vascular risk factors linked to multiple lacunar infarcts. Cerebrovasc Dis. 1998;8:152-157.

5. Staals J, van Raak L, Hilton A, Lodder J. Differences in long-term survival in two lacunar stroke types: a 15-year follow-up study in 782 cerebral infarct patients. Cerebrovasc Dis. 2008;25:26-31.

6. Kario K, Matsuo T, Kobayashi H, Asada R, Matsuo M. 'Silent' cerebral infarction is associated with hypercoagulability, endothelial cell damage, and high $\operatorname{Lp}(\mathrm{a})$ levels in elderly Japanese. Arterioscler Thromb Vasc Biol. 1996;16:734-741.

7. Kilpatrick TJ, Matkovic Z, Davis SM, McGrath CM, Dauer RJ. Hematologic abnormalities occur in both cortical and lacunar infarction. Stroke. 1993;24:1945-1950.

8. van Dijk EJ, Prins ND, Vermeer SE, Vrooman HA, Hofman A, Koudstaal PJ, Breteler MMB. Creactive protein and cerebral small-vessel disease; the Rotterdam scan study. Circulation. 2005;112:900-905.

9. Hassan A, Hunt BJ, O'Sullivan M, Parmar K, Bamford JM, Briley D, Brown MM, Thomas DJ, Markus HS. Markers of endothelial dysfunction in lacunar infarction and ischaemic leukoaraiosis. Brain. 2003;126:424-432.

10. Szolnoki Z, Somogyvari F, Kondacs A, Szabo M, Fodor L. Evaluation of the roles of the Leiden V mutation and ACE I/D polymorphism in subtypes of ischaemic stroke. J Neurol. 2001;248: 756-761.

11. Szolnoki Z, Somogyvari F, Kondacs A, Szabo M, Fodor L. Evaluation of the interactions of common genetic mutations in stroke subtypes. J Neurol. 2002;249:1391-1397.

12. Gormley K, Bevan S, Markus HS. Polymorphisms in genes of the renin-angiotensin system and cerebral small vessel disease. Cerebrovasc Dis. 2007;23:148-155.

13. Bamford J, Sandercock P, Jones L, Warlow C. The natural history of lacunar infarction: the Oxfordshire community stroke project. Stroke. 1987;18:545-551.

14. Fazekas F, Chawluk JB, Alavi A, Hurtig HI, Zimmerman RA. MR signal abnormalities at $1.5 \mathrm{~T}$ in Alzheimer's dementia and normal aging. AJR. 1987;149:351-356.

15. Solassol J, Marin P, Demettre E, Rouanet P, Bockaert J, Maudelonde T, Mange A. Proteomic detection of prostate-specific antigen using a serum fractionation procedure: potential implication for new low-abundance cancer biomarker detection. Anal Biochem. 2005;338:26-31.

16. Bons JA, de Boer D, van Dieijen-Visser MP, Wodzig WK. Standardization of calibration and quality control using surface enhanced laser desorption ionization-time of flight-mass spectrometry. Clin Chim Acta. 2006;366:249-256.

17. Bouwman F, Renes J, Mariman E. A combination of protein profiling and isotopomer analysis using matrix-assisted laser desorption/ionization-time of flight mass spectrometry reveals an active metabolism of the extracellular matrix of 3T3-L1 adipocytes. Proteomics. 2004;4:3855-3863.

18. Bouwman F, Suylen D, Renes J, Mariman E. Evaluation and improving the success rate of protein identification by peptide mass fingerprinting using matrix-assisted laser desorption/ionization time-of-flight mass spectrometry. Spectrom. 2005;19:2465-2468.

19. Smithies O, Connell G, Dixon G. Inheritance of haptoglobin subtypes. Am J Hum Genet. 1962; 14:14-21.

20. Van Vlierberghe H, Langlois M, Delanghe J. Haptoglobin polymorphisms and iron homeostasis in health and in disease. Clin Chim Acta. 2004;345:35-42.

21. Ross R. Atherosclerosis-an inflammatory disease. NEJM. 1999;340:115-126.

22. Matuszek M, Aristoteli L, Bannon P, Hendel P, Hughes C, Jessup W, Dean R, Kritharides L. Haptoglobin elutes from human atherosclerotic coronary arteries-a potential marker of arterial pathology. Atherosclerosis. 2003;168:389-396. 
23. Engstrom G, Lind P, Hedblad B, Stavenow L, Janzon L, Lindgarde F. Long-term effects of inflammation-sensitive plasma proteins and systolic blood pressure on incidence of stroke. Stroke. 2002;33:2744-2749.

24. Engstrom G, Lind P, Hedblad B, Stavenow L, Janzon L, Lindgarde F. Effects of cholesterol and inflammation-sensitive plasma proteins on incidence of myocardial infarction and stroke in men. Circulation. 2002;105:2632-2637.

25. Lodder J, Boiten J. Incidence, natural history, and risk factors in lacunar infarction. Adv Neurol. 1993;62:213-226.

26. Depypere HT, Langlois MR, Delanghe JR, Temmerman M, Dhont M. Haptoglobin polymorphism in patients with preeclampsia. Clin Chem Lab Med. 2006;44:924-928.

27. Carter K, Worwood M. Haptoglobin: a review of the major allele frequencies worldwide and their association with diseases. Int J Lab Hematol. 2007;29:92-110.

28. Weinberger M, Miller J, Fineberg N, Luft F, Grim C, Christian J. Association of haptoglobin with sodium sensitivity and resistance of blood pressure. Hypertension. 1987;10:443-446.

29. Ohira T, Shahar E, Chambless L, Rosamond W, Mosley T, Folsom A. Risk factors for ischemic stroke subtypes, the atherosclerosis risk in communities study. Stroke. 2006;37:2493-2498.

30. Markus HS, Khan U, Birns J, Evans A, Kalra L, Rudd A, Wolfe C, Jerrard-Dunne P. Differences in stroke subtypes between black and white patients with stroke: the South London Ethnicity and Stroke Study. Circulation. 2007;116:2157-2164.

31. Staals J, Lodder J. Hypertension and lacunar stroke. In: Mohler E, Townsend, R, ed. Advanced therapy in hypertension and vascular disease. Hamilton: B.C.Decker; 2006:152-160.

32. Wardlaw JM, Sandercock PAG, Dennis MS, Starr J. Is breakdown of the blood-brain barrier responsible for lacunar stroke, leukoaraiosis, and dementia? Stroke. 2003;34:806-812.

33. Chamoun V, Zeman A, Blennow K, Fredman P, Wallin A, Keir G, Giovannoni G, Thompson EJ. Haptoglobins as markers of blood-CSF barrier dysfunction: the findings in normal CSF. J Neurol Sci. 2001;182:117-121.

34. Delanghe J, Cambier B, Langlois $M$, de Buyzere $M$, Neels $H$, de Bacquer D, van Cauwelaert $P$. Haptoglobin polymorphism, a genetic risk factor on coronary artery bypass surgery. Atherosclerosis. 1997;132:215-219.

35. Delanghe J, Langlois M, Duprez D, de Buyzere M, Clement D. Haptoglobin polymorphism and peripheral arterial occlusive disease. Atherosclerosis. 1999;145:287-292.

36. Suleiman M, Aronson D, Asleh R, Kapelovich M, Roguin A, Meisel S. Haptoglobin polymorphism predicts 30-day mortality and heart failure in patients with diabetes and acute myocardial infarction. Diabetes. 2005;19:2802-2806.

37. Levy AP, Hochberg I, Jablonski K, Resnick HE, Lee ET, Best L, Howard BV. Haptoglobin phenotype is an independent risk factor for cardiovascular disease in individuals with diabetes: the Strong Heart Study. J Am Coll Cardiol. 2002;40:1984-1990.

38. Levy AP, Levy JE, Kalet-Litman S, Miller-Lotan R, Levy NS, Asaf R, Guetta J, Yang C, Purushothaman KR, Fuster V, Moreno PR. Haptoglobin genotype is a determinant of iron, lipid peroxidation, and macrophage accumulation in the atherosclerotic plaque. Arterioscler Thromb Vasc Biol. 2007;27:134-140.

39. Lammie GA. Hypertensive cerebral small vessel disease and stroke. Brain Pathol. 2002;12: 358-370. 

Haptoglobin polymorphism and lacunar stroke

J Staals

BMA Pieters

ILH Knottnerus

RPW Rouhl

RJ van Oostenbrugge

JR Delanghe

J Lodder

Curr Neurovasc Res 2008;5:153-158 


\section{Abstract}

Haptoglobin ( $\mathrm{Hp}$ ) 2-2 phenotype has been associated with peripheral and coronary artery disease and risk of vascular complications in diabetic patients, but any association of $\mathrm{Hp}$ polymorphism with cerebrovascular disease has not been explored so far. We aimed to study Hp polymorphism in a sample of 124 patients with a rather homogeneous type of cerebrovascular disease, namely first symptomatic lacunar stroke due to small vessel disease, in comparison with a large $(n=918)$ control group. $\mathrm{Hp}$ phenotypes were determined using starch gel electrophoresis.

Hp1 allele frequency was significantly higher in patients than in controls $(0.480$ vs. $0.395, p<0.05)$, mainly due to a lower Hp2-2 phenotype frequency $(25.0 \%$ vs. $36.3 \%$; OR 0.59 ; $95 \% \mathrm{Cl} 0.38-0.90$; $\mathrm{p}<0.05$ ). This was even more pronounced in younger ( $\leq 60$ years) patients ( $\mathrm{Hp} 1$ allele frequency 0.539 ). The association between $\mathrm{Hp} 1$ and lacunar stroke suggests that $\mathrm{Hp}$ may serve different functions depending on the pathological processes in various types of vascular disease in different organs. The association between $\mathrm{Hp} 1$ and lacunar stroke may relate to blood-brain barrier dysfunction, to the association between hypertension and cerebral small vessel disease, or a special dependence of small vessel wall integrity on Hp2-2 related angiogenic potential. The presence of concomitant signs of cerebral small vessel disease weakened the association between $\mathrm{Hp} 1$ and lacunar stroke, which could reflect a difference in underlying vascular pathophysiology in which Hp phenotype may play a different role. 


\section{Introduction}

Haptoglobin ( $\mathrm{Hp}$ ) is a plasma glycoprotein, which is mainly synthesized by hepatocytes. It binds with high affinity to hemoglobin, thereby acting as a major antioxidant.1,2 Due to the existence of two different coding alleles, Hp1 and Hp2, determining the presence of alpha-1 and/or alpha-2-chains in the Hp-molecule, three $\mathrm{Hp}$ protein phenotypes occur: Hp1-1, Hp2-1 and Hp2-2, with consequent different protein patterns with functional differences, for example to antioxidant capacity.1,2 Hp2-2 phenotype has been associated with an increased risk of peripheral and coronary artery disease and the risk of vascular complications in patients with diabetes mellitus. ${ }^{2-6}$

Any association of $\mathrm{Hp}$ polymorphism with cerebrovascular disease has not been explored so far. Recently, using protein expression profile analysis, we identified a $\mathrm{Hp}$ alpha-2-chain protein expression difference between different types of symptomatic cerebral small vessel disease, suggesting a role for $\mathrm{Hp}$ polymorphism, however, patient numbers in that study were small. ${ }^{7}$ The aim of the present study was to further explore differences in $\mathrm{Hp}$ polymorphism frequencies in a large sample of patients with a rather homogeneous type of cerebrovascular disease, namely first symptomatic small vessel lacunar stroke, in comparison with a large control group. The second aim was to relate potential differences to concomitant presence of "silent" small vessel lesions on MR imaging, namely asymptomatic lacunar infarcts and white matter lesions (WMLs).

\section{Methods}

\section{Patients and controls}

Between May 2003 and November 2006, we recruited 124 patients who presented with a first-ever lacunar stroke (LAC) at the University Hospital Maastricht and the Maasland Hospital Sittard, the Netherlands. With informed consent and approval of the local Medical Ethical Committee, they participate in an ongoing LAC research project. LAC is defined as an acute lacunar stroke syndrome with MRI findings consisting of a T2-weighted hyperintense, sharply marginated subcortical small lesion of $<20 \mathrm{~mm}$ in diameter compatible to the clinical findings, or an acute stroke syndrome compatible with a specific lacunar syndrome in the absence of such MRI lesion. ${ }^{2}$

MR images (standard axial T2 and axial fluid attenuated inversion recovery (FLAIR) with slice thickness $5 \mathrm{~mm}$ ) were obtained with a 1.5 Tesla MR scanner (Philips). MRI scans were reviewed further for the presence of asymptomatic lacunar infarcts, which we defined as hyperintense lesions on T2 images with corresponding hypointense lesions with a hyperintense rim on FLAIR and a 
diameter of $<20 \mathrm{~mm}$. We distinguished LAC patients with one or more asymptomatic lacunar lesions $(\angle A C+)$ from those without such lesions ( $L A C-)$. Scans were also assessed for the presence of extensive WMLs defined according to Fazekas' classification as T2-weighted confluent deep white matter hyperintensities (score 2 or 3 on Fazekas' scale) and / or irregular periventricular hyperintensities extending into the deep white matter (score 3 on Fazekas' scale). ${ }^{9}$ We distinguished LAC patients with (WMLs+) from those without (WMLs-) extensive WMLs.

Several vascular risk factors were listed, such as age, sex, diabetes mellitus, ischemic heart disease and peripheral arterial disease. Hypertension was defined as use of antihypertensive medication or a mean daytime ambulatory blood pressure higher than $140 / 90 \mathrm{mmHg}$, recorded by a portable blood pressure monitoring device measuring blood pressure every 15 minutes at daytime, at least one month after stroke. Mean daytime systolic and diastolic pressure and mean pulse pressure were also calculated.

The control population consisted of a group of 918 healthy Caucasian blood donors (451 male, 467 female donors), which was investigated previously. ${ }^{1}$

\section{Laboratory tests}

Fasting blood samples were taken at least three months after stroke. Serum Hp concentrations were measured immunonephelometrically on a BNA nephelometer (Behringwerke, Marburg, Germany). Hp phenotypes were determined using starch gel electrophoresis of hemoglobin-supplemented serum, followed by peroxidase staining, according to Smithies. ${ }^{10}$

\section{Statistical analysis}

Analyses were performed using SPSS for Windows 11.0.1. Hp phenotype distribution and allele frequencies were compared between groups using $\chi^{2}$ analysis. Because studies suggest that the genetic component of small vessel disease is strongest at younger age, we considered young LAC patients ( $\leq 60$ years) separately. ${ }^{11-13}$ Clinical and laboratory values for LAC patients were grouped according to $\mathrm{Hp}$ phenotype and tested for differences using $\chi^{2}$ tests or ANOVA. Data are presented as absolute numbers with percentages between brackets, mean \pm SD or median with range. Where appropriate, odds ratio (OR) with $95 \%$ confidence interval $(\mathrm{Cl})$ and $p$-value are given. Statistical significance was considered at $p<0.05$. 


\section{Results}

Hp phenotype distribution and Hp allele frequency in all LAC patients and controls are shown in Table 4.1. The observed phenotypic distribution is in both groups in agreement with the Hardy-Weinberg equilibrium. Hp phenotypic distribution was significantly different between the two groups $\left(\chi^{2}=6.903\right.$, degrees of freedom $(d f)=2, p=0.032$ ). Hp1-1 phenotype frequency was higher in LAC, but the difference was not statistically significant (OR 1.47; $95 \% \mathrm{Cl} 0.92-2.36 ; p=0.103$ ). Hp2-2 phenotype frequency was lower in LAC (OR 0.59; 95\% Cl 0.38-0.90; $p=0.013$ ), and Hp1 allele frequency was significantly higher in LAC than in controls $(p=0.011)$.

Table 4.1 Hp phenotypes and allele frequencies in LAC patients and controls.

\begin{tabular}{lccc}
\hline & $\begin{array}{c}\text { LAC, all patients } \\
\mathrm{n}=124\end{array}$ & $\begin{array}{c}\text { LAC, } \leq 60 \text { years } \\
\mathrm{n}=38\end{array}$ & $\begin{array}{c}\text { Controls } \\
\mathrm{n}=918\end{array}$ \\
\hline $\begin{array}{l}\text { Phenotypes } \\
\text { Hp1-1 }\end{array}$ & $26(21.0 \%)$ & $9(23.7 \%)$ & $140(15.3 \%)$ \\
Hp2-1 & $67(54.0 \%)$ & $23(60.5 \%)$ & $445(48.5 \%)$ \\
Hp2-2 & $31(25.0 \%)^{*}$ & $6(15.8 \%)^{*}$ & $333(36.3 \%)$ \\
Allele frequency & & & \\
Hp1 & $0.480^{*}$ & $0.539^{*}$ & 0.395 \\
Hp2 & 0.520 & 0.461 & 0.605 \\
\hline
\end{tabular}

${ }^{*} \mathrm{p}<0.05$ vs. controls

When restricting the analysis to patients of 60 years or younger $(n=38), \mathrm{Hp}$ phenotype distribution differed from that in the control group $\left(\chi^{2}=7.066, \mathrm{df}=2\right.$, $\mathrm{p}=0.029$ ) (Table 4.1). Comparing Hp1-1 phenotype with controls yielded an OR of 1.72; $95 \% \mathrm{Cl} 0.80-3.72 ; \mathrm{p}=0.160$, and in case of $\mathrm{Hp} 2-2: \mathrm{OR} 0.33 ; 95 \% \mathrm{Cl}$ $0.14-0.80 ; p=0.010$. Hp1 allele frequency was significantly higher than in the control group $(p=0.012)$.

Table 4.2 shows the clinical characteristics and laboratory results in LAC patients according to their phenotype. In agreement with the expected phenotypedependent reference range, $\mathrm{Hp}$ concentration varied according to phenotype, with the lowest value in the Hp2-2 group. ${ }^{1}$ Except for hypertension, all other characteristics showed no significant differences among the three Hp phenotypes. The frequency of hypertension was significantly higher among the Hp1-1 patients than in the remaining ones $(p=0.037)$. In hypertensive patients, Hp1 allele frequency was significantly higher than in controls $(p=0.004)$ (Table 4.3). In nonhypertensive patients, allele frequency distribution was not significantly different from controls.

MRI findings of silent small vessel lesions (asymptomatic lacunar lesions and extensive WMLs) are presented in Table 4.2 and Table 4.4. In LAC- $(n=42$, mean age $62 \pm 11$ years) Hp1 allele frequency was significantly higher compared to 
controls ( $p=0.032)$. In $L A C+(n=82$, mean age $65 \pm 12$ years) Hp1 allele frequency was also higher than in controls, although not significantly $(p=0.086)$. In WMLs$(n=77$, mean age $61 \pm 12$ years) Hp1 allele frequency was significantly higher compared to controls $(p=0.038)$. In WMLs+ $(n=47$, mean age $69 \pm 9$ years $) H p 1$ allele frequency was also higher than in controls, although not significantly $(p=0.070)$. Subgroups of younger patients were too small to analyse.

Table 4.2 Clinical characteristics, laboratory values and MRI findings according to Hp phenotypes of the LAC patients.

\begin{tabular}{|c|c|c|c|c|c|}
\hline & $\begin{array}{l}\text { Hp1-1 } \\
n=26\end{array}$ & $\begin{array}{c}H p 2-1 \\
n=67\end{array}$ & $\begin{array}{c}\mathrm{Hp} 2-2 \\
\mathrm{n}=31\end{array}$ & $\begin{array}{c}\text { All patients } \\
n=124\end{array}$ & p-value \\
\hline Age (years) & $63.7 \pm 11.9$ & $64.0 \pm 12.5$ & $64.9 \pm 10.4$ & $64.2 \pm 11.7$ & NS \\
\hline Male sex & $16(61.5 \%)$ & $42(62.7 \%)$ & $18(58.1 \%)$ & $76(61.3 \%)$ & NS \\
\hline Haptoglobin (g/l) & $1.24 \pm 0.45$ & $1.05 \pm 0.55$ & $0.79 \pm 0.35$ & $1.03 \pm 0.51$ & 0.003 \\
\hline Diabetes mellitus & $3(11.5 \%)$ & 7 (10.4\%) & $4(12.9 \%)$ & $14(11.3 \%)$ & NS \\
\hline Ischemic heart disease & $3(11.5 \%)$ & 14 (20.9\%) & $2(6.5 \%)$ & $19(15.3 \%)$ & NS \\
\hline Peripheral arterial disease & $1(3.8 \%)$ & $4(6.0 \%)$ & $0(0.0 \%)$ & $5(4.0 \%)$ & NS \\
\hline Hypertension & $25(96.2 \%)$ & $52(77.6 \%)$ & $25(80.6 \%)$ & $102(82.3 \%)$ & $0.03^{*}$ \\
\hline \multicolumn{6}{|l|}{ Mean daytime (mmHg) } \\
\hline systolic pressure & $147 \pm 18$ & $140 \pm 17$ & $147 \pm 16$ & $143 \pm 17$ & NS \\
\hline diastolic pressure & $87 \pm 13$ & $84 \pm 12$ & $88 \pm 11$ & $85 \pm 12$ & NS \\
\hline pulse pressure & $59 \pm 9$ & $57 \pm 10$ & $59 \pm 12$ & $58 \pm 10$ & NS \\
\hline Median asympt. lacunar lesion count & $1(0-10)$ & $1(0-10)$ & $1(0-10)$ & $1(0-10)$ & NS \\
\hline Asymptomatic lacunar lesions & 17 (65.4\%) & $42(62.7 \%)$ & $23(74.2 \%)$ & $82(66.1 \%)$ & NS \\
\hline Median count & $2(1-10)$ & $2(1-10)$ & $2(1-10)$ & $2(1-10)$ & \\
\hline Extensive WMLs & $9(34.6 \%)$ & 27 (40.3\%) & $11(35.5 \%)$ & 47 (37.9\%) & NS \\
\hline
\end{tabular}

NS= not significant; ${ }^{*} \mathrm{Hp} 1-1$ vs. $2-1$ and $2-2$

Table 4.3 Hp phenotypes and allele frequencies in LAC patients according to the presence or absence of hypertension.

\begin{tabular}{lccc}
\hline & $\begin{array}{c}\text { Nonhypertensive } \\
\mathrm{n}=22\end{array}$ & $\begin{array}{c}\text { Hypertensive } \\
\mathrm{n}=102\end{array}$ & $\begin{array}{c}\text { Controls } \\
\mathrm{n}=918\end{array}$ \\
\hline $\begin{array}{c}\text { Phenotypes } \\
\text { Hp1-1 }\end{array}$ & $1(4.5 \%)$ & $25(24.5 \%)^{*}$ & $140(15.3 \%)$ \\
Hp2-1 & $15(68.2 \%)$ & $52(51.0 \%)$ & $445(48.5 \%)$ \\
Hp2-2 & $6(27.3 \%)$ & $25(24.5 \%)^{*}$ & $333(36.3 \%)$ \\
Allele frequency & & & \\
Hp1 & 0.386 & $0.500^{*}$ & 0.395 \\
Hp2 & 0.614 & 0.500 & 0.605 \\
\hline
\end{tabular}

${ }^{*} p<0.05$ vs. controls 
Table 4.4 Hp phenotypes and allele frequencies in LAC patients according to the presence or absence of silent small vessel lesions.

\begin{tabular}{lcccrc}
\hline & $\begin{array}{c}\text { LAC- } \\
\mathrm{n}=42\end{array}$ & $\begin{array}{c}\text { LAC+ } \\
\mathrm{n}=82\end{array}$ & $\begin{array}{c}\text { WMLs- } \\
\mathrm{n}=77\end{array}$ & $\begin{array}{c}\text { WMLs+ } \\
\mathrm{n}=47\end{array}$ & \multicolumn{1}{c}{$\begin{array}{c}\text { Controls } \\
\mathrm{n}=918\end{array}$} \\
\hline $\begin{array}{l}\text { Phenotypes } \\
\text { Hp 1-1 }\end{array}$ & $9(21.4 \%)$ & $17(20.7 \%)$ & $17(22.1 \%)$ & $9(19.1 \%)$ & $140(15.3 \%)$ \\
Hp 2-1 & $25(59.5 \%)$ & $42(51.2 \%)$ & $40(51.9 \%)$ & $27(57.4 \%)$ & $445(48.5 \%)$ \\
Hp 2-2 & $8(19.0 \%)^{*}$ & $23(28.0 \%)$ & $20(26.0 \%)$ & $11(23.4 \%)$ & $333(36.3 \%)$ \\
Allele frequency & & & & & \\
Hp 1 & $0.512^{*}$ & 0.463 & $0.481^{*}$ & 0.479 & 0.395 \\
Hp 2 & 0.488 & 0.537 & 0.519 & 0.521 & 0.605 \\
\hline
\end{tabular}

* $p<0.05$ vs. controls

\section{Discussion}

In this first study exploring $\mathrm{Hp}$ polymorphism in symptomatic cerebral small vessel disease we found that the Hp1 allele was related to lacunar stroke when compared to healthy volunteers, whereas Hp2-2 phenotype and $\mathrm{Hp} 2$ allele frequency were inversely related. Point estimates for Hp1-1 phenotype also pointed to an association with small vessel stroke, but failed to be statistically significant. When we restricted the analyses to patients of 60 years or younger, these associations became even more pronounced. This adds to the validity of our findings because the genetic component in the etiology of LAC seems to be strongest at younger age, as the effect of concomitant environmental risk factors may become more pronounced over time.11-13

$\mathrm{Hp}$ has various functional properties and different $\mathrm{Hp}$ phenotypes have been associated with various diseases. One of these is atherosclerosis, which can in part be regarded as an immune-mediated inflammatory process. ${ }^{14}$ One of the initiating steps in this process is the oxidation of LDL cholesterol. $\mathrm{Hp}$ is an antioxidant, protecting against oxidation of LDL. Hp1-1 has higher antioxidant capacity than $\mathrm{Hp} 2-2.1,2,15,16 \mathrm{Hp}$ also has immunomodulatory properties. It plays an important role in the down-regulation of inflammatory activity, by stimulating macrophages to secrete the anti-inflammatory cytokine IL-10, and limiting the oxidation of arachidonic acid, thereby inhibiting prostaglandin synthesis. These effects are also more pronounced in $\mathrm{Hp} 1-1.2,16$ These data suggest that $\mathrm{Hp}$ plays a role in the atherosclerotic inflammatory process, and that Hp1-1 mitigates this process at various levels. The protective effect of Hp1-1 has been validated by clinical studies, that showed especially Hp2-2 phenotype to be associated with coronary and peripheral artery disease, and with vascular complications in diabetes mellitus. ${ }^{3-6,17}$ However, it remains unclear whether the role of $\mathrm{Hp}$ in atherosclerosis can simply be attributed to the above-described properties. Hp2-2, more than Hp1-1, acts as an angiogenic factor, promoting endothelial cell growth and differentiation of new blood vessels. ${ }^{18}$ This contradicts Hp2-2's relation with more severe vascular complications. 
Also, the role of $\mathrm{Hp}$ in blood pressure related vascular complications is not unequivocal: Hp2-2 was related to severity of non-cerebral vascular complications and therapy resistance in hypertension. ${ }^{17}$ However, Hp1-1 subjects have higher casual blood pressure readings and are more sodium-sensitive, and hypertensive Hp1-1 subjects are younger at diagnosis. ${ }^{17,19} \mathrm{Hp}$ concentration varies with phenotype, with highest values in Hp1-1.1 High Hp levels appeared to be related to elevated blood pressure and increased risk of stroke. ${ }^{20}$ In our study, Hp1-1 patients significantly more often had a diagnosis of hypertension, although we found no difference in mean blood pressures between the $\mathrm{Hp}$ phenotype groups, but measurements had been performed without cessation of antihypertensive medication. Hypertension is a far more important risk factor for cerebral small vessel disease than for non-cerebral atherosclerotic disease and prevalences up to 80 percent have been reported in LAC. ${ }^{21}$ Most of our LAC patients indeed were hypertensive, and in this group we found an association with the Hp1 allele which was absent in the nonhypertensive group. Interestingly, Hp1 allele frequency varies depending on racial origin and is higher in black populations compared to whites, whereas sodium-sensitive hypertension and LAC are also more common in black populations.2,22,23 Also of interest here are the findings of Depypere et al., who found Hp1 allele associated with pre-ecclampsia and with more severe hypertension in pre-ecclamptic patients. ${ }^{24}$ Pre-ecclampsia is a toxemic and hypertensive vasculopathy involving the cerebral small vessels, and its pathophysiology shows similarity with that of LAC. ${ }^{25,26}$ Whether the association between Hp phenotype and LAC is based on an effect on blood pressure regulation, or that $\mathrm{Hp}$ phenotype relates to LAC via other mechanisms in which hypertension is just a conditionally attendant factor, remains unclear. How Hp may influence blood pressure regulation is uncertain; it may be related to salt sensitivity.

Our findings do not oppose those of other studies, but together with these suggest that $\mathrm{Hp}$ may serve different functions depending on the significance of certain pathological processes in various types of vascular disease. The nature of these processes is likely to depend on the type of vasculature involved, and may also be organ specific. Cerebral small vessel disease constitutes a quite distinct vascular pathology, in which the antioxidant and immunomodulatory properties of $\mathrm{Hp}$ may play a less important role than in large vessel atherosclerosis. Hemorrhage and rupture of instable atherosclerotic plaques, in which $\mathrm{Hp} 2$ may play a critical role, are no significant mechanisms in LAC, in which occlusive thrombosis of a microatheroma or lipohyalinosis are generally the underlying vessel lesions. ${ }^{27,28}$

An important difference between brain and other organs is the blood-brain barrier, which guards the stable composition of the extravascular fluid in neural tissue, regulates selective passage of plasma content and thus protects neurons from possible neurotoxic plasma components. It may be that especially the cerebral small vessels depend on angiogenic factors to maintain their integrity, because we found an inverse association between Hp2-2 and LAC and Hp2-2 is most strongly 
associated with angiogenesis. Barrier failure with leakage of plasma components into brain tissue might be an early stage of the process that ultimately leads to lacunar infarcts. ${ }^{29}$ Related to its smaller size, Hp 1-1 can more easily pass the intact blood-brain barrier than $\mathrm{Hp}$ 2-2 and the passage of $\mathrm{Hp}$ is increased in barrier dysfunction. ${ }^{30}$ The effects of $\mathrm{Hp}$ in neural tissue are not known, however, massive leakage might diminish the mitigating effects of Hp1-1 protein activity on the vascular endothelium and might also damage neural tissue. Of course, these hypotheses need further exploration.

The association between Hp1 allele frequency and LAC was less strong and not statistically significant in the presence of concomitant signs of "silent" small vessel lesions (asymptomatic lacunar lesions or extensive WMLs), compared with the absence of such lesions. These findings may support the idea of two different LAC entities. Pathology studies have shown two underlying vascular pathologies of small vessel disease: lipohyalinosis, which was found mainly in brains with multiple lacunar lesions and WMLs, and microatheromatosis in cases with a single lacunar lesion. ${ }^{27,28}$ Earlier we hypothesized that the two LAC subgroups that can be distinguished on neuro-imaging according to the presence or absence of silent lesions represent these distinct vascular pathologies. ${ }^{31}$ They differ in vascular risk profile, prognosis on functional outcome, stroke recurrence rate and short- and long-term mortality. ${ }^{31-33}$ The underlying pathogenetic mechanisms are probably different and risk factors may play a more or less important role. However, as the $L A C+$ and WMLs+ subgroups were older, the results may also be interpreted as to show that the genetic component in the etiology of LAC weakens over time, as the effect of concomitant environmental risk factors becomes more pronounced. Younger subgroups were too small to analyse. To clear this issue a larger series is needed.

Our study has some other limitations. First, we did not study the relation between $\mathrm{Hp}$ phenotype and ischemic stroke in general. However, the cause in territorial brain infarcts may be rather heterogeneous, and includes local thrombosis, arteryto-artery embolism, dissection, and cardiogenic embolism. LAC in our series most likely resulted from local obstruction of one small penetrating artery and it constitutes, therefore, a homogeneous stroke type. A second limitation concerns the selection of the control population. Although large in number, controls were not age and sex matched, and we did not obtain data on vascular risk factors, whereas brain imaging to exclude silent lesions, was not performed. However, potential selection would have biased towards an under-rating rather than an overestimation of the associations we found.

In summary, the present study shows an association between $\mathrm{Hp} 1$, or an inverse association between $\mathrm{Hp} 2$, and LAC. It may relate to blood-brain barrier damage, to the association between hypertension and cerebral small vessel disease, or a special dependence of small vessel wall integrity on vascular regeneration potential. These possibilities are currently being explored further. 


\section{References}

1. Van Vlierberghe $\mathrm{H}$, Langlois $\mathrm{M}$, Delanghe J. Haptoglobin polymorphisms and iron homeostasis in health and in disease. Clin Chim Acta. 2004;345:35-42.

2. Carter K, Worwood M. Haptoglobin: a review of the major allele frequencies worldwide and their association with diseases. Int J Lab Hematol. 2007;29:92-110.

3. Delanghe J, Langlois M, Duprez D, de Buyzere M, Clement D. Haptoglobin polymorphism and peripheral arterial occlusive disease. Atherosclerosis. 1999;145:287-292.

4. Delanghe J, Cambier B, Langlois M, de Buyzere M, Neels H, de Bacquer D, van Cauwelaert P. Haptoglobin polymorphism, a genetic risk factor on coronary artery bypass surgery. Atherosclerosis. 1997;132:215-219.

5. Nakhoul F, Zoabi R, Kanter Y, Zoabi M, Skorecki K, Hochberg I, Leibu R, Miller B, Levy A. Haptoglobin phenotype and diabetic nephropathy. Diabetologia. 2001;44:602-604.

6. Levy AP, Hochberg I, Jablonski K, Resnick HE, Lee ET, Best L, Howard BV. Haptoglobin phenotype is an independent risk factor for cardiovascular disease in individuals with diabetes: the Strong Heart Study. J Am Coll Cardiol. 2002;40:1984-1990.

7. Staals J, Bons JAP, van Oostenbrugge RJ, Knottnerus ILH, van Dieijen-Visser MP, Bouwman FG, Mariman EC, Delanghe JR, Lodder J, Wodzig WKWH. A SELDI-TOF-MS study in lacunar stroke with subsequent haptoglobin phenotyping. Curr Neurovasc Res. 2008;5:93-98.

8. Bamford J, Sandercock P, Jones L, Warlow C. The natural history of lacunar infarction: the Oxfordshire community stroke project. Stroke. 1987;18:545-551.

9. Fazekas F, Chawluk JB, Alavi A, Hurtig HI, Zimmerman RA. MR signal abnormalities at $1.5 \mathrm{~T}$ in Alzheimer's dementia and normal aging. AJR. 1987;149:351-356.

10. Smithies 0 . Zone electrophoresis in starch gels: group variations in the serum proteins of normal human adults. Biochem J. 1955;61:629-641.

11. Schulz UGR, Flossmann E, Rothwell PM. Heritability of ischemic stroke in relation to age, vascular risk factors, and subtypes of incident stroke in population-based studies. Stroke. 2004;35: 819-825.

12. Jerrard-Dunne P, Cloud G, Hassan A, Markus HS. Evaluating the genetic component in ischemic stroke subtypes. A family history study. Stroke. 2003;34:1364-1369.

13. Jood K, Ladenvall C, Rosengren A, Blomstrand C, Jern C. Family history in ischemic stroke before 70 years of age. The Sahlgrenska Academy Study on ischemic stroke. Stroke. 2005;36: $1383-1387$.

14. Ross R. Atherosclerosis-an inflammatory disease. NEJM. 1999;340:115-126.

15. Levy AP, Levy JE, Kalet-Litman S, Miller-Lotan R, Levy NS, Asaf R, Guetta J, Yang C, Purushothaman KR, Fuster V, Moreno PR. Haptoglobin genotype is a determinant of iron, lipid peroxidation, and macrophage accumulation in the atherosclerotic plaque. Arterioscler Thromb Vasc Biol. 2007;27:134-140.

16. Levy AP. Application of pharmacogenomics in the prevention of diabetic cardiovascular disease: mechanistic basis and clinical evidence for utilization of the haptoglobin genotype in determining benefit from antioxidant therapy. Pharmacol Ther. 2006;112:501-512.

17. Delanghe J, Duprez D, de Buyzere M, Bergez B, Callens B, Leroux-Roels G, Clement D. Haptoglobin polymorphism and complications in established essential arterial hypertension. J Hypertens. 1993;11:861-867.

18. Cid MC, Grant DS, Hoffman GS, Auerbach R, Fauci AS, Kleinman HK. Identification of haptoglobin as an angiogenic factor in sera from patients with systemic vasculitis. J Clin Invest. 1993;91: 977-985.

19. Weinberger M, Miller J, Fineberg N, Luft F, Grim C, Christian J. Association of haptoglobin with sodium sensitivity and resistance of blood pressure. Hypertension. 1987;10:443-446.

20. Engstrom G, Lind P, Hedblad B, Stavenow L, Janzon L, Lindgarde F. Long-term effects of inflammation-sensitive plasma proteins and systolic blood pressure on incidence of stroke. Stroke. 2002;33:2744-2749.

21. Staals J, Lodder J. Hypertension and lacunar stroke. In: Mohler E, Townsend, R, ed. Advanced therapy in hypertension and vascular disease. Hamilton: B.C.Decker; 2006:152-160. 
22. Ohira T, Shahar E, Chambless L, Rosamond W, Mosley T, Folsom A. Risk factors for ischemic stroke subtypes, the atherosclerosis risk in communities study. Stroke. 2006;37:2493-2498.

23. Markus HS, Khan U, Birns J, Evans A, Kalra L, Rudd A, Wolfe C, Jerrard-Dunne P. Differences in stroke subtypes between black and white patients with stroke: the South London Ethnicity and Stroke Study. Circulation. 2007;116:2157-2164.

24. Depypere HT, Langlois MR, Delanghe JR, Temmerman M, Dhont M. Haptoglobin polymorphism in patients with preeclampsia. Clin Chem Lab Med. 2006;44:924-928.

25. Cipolla MJ, Vitullo L, DeLance N, Hammer E. The cerebral endothelium during pregnancy: A potential role in the development of eclampsia. Endothelium. 2005;12:5-9.

26. Ringelstein EB, Knecht S. Cerebral small vessel diseases: manifestations in young women. Curr Opin Neurol. 2006;19:55-62.

27. Lammie GA, Brannan F, Slattery J, Warlow CP. Nonhypertensive cerebral small-vessel disease. An autopsy study. Stroke. 1997;28:2222-2229.

28. Fisher CM. The arterial lesions underlying lacunes. Acta neuropath (Berl). 1969;12:1-15.

29. Wardlaw JM, Sandercock PAG, Dennis MS, Starr J. Is breakdown of the blood-brain barrier responsible for lacunar stroke, leukoaraiosis, and dementia? Stroke. 2003;34:806-812.

30. Chamoun V, Zeman A, Blennow K, Fredman P, Wallin A, Keir G, Giovannoni G, Thompson EJ. Haptoglobins as markers of blood-CSF barrier dysfunction: the findings in normal CSF. J Neurol Sci. 2001;182:117-121.

31. Boiten J, Lodder J, Kessels F. Two clinically distinct lacunar infarct entities? A hypothesis. Stroke. 1993;24:652-656.

32. de Jong G, Kessels F, Lodder J. Two types of lacunar infarcts, further arguments from a study on prognosis. Stroke. 2002;33:2072-2076.

33. Staals J, van Raak L, Hilton A, Lodder J. Differences in long-term survival in two lacunar stroke types: a 15-year follow-up study in 782 cerebral infarct patients. Cerebrovasc Dis. 2008;25:26-31. 



\section{Chapter}

\section{Haptoglobin phenotype correlates with cerebral deep white matter lesions in hypertensive patients}

J Staals

LHG Henskens

JR Delanghe

$R J$ van Oostenbrugge

AG Kessels

AA Kroon

PW de Leeuw

J Lodder

Submitted 


\section{Abstract}

\section{Objective}

Haptoglobin ( $\mathrm{Hp}$ ) phenotype has been associated with extracerebral atherosclerotic disease and symptomatic cerebral small vessel disease. We examined the relationship between $\mathrm{Hp}$ phenotype and early silent signs of hypertensive cerebral small vessel disease, namely asymptomatic lacunar infarcts (aLACs), deep and periventricular white matter lesions (WMLs).

\section{Methods}

$\mathrm{Hp}$ phenotype was determined using starch gel electrophoresis in 154 hypertensive patients without symptomatic vascular disease. Brain MR images were analyzed for presence of aLACs. Volumes of deep and periventricular WMLs were quantitatively measured. Patients were ranked in 5 categories according to ascending WMLs volumes.

\section{Results}

We found 26 (16.9\%) Hp1-1, 90 (58.4\%) Hp2-1 and 38 (24.7\%) Hp2-2. Compared to Hp2-2, Hp1-1 was associated with larger deep WMLs volumes when adjusted for age, sex, brain volume, 24-hour mean arterial pressure, duration of hypertension and previous antihypertensive treatment (ordinal regression analysis, odds ratio $2.77,95 \%$ confidence interval 1.07-7.10, $p=0.034$ ). No association was found between $\mathrm{Hp}$ phenotype and periventricular WMLs or the presence of aLACs.

\section{Conclusion}

We discuss that the association between Hp1-1 phenotype and the extent of hypertensive deep white matter damage may relate to lower regenerating power against endothelial injury. This functional property of $\mathrm{Hp}$ phenotype may be vasculature-specific, as we found no association with the other signs of cerebral small vessel disease. 


\section{Introduction}

Haptoglobin ( $\mathrm{Hp})$ is a hemoglobin-binding plasma glycoprotein. Three different protein phenotypes occur: Hp1-1, Hp2-1 and Hp2-2, genetically determined by two alleles: $\mathrm{Hp} 1$ and $\mathrm{Hp} 2 .{ }^{1}$ The phenotypes show several functional differences that may be important in vascular disease: Hp1-1 has more antioxidant and immunomodulatory capacities, less angiogenic potential, and has been related to higher blood pressures than $\mathrm{Hp} 2-2 .^{1,2}$

The distinct functional properties of the $\mathrm{Hp}$ phenotypes may have different importance in various vascular diseases. Hp2-2 has been associated with an increased risk of peripheral and coronary large artery disease ${ }^{3-5}$, and with the risk of late vascular complications in patients with diabetes mellitus ${ }^{6}$, whereas we recently found the $\mathrm{Hp} 1$ allele to be associated with symptomatic cerebral small vessel disease (SVD), i.e. lacunar stroke. ${ }^{7}$

White matter lesions (WMLs) and asymptomatic lacunar lesions (aLACs) are "silent" signs of cerebral SVD, for which hypertension is the major risk factor. They can be regarded as early signs of hypertensive cerebrovascular end-organ damage, and are associated with an increased risk of future stroke and cognitive decline..$^{8,9}$ We examined the relationship between $\mathrm{Hp}$ phenotypes and these early silent signs of cerebral SVD in hypertensive patients.

\section{Methods}

\section{Patients}

Between July 2004 and March 2006, all consecutive patients aged 18-90 years referred to the outpatient clinic of internal medicine in our hospital for evaluation of hypertension were screened for inclusion in a study on hypertension and silent cerebrovascular disease, as described in detail elsewhere. ${ }^{10}$ Patients had no indication of secondary hypertension, chronic renal failure, diabetes mellitus, ischemic or valvular heart disease, atrial fibrillation, history of transient ischemic attacks or stroke. Patients underwent 24-hour blood pressure (BP) monitoring and brain MR imaging. The local Medical Ethics Committee approved the study and all patients gave written informed consent.

\section{Blood pressure measurements}

Hypertension was defined as an untreated $\mathrm{BP} \geq 140 \mathrm{mmHg}$ systolic or $\geq 90 \mathrm{mmHg}$ diastolic with conventional office measurements. Ambulatory BP monitoring (ABPM) over 24-hours with discontinuation of antihypertensive drugs at least two weeks before measurement was performed as described elsewhere. ${ }^{10}$ Mean 24-hour 
systolic BP, diastolic BP, and mean arterial BP (MAP) were calculated based on duplicate ABPMs. In four patients only a single ABPM was available.

\section{MRI scoring}

Brain 1.5-T MR imaging was performed to obtain axial T2-weighted and fluidattenuated inversion recovery (FLAIR) images (24 slices with a thickness of $5 \mathrm{~mm}$ and a $0.5 \mathrm{~mm}$ interslice gap). Images were analysed for the presence of aLACs, WMLs volume and total brain volume. aLACs were defined as sharply demarcated hyperintense lesions on T2-weighted images, with corresponding FLAIR hypointense signal with a surrounding higher-intense gliotic rim, 3-15 mm in diameter and situated in stem, basal ganglia, internal capsule or thalamus. WMLs were identified as hyperintense areas on T2-weighted and FLAIR images. We distinguished deep and periventricular WMLs because the etiology of these subtypes may differ. ${ }^{11}$ WMLs connected to the lateral ventricles were defined as periventricular (pWMLs), otherwise they were defined as deep (dWMLs). Quantitative volume measurements of both dWMLs and pWMLs were performed semi-automatically using in-house developed software (GIANT; Department of Psychiatry and Neuropsychology, Maastricht University, the Netherlands) as described previously. ${ }^{12}$ Brain volume measurements were performed fully automatically using the same software.

\section{Hp phenotyping}

Venous blood samples were taken during follow-up. Collection of serum samples was standardized by using a clotting time of 30 minutes at room temperature, spinning for 10 minutes at 2560 RPM (1500 g), and storage in aliquots within one hour after blood collection at $-80^{\circ} \mathrm{C}$. Hp phenotypes were determined using starch gel electrophoresis of hemoglobin-supplemented serum, followed by peroxidase staining, according to Smithies. ${ }^{13}$

\section{Statistical analysis}

Statistical analyses were performed using SPSS version 15.0 for Windows. Data are presented as absolute numbers with percentages between brackets, mean \pm standard deviation or median with range in case of nonparametric data. Where appropriate, odds ratio (OR) with 95\% confidence interval $(\mathrm{Cl})$ and p-value are given. Statistical significance was considered at $p<0.05$.

Hardy-Weinberg equilibrium was assessed using $\chi^{2}$ test with 1 degree of freedom. The relationship between Hp phenotypes and presence of aLACs was assessed by logistic regression analysis, adjusted for age, sex, and several factors that may influence the impact of hypertension, i.e. self-reported duration of hypertension, previous antihypertensive treatment and the level of BP represented by 24-hour 
MAP. Additionally we performed an exploratory analysis in which we also adjusted for other cardiovascular risk factors (fasting glucose levels, total cholesterol level, current smoking).

Because of skewed distribution of dWMLs volume, the relationship between dWMLs volume and $\mathrm{Hp}$ phenotypes was assessed by Mann-Whitney $U$ testing. Then, patients were ranked in five categories with equal numbers according to dWMLs volume. Ordinal logistic regression analyses were performed, with adjustment for age, sex, brain volume, self-reported duration of hypertension, previous antihypertensive treatment and 24-hour MAP. We additionally adjusted for fasting glucose levels, total cholesterol level, and current smoking. Analysis of pWMLs was performed in the same way.

\section{Results}

One hundred sixty patients were included. Hp phenotype could not be obtained due to technical reasons in six, leaving 154 patients for analyses. Baseline characteristics are presented in Table 5.1. Generally speaking, middle-aged mildto-moderate hypertensive patients were included. Hp1:Hp2 allele frequency was 0.46:0.54. Hp phenotype distribution was not in Hardy-Weinberg equilibrium $\left(\chi^{2}=4.768 ; p=0.029\right)$. According to phenotypes, 24-hour MAP was $114 \pm 13 \mathrm{mmHg}$ in Hp1-1, 112 \pm 12 mmHg in Hp2-1 and 111 12 mmHg in Hp2-2.

Table 5.1 Baseline characteristics of all patients.

\begin{tabular}{lc}
\hline Characteristics & All patients $(\mathrm{n}=154)$ \\
\hline Age (years) & $52.9 \pm 11.7$ \\
Male sex & $82(53 \%)$ \\
24-hour systolic BP (mmHg) & $150 \pm 18$ \\
24-hour diastolic BP (mmHg) & $93 \pm 11$ \\
24-hour MAP $(\mathrm{mmHg})$ & $112 \pm 12$ \\
Current smoking & $24(16 \%)$ \\
Total cholesterol (mmol/l) & $5.9 \pm 1.2$ \\
Fasting glucose $\left(\mathrm{mmol}^{\prime}\right)$ & $5.4 \pm 0.6$ \\
Duration of hypertension (years, range) & $3.6(0.1-57.3)$ \\
Previous antihypertensive treatment & $128(83 \%)$ \\
Asymptomatic lacunar infarcts & $33(21 \%)$ \\
Total WMLs volume (mm ${ }^{3}$, range) & $952(27-46837)$ \\
dWMLs volume $\left(\mathrm{mm}^{3}\right.$, range) & $63(0-22014)$ \\
pWMLs volume $\left(\mathrm{mm}^{3}\right.$, range) & $704(23-36348)$ \\
Brain volume $\left(\mathrm{cm}^{3}\right)^{*}$ & $1270.32 \pm 120.35$ \\
Hp phenotypes & \\
Hp1-1 & $26(16.9 \%)$ \\
Hp2-1 & $90(58.4 \%)$ \\
Hp2-2 & $38(24.7 \%)$ \\
\hline
\end{tabular}

* $\mathrm{n}=152$. 


\section{Silent lacunar infarcts}

We observed 44 aLACs in 33 (21\%) patients. After adjustment for age, sex, duration of hypertension, previous antihypertensive treatment and 24-hour MAP, there was no statistically significant association between $\mathrm{Hp}$ phenotype and the presence of aLACs (Table 5.2). Additional adjustment for glucose, cholesterol and smoking did not change results substantially (data not shown).

Table 5.2 Hp phenotypes according to aLACs status and logistic regression associations between $\mathrm{Hp}$ phenotypes and presence of aLACs.

\begin{tabular}{lcccc}
\hline Hp phenotype & $\begin{array}{c}\text { aLACs absent } \\
\mathrm{n}=121\end{array}$ & $\begin{array}{c}\text { aLACs present } \\
\mathrm{n}=33\end{array}$ & $\begin{array}{c}\text { Unadjusted } \\
\text { OR (95\% Cl) }\end{array}$ & $\begin{array}{c}\text { Adjusted * } \\
\text { OR (95\% Cl) }\end{array}$ \\
\hline $1-1$ & $20(16.5 \%)$ & $6(18.2 \%)$ & $1.98(0.53-7.34)$ & $2.28(0.57-9.14)$ \\
$2-1$ & $68(56.2 \%)$ & $22(66.7 \%)$ & $2.14(0.74-6.14)$ & $2.50(0.82-7.58)$ \\
$2-2$ & $33(27.3 \%)$ & $5(15.1 \%)$ & Reference & Reference \\
\hline
\end{tabular}

* Adjusted for age, sex, duration of hypertension, previous antihypertensive treatment and 24-hour MAP

\section{White matter lesions}

In two of the 154 patients brain volume could not be obtained because of insufficient scan quality, leaving 152 patients in these analyses. Compared to Hp22, subjects with Hp1-1 had larger dWMLs volumes (Mann-Whitney $U$ test, $p=0.038$ ), and had higher categories of dWMLs volumes (Table 5.3, ordinal regression model, $p=0.043$ ) which did not change substantially after adjustment for age, sex, brain volume, duration of hypertension, previous antihypertensive treatment and 24-hour MAP ( $p=0.034)$. Additional adjustment for glucose, cholesterol and smoking slightly changed the result (OR 3.04 (95\% Cl 1.14-8.14); $\mathrm{p}=0.027$ ).

There was no statistically significant association between $\mathrm{Hp}$ phenotype and volume of pWMLs.

Table 5.3 Ordinal regression model for Hp phenotypes and deep or periventicular WMLs volumes in ordinal categories.

\begin{tabular}{lccc}
\hline Hp phenotype & Deep WMLs volume \\
& Median $\left(\right.$ range $\left(\mathrm{mm}^{3}\right)$ & $\begin{array}{c}\text { Dedjusted OR }(95 \% \mathrm{Cl}) \\
\text { Unadjusted OR }(95 \% \mathrm{Cl})\end{array}$ \\
\hline $1-1$ & $141(0-22014)$ & $2.51(1.03-6.17)^{\dagger}$ & $2.77(1.07-7.10)^{\dagger}$ \\
$2-1$ & $43(0-8699)$ & $1.15(0.59-2.25)$ & $1.31(0.64-2.66)$ \\
$2-2$ & $45(0-15780)$ & Reference & Reference \\
\hline \multicolumn{4}{c}{ Periventricular WMLs volume } \\
\hline $1-1$ & Median (range) $\left(\mathrm{mm}^{3}\right)$ & Unadjusted OR (95\% Cl) & Adjusted OR $(95 \% \mathrm{Cl})$ * \\
$2-1$ & $761(247-24823)$ & $1.88(0.77-4.53)$ & $1.92(0.75-4.90)$ \\
$2-2$ & $800(23-36348)$ & $1.21(0.62-2.39)$ & $1.43(0.70-2.92)$ \\
\hline
\end{tabular}

OR represents the proportional OR for being in a higher ordinal category of WMLs volume for the presented $\mathrm{Hp}$ phenotype compared to $\mathrm{Hp} \mathrm{2-2.} \mathrm{*} \mathrm{Adjusted} \mathrm{for} \mathrm{age,} \mathrm{sex,} \mathrm{brain} \mathrm{volume,} \mathrm{duration} \mathrm{of}$ hypertension, previous antihypertensive treatment and 24-hour MAP. ${ }^{\dagger} p<0.05$ 


\section{Discussion}

This study shows that hypertensive patients with the Hp1-1 phenotype, not known with clinical vascular disease, have more severe deep white matter damage than those with the Hp2-2 phenotype. No association was found between Hp phenotype and other early silent signs of cerebral SVD, i.e. pWMLs and aLACs.

Our results add to a former study in which we showed an association between the Hp1 allele and symptomatic cerebral SVD. ${ }^{7}$ Contrarily, Hp2-2 is a risk factor for developing coronary and peripheral arterial occlusive lesions. . $^{3,4}$ In diabetic individuals Hp2-2 was a positive predictor of cardiovascular disease, including stroke. ${ }^{6}$ However, individual stroke data were not reported, and stroke subtypes were not considered. We assume that different functional properties of $\mathrm{Hp}$ phenotypes play a vasculature-specific role and this may explain the different associations of the $\mathrm{Hp}$ phenotype with various vascular diseases.

The Hp2-2 phenotype is characterized by stronger immunological reactivity and less antioxidant capacity than Hp1-1.1,14,15 Immunological and oxidative processes are important reactions in large vessel atherogenesis. ${ }^{16}$ Cerebral SVD is a distinct vasculopathy in which processes such as impaired endothelial integrity of the blood-brain barrier may play a more important initiating role. ${ }^{17,18}$ The blood-brain barrier is a unique function of the cerebral small vessels. Failure of the blood-brain barrier with leakage of plasma components into the brain tissue eventually leads to neuronal damage. ${ }^{18}$ One of the possibilities that may be considered in the contribution of Hp phenotype to cerebral SVD is its effect on the blood-brain barrier. Haptoglobin has been identified as an angiogenic factor, regulating endothelial cell tube formation. ${ }^{19,20} \mathrm{Hp} 2-2$ is most active, whereas Hp1-1 has the least angiogenic activity. ${ }^{19}$ Although Hp2-2 is a risk factor for development of peripheral artery disease, patients with severe disease and Hp2-2 had longer walking distances than those with Hp1-1, suggesting better collateral vessel formation. ${ }^{4}$ Recently we found that in vitro cluster formation of endothelial progenitor cells was lower with Hp1-1 serum compared to Hp2-2.21 Consequently, individuals with the Hp1-1 phenotype may have less regenerating power against endothelial and blood-brain barrier injury.

Hypertension contributes to endothelial damage. $\mathrm{Hp}$ phenotype has been associated with BP regulation. Hp1-1 individuals have higher casual BP readings and are more sodium-sensitive, whereas hypertensive Hp1-1 subjects are younger at diagnosis. ${ }^{5,22}$ In pre-ecclampsia, a hypertensive small vessel vasculopathy in pregnancy in which endothelial dysfunction is involved, the Hp1 allele was related to more severe hypertension. ${ }^{23}$ However, in our study the association between Hp1-1 and dWMLs volume was independent of BP level, which argues against an effect of $\mathrm{Hp}$ in cerebral SVD pathogenesis based on BP alone. We also corrected for other factors that may influence the impact of hypertension, i.e. duration of hypertension and previous antihypertensive treatment, although we could not 
correct for duration of treatment and degree of BP control. As Hp1-1 individuals are more sodium-sensitive, and will consequently react better on diuretics, and whereas renin-angiotensin inhibitors may influence endothelial function, type of medication is also a possible intervening factor that we did not correct for.

The different results for deep and periventricular WMLs add to earlier studies that showed differences regarding genetic factors, vascular risk factors, progression rate and clinical consequences in terms of cognitive impairment.24-29 They are indicative of distinct subtypes of WMLs. The deep white matter is supplied by long medullary arteries arising from large cerebral surface arteries, while the periventricular white matter is a borderzone between these vessels and deep small perforating arterioles that also supply the basal ganglia (which is the area where silent aLACs occur). ${ }^{30}$ The role of $\mathrm{Hp}$ may differ between these vascular areas.

The Hardy-Weinberg disbalance in our study is caused by the rather low Hp2-2 frequency of $25 \%$. The expected phenotype distribution in a Western-European population is $16: 48: 36 \%$ (Hp1-1:2-1:2-2). ${ }^{1}$ As Hp2-2 is linked to large vessel disease, and Hp1-1 is possibly linked to BP regulation, the Hardy-Weinberg disbalance is probably related to the selection of hypertensive patients without symptomatic (mainly large vessel) vascular disease. This may limit the generalizability of our results.

A limitation of our study is the cross-sectional design. Any cause-effect relationship between $\mathrm{Hp}$ phenotype and cerebral SVD should ideally be examined in a longitudinal study, in which not only progression of silent lesions but also the occurrence of clinically apparent stroke could be included. However, this would need a large patient group and a long period of follow-up. Secondly, our sample size is rather small, which cannot rule out any association between Hp phenotype and different signs of cerebral SVD. However, at least our findings indicate a difference in degree of association, which is strongest with dWMLs. Finally, it should be emphasized that statistical significance cannot be interpreted without biological plausibility. Studies on how Hp phenotype determines susceptibility to cardiovascular disease mainly focused on extracerebral diabetic vascular disease. ${ }^{14}$ Studies on the role of $\mathrm{Hp}$ phenotype in cerebrovascular disease and blood-brain barrier function are awaiting.

In conclusion, we found Hp1-1 phenotype to be associated with the extent of hypertensive deep white matter damage, one of the early signs of cerebral SVD. This may relate to less regenerating power against vascular endothelial injury. 


\section{References}

1. Van Vlierberghe $\mathrm{H}$, Langlois $\mathrm{M}$, Delanghe J. Haptoglobin polymorphisms and iron homeostasis in health and in disease. Clin Chim Acta. 2004;345:35-42.

2. Langlois MR, Delanghe JR. Biological and clinical significance of haptoglobin polymorphism in humans. Clin Chem. 1996;42:1589-1600.

3. Delanghe J, Cambier B, Langlois M, de Buyzere M, Neels H, de Bacquer D, van Cauwelaert P. Haptoglobin polymorphism, a genetic risk factor on coronary artery bypass surgery. Atherosclerosis. 1997;132:215-219.

4. Delanghe J, Langlois M, Duprez D, de Buyzere M, Clement D. Haptoglobin polymorphism and peripheral arterial occlusive disease. Atherosclerosis. 1999;145:287-292.

5. Delanghe J, Duprez D, de Buyzere M, Bergez B, Callens B, Leroux-Roels G, Clement D. Haptoglobin polymorphism and complications in established essential arterial hypertension. J Hypertens. 1993;11:861-867.

6. Levy AP, Hochberg I, Jablonski K, Resnick HE, Lee ET, Best L, Howard BV. Haptoglobin phenotype is an independent risk factor for cardiovascular disease in individuals with diabetes: the Strong Heart Study. J Am Coll Cardiol. 2002;40:1984-1990.

7. Staals J, Pieters BMA, Knottnerus ILH, Rouhl RPW, van Oostenbrugge RJ, Delanghe J, Lodder J. Haptoglobin polymorphism and lacunar stroke. Curr Neurovasc Res. 2008;5:153-158.

8. Vermeer SE, Hollander M, van Dijk EJ, Hofman A, Koudstaal PJ, Breteler MMB. Silent brain infarcts and white matter lesions increase stroke risk in the general population: the Rotterdam Scan Study. Stroke. 2003;34:1126-1129.

9. Prins ND, van Dijk EJ, den Heijer T, Vermeer SE, Jolles J, Koudstaal PJ, Hofman A, Breteler MMB. Cerebral small-vessel disease and decline in information processing speed, executive function and memory. Brain. 2005;128:2034-2041.

10. Henskens LH, van Oostenbrugge RJ, Kroon AA, de Leeuw PW, Lodder J. Brain microbleeds are associated with ambulatory blood pressure levels in a hypertensive population. Hypertension. 2008;51:62-68.

11. Pantoni L, Garcia JH. Pathogenesis of leukoaraiosis, a review. Stroke. 1997;28:652-659.

12. Henskens LH, Kroon AA, van Oostenbrugge RJ, Gronenschild EH, Fuss-Lejeune MM, Hofman PA, Lodder J, de Leeuw PW. Increased aortic pulse wave velocity is assocated with silent cerebral small-vessel disease in hypertensive patients. Hypertension. 2008;52:1120-1126.

13. Smithies 0 , Connell G, Dixon G. Inheritance of haptoglobin subtypes. Am J Hum Genet. 1962;14:14-21.

14. Levy AP. Application of pharmacogenomics in the prevention of diabetic cardiovascular disease: mechanistic basis and clinical evidence for utilization of the haptoglobin genotype in determining benefit from antioxidant therapy. Pharmacol Ther. 2006;112:501-512.

15. Levy AP, Levy JE, Kalet-Litman S, Miller-Lotan R, Levy NS, Asaf R, Guetta J, Yang C, Purushothaman KR, Fuster V, Moreno PR. Haptoglobin genotype is a determinant of iron, lipid peroxidation, and macrophage accumulation in the atherosclerotic plaque. Arterioscler Thromb Vasc Biol. 2007;27:134-140.

16. Ross R. Atherosclerosis-an inflammatory disease. NEJM. 1999;340:115-126.

17. Hassan A, Hunt BJ, O'Sullivan M, Parmar K, Bamford JM, Briley D, Brown MM, Thomas DJ, Markus HS. Markers of endothelial dysfunction in lacunar infarction and ischaemic leukoaraiosis. Brain. 2003;126:424-432.

18. Wardlaw JM, Sandercock PAG, Dennis MS, Starr J. Is breakdown of the blood-brain barrier responsible for lacunar stroke, leukoaraiosis, and dementia? Stroke. 2003;34:806-812.

19. Cid MC, Grant DS, Hoffman GS, Auerbach R, Fauci AS, Kleinman HK. Identification of haptoglobin as an angiogenic factor in sera from patients with systemic vasculitis. J Clin Invest. 1993;91: 977-985.

20. Lohr NL, Warltier DC, Chilian Wm, Weihrauch D. Haptoglobin expression and activity during coronary collateralization. Am J Physiol Heart Circ Physiol. 2004;288:H1389-1395. 
21. Rouhl RPW, van Oostenbrugge RJ, Damoiseaux JGMC, Debrus-Palmans LL, Theunissen ROMFIH, Knottnerus ILH, Staals JEA, Delanghe JR, Cohen Tervaert JW, Lodder J. Haptoglobin phenotype may alter endothelial progenitor cell cluster formation in cerebral small vessel disease. Curr Neurovasc Res. 2009;6:32-41.

22. Weinberger M, Miller J, Fineberg N, Luft F, Grim C, Christian J. Association of haptoglobin with sodium sensitivity and resistance of blood pressure. Hypertension. 1987;10:443-446.

23. Depypere HT, Langlois MR, Delanghe JR, Temmerman M, Dhont M. Haptoglobin polymorphism in patients with preeclampsia. Clin Chem Lab Med. 2006;44:924-928.

24. Gouw AA, van der Flier WM, Fazekas F, van Straaten ECW, Pantoni L, Poggesi A, Inzitari D, Erkinjuntti T, Wahlund LO, Waldemar G, Schmidt R, Scheltens P, Barkhof F. Progression of white matter hyperintensities and incidence of new lacunes over a 3-year period. Stroke. 2008;39:1414-1420.

25. Delano-Wood L, Abeles N, Sacco JM, Wierenga CE, Horne NR, Bozoki A. Regional white matter pathology in mild cognitive impairment. Stroke. 2008;39:794-799.

26. Sachdev $P$, Wen W. Should we distinguish between periventricular and deep white matter hyperintensities? Stroke. 2005;36:2342-2343.

27. Lazarus R, Prettyman R, Cherryman G. White matter lesions on magnetic resonance imaging and their relationship with vascular risk factors in memory clinic attenders. Int J Geriatr Psychiatry. 2005;20:274-279.

28. Henskens LH, Kroon AA, van Boxtel MP, Hofman PA, de Leeuw PW. Associations of the angiotensin II type 1 receptor A1166C and the endothelial nitric oxide synthase G894T gene polymorphisms with silent subcortical white matter lesions in essential hypertension. Stroke. 2005;36:18691873.

29. de Leeuw F, Richard F, de Groot JC, van Duijn CM, Hofman A, van Gijn J, Breteler MM. Interaction between hypertension, apoE, and cerebral white matter lesions. Stroke. 2004;35:1057-1060.

30. Donnan G, Norrving B, Bamford J, Bogousslavsky J. Subcortical stroke. New York: Oxford University Press; 2002. 


\section{Chapter}

Are asymptomatic lacunar infarcts and white matter lesions associated with ambulatory blood pressure characteristics in lacunar stroke patients? 


\section{Abstract}

Introduction

Beyond the qualitative label "hypertension", there is limited and conflicting information about the relationship between ambulatory blood pressure (BP) levels and silent cerebral small vessel lesions (asymptomatic lacunar infarcts and white matter lesions) in lacunar stroke patients.

\section{Methods}

In 143 first-ever lacunar stroke patients we performed 24-hour ambulatory BP monitoring after the acute stroke phase. On MRI scans we classified the number of asymptomatic lacunar infarcts in 3 categories $(0,1-2, \geq 3)$, and graded the severity of deep and periventricular white matter lesions in 4 ordinal categories.

\section{Results}

After adjusting for age, sex and number of antihypertensive drugs, both higher day and night systolic and diastolic ambulatory BP levels were significantly associated with asymptomatic lacunar infarcts (ordinal regression analyses, odds ratios 1.5-1.6 per SD increase in BP, all $p<0.05$ ). Nocturnal dipping profile was not related to asymptomatic lacunar infarcts. None of the BP characteristics was significantly associated with deep or periventricular white matter lesions.

\section{Conclusion}

Our results underline the role of a high 24-hour BP load as risk factor for the presence of silent lacunar lesions. However, the relationship between BP and white matter lesions might be more complex. Both higher and lower BP levels may have damaging as well as protective effects, obscuring a clear effect of $\mathrm{BP}$ on white matter lesions in our study. 


\section{Introduction}

Asymptomatic lacunar infarcts (aLACs) and white matter lesions (WMLs) in lacunar stroke patients are predictors of recurrent stroke, cognitive decline, and worse prognosis on functional outcome and mortality. ${ }^{1-5}$ Hypertension is an important modifiable risk factor for these "silent" small vessel lesions.1,6

As ambulatory blood pressure (BP) has been proven a stronger predictor of hypertension-related brain damage than office BP measurements, BP is preferably measured by ambulatory BP monitoring (ABPM).7,8 Moreover, ABPM gives additional information about circadian BP characteristics. Studies in stroke-free patients have shown that both higher daytime BP and nighttime BP are associated with aLACS and WMLs. ${ }^{7,-15}$ Furthermore, a reduced nocturnal BP decline (reduced dipping) has been associated with aLACs and WMLs $9,12-14,16$, although this has not been confirmed by all studies. ${ }^{11,15,17,18}$

While associations between ambulatory BP characteristics and aLACs and WMLs have quite extensively been studied in stroke-free (mainly hypertensive) patients, studies in lacunar stroke patients are few. ${ }^{19-22}$ However, in daily practice it is often lacunar stroke patients in whom we are confronted with these silent lesions on brain imaging. Therefore, we studied the relationship between various ambulatory BP characteristics and aLACs and WMLs in first-ever lacunar stroke patients.

\section{Methods}

Between June 2003 and January 2008 we prospectively recruited patients with a first-ever lacunar stroke at Maastricht University Medical Centre, and between September 2004 and April 2007 also at Orbis Medical Centre Sittard, the Netherlands. Lacunar stroke was defined as an acute stroke syndrome with a recent, small, deep infarct on imaging (mostly CT, or MRI when available) compatible with the clinical findings. If no symptomatic lesion was visible, we used established criteria of specific clinical lacunar syndromes. ${ }^{23}$ As we aimed to study patients who most likely had their stroke from local small vessel disease, patients with a potential cardioembolic source or carotid artery stenosis $>50 \%$ were not eligible for inclusion. With informed consent the patients participated in a lacunar stroke research project, which has been approved of by the local Medical Ethical Committee. All included patients underwent MRI, which showed a symptomatic lacunar infarct, defined as a T2-weighted hyperintense, sharply marginated subcortical small lesion of $<20 \mathrm{~mm}$ in diameter compatible with the clinical findings, or no definite symptomatic lesion. We documented the presence of diabetes mellitus, current smoking, and cholesterol level $>5 \mathrm{mmol} / \mathrm{l}$. We defined hypertension at time of presentation with stroke as known hypertension from medical history (treated or not) or at least two BP recordings $>140 / 90 \mathrm{mmHg}$ before stroke. 


\section{MRI scoring}

MRI scans (1.5T, Philips, the Netherlands) were obtained as soon as possible and at least within six months after stroke. The protocol consisted of axial T2-weighted fast spin echo [TR shortest; TE $100 \mathrm{~ms}$; flip angle $90^{\circ}$; field of view (FOV) $230 \mathrm{~mm}$; matrix 512x512] and FLAIR [TR 8000 ms; TE 120 ms; inversion time 2000 ms; FOV $230 \mathrm{~mm}$; matrix 256x256 reconstructed to 512x512], with slice thickness $5 \mathrm{~mm}$ and gaps $0.5 \mathrm{~mm}$. Two vascular neurologists assessed by consensus the number of aLACs and severity of WMLs. Prior to this study, inter-observer agreement was determined to be good to excellent. ${ }^{24}$ We defined aLACs as T2-weighted hyperintense lesions with corresponding FLAIR hypointense lesions with a hyperintense rim, a diameter of $<20 \mathrm{~mm}$ and not compatible with clinical findings. The number of aLACs was classified in 3 categories: $0,1-2$ or $\geq 3$. We defined WMLs as diffuse T2-weighted hyperintensities adjacent to the ventricles (periventricular: pWMLs) or deep subcortical (deep: dWMLs) and classified them according to Fazekas' scale (dWMLs: $0=$ none; $1=$ punctuated; $2=$ partially confluent; $3=$ large confluent. pWMLs: $0=$ none; $1=$ caps; $2=$ smooth halo; $3=$ extending into deep white matter). ${ }^{25}$

\section{Blood pressure measurements}

ABPM was performed after the acute stroke phase, between one and six months post-stroke. We used Mobil O Graph automatic portable equipment (IEM GbmH, Stolberg, Germany) with a B/A rating from the British Hypertension Society. Measurements over a 24-hour period were obtained every 15 minutes during day (07.00-23.00) and every 30 minutes during night (23.00-07.00). Patients continued all their prescribed medication and the number of antihypertensive drugs was registered. They kept a record of retiring and rising times. We determined day and night periods by excluding a 2-hour transition period around the reported rising and retiring times. ${ }^{26}$ Measurement data were not edited manually. Valid recordings required a minimum of 15 daytime and 8 nighttime measurements, as recommended by the British Hypertension Society. We calculated mean 24-hour, day and night systolic (SBP) and diastolic (DBP) BP. We calculated nocturnal SBP dipping as: (day SBP-night SBP)/day SBP $* 100 \%$. We distinguished non-dipping ( $N$ : dipping <10\%), dipping (D: dipping 10-20\%) and extreme dipping (E: dipping >20\%) profiles. ${ }^{18}$

\section{Statistical analysis}

Statistical analyses were performed using SPSS 15.0. Data are presented as N (\%), as mean $\pm \mathrm{SD}$ for parametric data, or as median (range) for nonparametric data. 
We determined differences between groups by $\chi^{2}$ test or t-test. The relationship between the various BP characteristics and the number of aLACs, classified in three ordinal categories, was assessed by ordinal logistic regression analyses, additionally adjusted for age, sex, and the number of antihypertensive drugs in use by each patient. We finally adjusted for diabetes mellitus, smoking or hypercholesterolemia. Analyses of dWMLs and pWMLs (each in four ordinal categories) were performed in the same way. Odds ratios (OR) are given with $95 \%$ $\mathrm{Cl}$. Statistical significance was considered at $p<0.05$.

\section{Results}

Of 280 first-ever lacunar stroke patients at Maastricht University Medical Centre, 36 were not eligible due to carotid stenosis or possible cardioembolic source, 112 decided not to participate, and 18 were excluded because of inadequate MRI or ABPM data, leaving 114 patients. There were more males among the included than the remaining patients $(64.0$ vs. $45.4 \%$ male, $p=0.004)$, and included patients were younger $(65.0 \pm 12.1$ vs. $69.8 \pm 12.1$ years, $p=0.003)$. We recruited 29 patients from Orbis Medical Centre Sittard (number and characteristics of nonincluded patients were not listed), which totals 143 patients. Table 6.1 presents their characteristics.

Table 6.1 Characteristics of all patients.

\begin{tabular}{lc}
\hline Characteristics & All patients $(\mathbf{n}=143)$ \\
\hline Age (years) & $63.0 \pm 12.2$ \\
Male sex & $87(60.8 \%)$ \\
Diabetes mellitus & $18(12.6 \%)$ \\
Current smoking & $56(39.2 \%)$ \\
Cholesterol $>5$ mmol/I & $115(80.4 \%)$ \\
Hypertension & $92(64.3 \%)$ \\
Use of antihypertensive drugs & $88(61.5 \%)$ \\
Number of drugs & $1(0-5)$ \\
24h SBP $(\mathrm{mmHg})$ & $139 \pm 17$ \\
DBP $(\mathrm{mmHg})$ & $83 \pm 12$ \\
Day SBP $(\mathrm{mmHg})$ & $144 \pm 18$ \\
DBP $(\mathrm{mmHg})$ & $86 \pm 13$ \\
Night SBP $(\mathrm{mmHg})$ & $125 \pm 19$ \\
DBP $(\mathrm{mmHg})$ & $73 \pm 12$ \\
Dipping $\%$ & $13 \pm 8$ \\
Dipping profile: N & $49(34 \%)$ \\
$\quad \mathrm{D}$ & $64(45 \%)$ \\
\hline
\end{tabular}




\section{Asymptomatic lacunar infarcts}

aLACs were observed in 90 (62.9\%) patients: 53 (37.1\%) had 1 or 2 aLACs and 37 (25.9\%) had $\geq 3$ aLACs. Table 6.2 shows ABPM results. Higher 24-hour BPs, night BPs, and day BPs were significantly associated with aLACs after adjusting for age, sex and number of antihypertensive drugs. Additional adjustment for diabetes mellitus, smoking or hypercholesterolemia did not affect the associations substantially (results not shown). Neither relative SBP dipping nor dipping profile was significantly associated with aLACs.

Table 6.2 Ambulatory BP characteristics in relation to asymptomatic lacunar infarcts.

\begin{tabular}{|c|c|c|c|c|c|}
\hline $\begin{array}{l}\text { Mean BP } \\
(\mathrm{mmHg})\end{array}$ & $\begin{array}{l}\text { aLACs } 0 \\
(n=53)\end{array}$ & $\begin{array}{c}\text { aLACs } 1-2 \\
(n=53)\end{array}$ & $\begin{array}{c}\text { aLACs } \geq 3 \\
(n=37)\end{array}$ & $\begin{array}{l}\text { Unadjusted } \\
\text { OR }(95 \% \mathrm{Cl}) \\
\end{array}$ & $\begin{array}{c}\text { Adjusted } \\
\text { OR }(95 \% \mathrm{Cl})\end{array}$ \\
\hline \multicolumn{6}{|l|}{$24 \mathrm{~h}$} \\
\hline SBP & $135 \pm 15$ & $139 \pm 17$ & $146 \pm 19$ & $1.55(1.13-2.11)^{\dagger}$ & $1.57(1.15-2.15)^{\dagger}$ \\
\hline DBP & $81 \pm 10$ & $83 \pm 12$ & $86 \pm 14$ & $1.36(1.00-1.86)$ & $1.67(1.18-2.36)^{\dagger}$ \\
\hline \multicolumn{6}{|l|}{ Day } \\
\hline SBP & $141 \pm 16$ & $143 \pm 18$ & $150 \pm 20$ & $1.43(1.06-1.98)^{*}$ & $1.51(1.09-2.05)^{*}$ \\
\hline DBP & $84 \pm 10$ & $86 \pm 13$ & $89 \pm 15$ & $1.30(0.95-1.77)$ & $1.62(1.15-2.30) \dagger$ \\
\hline \multicolumn{6}{|l|}{ Night } \\
\hline SBP & $120 \pm 17$ & $126 \pm 19$ & $132 \pm 20$ & $1.58(1.16-2.19)^{\dagger}$ & $1.55(1.12-2.14)^{\dagger}$ \\
\hline DBP & $71 \pm 11$ & $73 \pm 12$ & $77 \pm 13$ & $1.46(1.06-1.99)^{*}$ & $1.59(1.15-2.22)^{\dagger}$ \\
\hline SBP dipping (\%) & $15 \pm 8$ & $12 \pm 9$ & $12 \pm 8$ & $0.77(0.57-1.05)$ & $0.82(0.60-1.14)$ \\
\hline Profile: N & 15 (28\%) & $20(38 \%)$ & $14(38 \%)$ & $1.19(0.60-2.37)$ & $1.07(0.53-2.16)$ \\
\hline D & $24(45 \%)$ & $22(41 \%)$ & $18(49 \%)$ & Reference & Reference \\
\hline E & $14(26 \%)$ & 11 (21\%) & $5(13 \%)$ & $0.62(0.27-1.40)$ & $0.69(0.30-1.58)$ \\
\hline
\end{tabular}

Results of ordinal regression analyses presented as OR with 1 SD increase in the relevant BP, with 1 SD increase in the relative nocturnal SBP dip, or with the presence of the relevant dipping profile. Adjusted for age, sex and number of antihypertensive drugs. * $p<0.05 \quad p<0.01$

\section{White matter lesions}

Table 6.3 and 6.4 show the mean BP data in relation to pWMLs and dWMLs, respectively. None of the BP characteristics was significantly associated to pWMLS or dWMLs in adjusted regression analyses. 
Table 6.3 Ambulatory BP characteristics in relation to periventricular white matter lesions.

\begin{tabular}{|c|c|c|c|c|c|c|}
\hline $\begin{array}{l}\text { Mean BP } \\
(\mathrm{mmHg})\end{array}$ & $\begin{array}{c}\text { pWMLs } 0 \\
(n=56)\end{array}$ & $\begin{array}{c}\text { pWMLs } 1 \\
(n=41)\end{array}$ & $\begin{array}{c}\text { pWMLs } 2 \\
(n=8)\end{array}$ & $\begin{array}{c}\text { pWMLs } 3 \\
(n=38)\end{array}$ & $\begin{array}{l}\text { Unadjusted } \\
\text { OR }(95 \% \mathrm{Cl})\end{array}$ & $\begin{array}{c}\text { Adjusted } \\
\text { OR }(95 \% \mathrm{Cl})\end{array}$ \\
\hline \multicolumn{7}{|l|}{$24 h$} \\
\hline SBP & $138 \pm 17$ & $140 \pm 20$ & $139 \pm 16$ & $139 \pm 15$ & $1.05(0.78-1.42)$ & $1.09(0.78-1.52)$ \\
\hline DBP & $84 \pm 12$ & $83 \pm 14$ & $85 \pm 9$ & $81 \pm 10$ & $0.89(0.66-1.21)$ & $1.36(0.95-1.95)$ \\
\hline \multicolumn{7}{|l|}{ Day } \\
\hline SBP & $143 \pm 17$ & $146 \pm 21$ & $143 \pm 15$ & $143 \pm 17$ & $1.02(0.75-1.36)$ & $1.07(0.78-1.48)$ \\
\hline DBP & $87 \pm 12$ & $87 \pm 15$ & $87 \pm 10$ & $84 \pm 11$ & $0.86(0.63-1.16)$ & $1.34(0.94-1.93)$ \\
\hline \multicolumn{7}{|l|}{ Night } \\
\hline SBP & $123 \pm 19$ & $126 \pm 22$ & $127 \pm 19$ & $127 \pm 15$ & $1.16(0.86-1.58)$ & $1.12(0.81-1.55)$ \\
\hline DBP & $73 \pm 12$ & $73 \pm 14$ & $76 \pm 9$ & $73 \pm 9$ & $1.04(0.77-1.41)$ & $1.36(0.98-1.90)$ \\
\hline SBP dipping (\%) & $14 \pm 8$ & $14 \pm 9$ & $11 \pm 5$ & $11 \pm 9$ & $0.75(0.55-1.02)$ & $0.88(0.63-1.23)$ \\
\hline Profile: $\mathrm{N}$ & $18(32 \%)$ & $10(24 \%)$ & $3(38 \%)$ & $18(47 \%)$ & $1.42(0.72-2.79)$ & $1.14(0.55-2.37)$ \\
\hline $\mathrm{D}$ & $24(43 \%)$ & $21(51 \%)$ & $5(62 \%)$ & $14(37 \%)$ & Reference & Reference \\
\hline $\mathrm{E}$ & $14(25 \%)$ & $10(24 \%)$ & $0(0 \%)$ & $6(16 \%)$ & $0.71(0.32-1.59)$ & $0.95(0.39-2.27)$ \\
\hline
\end{tabular}

Results of ordinal regression analyses presented as OR with 1 SD increase in the relevant BP, with 1 SD increase in the relative nocturnal SBP dip, or with the presence of the relevant dipping profile. Adjusted for age, sex and number of antihypertensive drugs.

Table 6.4 Ambulatory BP characteristics in relation to deep white matter lesions.

\begin{tabular}{lcccccc}
\hline $\begin{array}{l}\text { Mean BP } \\
(\mathrm{mmHg})\end{array}$ & $\begin{array}{c}\text { dWMLs 0 } \\
(\mathrm{n}=42)\end{array}$ & $\begin{array}{c}\text { dWMLs 1 } \\
(\mathrm{n}=58)\end{array}$ & $\begin{array}{c}\text { dWMLs 2 } \\
(\mathrm{n}=18)\end{array}$ & $\begin{array}{c}\text { dWMLs 3 } \\
(\mathrm{n}=25)\end{array}$ & $\begin{array}{c}\text { Unadjusted } \\
\text { OR }(95 \% \mathrm{Cl})\end{array}$ & $\begin{array}{c}\text { Adjusted } \\
\text { OR }(95 \% \mathrm{Cl})\end{array}$ \\
\hline 24h & & & & & & \\
SBP & $140 \pm 20$ & $140 \pm 17$ & $133 \pm 14$ & $140 \pm 17$ & $0.92(0.68-1.23)$ & $0.95(0.69-1.30)$ \\
DBP & $85 \pm 12$ & $83 \pm 13$ & $78 \pm 8$ & $83 \pm 11$ & $0.79(0.59-1.07)$ & $1.14(0.82-1.59)$ \\
Day & & & & & & \\
SBP & $144 \pm 20$ & $145 \pm 18$ & $139 \pm 14$ & $143 \pm 18$ & $0.91(0.67-1.22)$ & $0.96(0.71-1.31)$ \\
DBP & $89 \pm 12$ & $86 \pm 14$ & $81 \pm 8$ & $85 \pm 12$ & $0.77(0.57-1.04)$ & $1.12(0.80-1.58)$ \\
Night & & & & & & \\
SBP & $125 \pm 22$ & $126 \pm 19$ & $120 \pm 13$ & $128 \pm 17$ & $1.00(0.74-1.36)$ & $0.94(0.70-1.31)$ \\
DBP & $74 \pm 13$ & $73 \pm 13$ & $71 \pm 7$ & $74 \pm 10$ & $0.94(0.70-1.28)$ & $1.20(0.87-1.65)$ \\
SBP dipping (\%) & $13 \pm 9$ & $13 \pm 8$ & $14 \pm 7$ & $11 \pm 9$ & $0.84(0.62-1.14)$ & $1.02(0.73-1.41)$ \\
Profile: N & $13(31 \%)$ & $17(29 \%)$ & $6(33 \%)$ & $13(52 \%)$ & $1.60(0.81-3.17)$ & $1.40(0.69-2.85)$ \\
$\quad$ D & $19(45 \%)$ & $29(50 \%)$ & $8(44 \%)$ & $8(32 \%)$ & Reference & Reference \\
$\quad$ E & $10(24 \%)$ & $12(21 \%)$ & $4(22 \%)$ & $4(16 \%)$ & $0.95(0.43-2.10)$ & $1.40(0.61-3.21)$ \\
\hline
\end{tabular}

Results of ordinal regression analyses presented as OR with 1 SD increase in the relevant BP, with 1 SD increase in the relative nocturnal SBP dip, or with the presence of the relevant dipping profile. Adjusted for age, sex and number of antihypertensive drugs.

\section{Discussion}

The present study shows that in first-ever lacunar stroke patients both day and night ambulatory BP levels are significantly associated with aLACs, independent of age, sex and use of antihypertensive medication. No association was found with the severity of periventricular or deep WMLs.

Early CT-studies showed that lacunar stroke patients with silent lacunar lesions 
were more often hypertensive than patients with a single symptomatic lacunar infarct. ${ }^{27}$ Instead of using the arbitrarily defined and qualitative label of hypertension, based on few office BP measurements in most studies, we performed ABPM. This gives a better presentation of real mean BP, allows exploration of circadian BP profiles, and allows exploring BP quantitatively as a continuous variable. The association between ambulatory BP levels and aLACs in our study is stronger than reported by Chamorro et al. ${ }^{22}$ They found a higher day DBP in lacunar stroke patients with coexisting silent infarcts, but other ambulatory BP characteristics were unrelated. However, their patient group consisted of only 43 patients. Yamamoto et al. found no association between ambulatory BP and aLACs, but performed ABPM within four weeks after lacunar stroke (in the acute stroke phase BP levels can be elevated in reaction to stroke) and used dichotomized instead of continuous BP levels. ${ }^{21}$

A high BP during day and night, i.e. a high cumulative 24-hour BP load, probably plays a role in causing dysfunction of the small vessel endothelium, which constitutes the blood brain barrier. Dysfunction of the blood-brain barrier is considered a main pathogenetic feature in small vessel disease. ${ }^{28}$

Asymptomatic LACs are strongly related to WMLs. Remarkably, we found no association between ambulatory BP levels and WMLs. However, although both WMLs and aLACs are signs of small vessel disease, they occur in different vascular territories in which the effect of risk factors may differ. The long medullary arteries of the white matter are pathologically characterized by thickening of the vessel wall with luminal narrowing, leading to chronic hypoperfusion but without frank occlusion and infarcts as in lacunar infarcts. ${ }^{29}$ Hypothetically, BP might play a complex, dual role in WMLs: high BP levels constitute an initial causal factor in small vessel pathology, by causing blood-brain barrier dysfunction. However, once the small arteries are diseased, low BP levels, as well as excessive nocturnal dipping or great BP variability, may worsen white matter damage by contributing to hypoperfusion. Therefore, depending on the stage of the small vessel damage, similar BP levels may enhance or forestall further damage in different patients. Several studies in stroke-free healthy or hypertensive patients showed a clear positive association between BP levels and WMLs. ${ }^{7,9-15}$ However, our study group consisted of symptomatic stroke patients (implying that small vessels are already diseased) and included both hypertensive and non-hypertensive patients.

Indirect evidence for a possible dual effect of BP comes from studies on the relationship between WMLs and cognitive impairment. In a longitudinal study of lacunar stroke patients, worsening of WMLs and cognition was found in patients with a decline in BP levels at follow-up. ${ }^{30}$ In populations with older people or stroke patients, an inversed U-shape between BPs and cognitive function has been found. 31,32 Although a substudy of the PROGRESS-trial suggested that an active BPlowering regime could delay the progression of WMLs in patients with a history of stroke, the safety of indiscriminate BP reduction is not beyond dispute. ${ }^{33,34}$ 
Nocturnal dipping did not relate to the presence of aLACs or WMLs in our study. Most studies in stroke-free patients found reduced dipping to be associated with aLACs and WMLs, 12-14,16, while some others failed to show such an association. ${ }^{11,15}$ Even a reversed association has been reported. ${ }^{17}$ Kario et al. showed a so-called J-curved relationship: aLACs and WMLs were related to reduced as well as extreme dipping. ${ }^{18}$ Studies in lacunar stroke patients also yielded conflicting results. ${ }^{19-21}$ The fact that there is no consensus on how to define nocturnal dipping and its poor reproducibility might contribute to these conflicting results. ${ }^{35,36}$ Although nocturnal dipping might seem to have important implications, especially in contributing to hypoperfusion in the pathogenesis of WMLs, its clinical relevance above 24-hour BP levels remains controversial. ${ }^{35}$

Our study has limitations. Firstly, it is cross-sectional. Results of ABPM represent the actual BP level without accounting for BP level in the past. We cannot exclude the possibility that BP level changes after stroke, or has been influenced by silent cerebral damage. Follow-up studies are needed to confirm a causal relation between BP level and (progression of) silent lesions. Secondly, more than half of our patients were on antihypertensive treatment during ABPM, which might have mitigated mean BP levels. We adjusted for the use of antihypertensive drugs, but not for the duration of their use. Thirdly, we used a visual rating scale to define WMLs severity. Although it correlates acceptably with quantitative lesion volumes, it may show a so-called ceiling effect. 37,38

In summary, we studied the association between ambulatory BP and silent signs of small vessel disease in lacunar stroke patients. Our results underline the role of a high 24-hour BP load as a risk factor for the presence of silent lacunar lesions, while BP may relate to WMLs in a more complex way. Future BP controlling studies in lacunar stroke patients should therefore address both day and night BP, and should pay extra attention to the presence of WMLs and its consequences. 


\section{References}

1. Vermeer SE, Longstreth WT, Koudstaal PJ. Silent brain infarcts: a systematic review. Lancet Neurol. 2007;6:611-619.

2. Kuller LH, Longstreth WT, Arnold AM, Bernick C, Bryan RN, Beauchamp NJ. White matter hyperintensity on cranial magnetic resonance imaging: a predictor of stroke. Stroke. 2004; 35:1821-1825.

3. Prins ND, van Dijk EJ, den Heijer T, Vermeer SE, Jolles J, Koudstaal PJ, Hofman A, Breteler MMB. Cerebral small-vessel disease and decline in information processing speed, executive function and memory. Brain. 2005;128:2034-2041.

4. Staals J, van Raak L, Hilton A, Lodder J. Differences in long-term survival in two lacunar stroke types: a 15-year follow-up study in 782 cerebral infarct patients. Cerebrovasc Dis. 2008;25:26-31.

5. de Jong G, Kessels F, Lodder J. Two types of lacunar infarcts, further arguments from a study on prognosis. Stroke. 2002;33:2072-2076.

6. de Leeuw F-E, de Groot JC, Oudkerk M, Witteman JCM, Hofman A, van Gijn J, Breteler MMB. Hypertension and cerebral white matter lesions in a prospective cohort study. Brain. 2002; 125:765-772.

7. Shimada K, Kawamoto A, Matsubayashi K, Ozawa T. Silent cerebrovascular disease in the elderly, correlation with ambulatory pressure. Hypertension. 1990;16:692-699.

8. Ohkubo T, Hozawa A, Nagai K, Kikuya M, Tsuji I, Ito S, Satoh H, Hisamichi S, Imai Y. Prediction of stroke by ambulatory blood pressure monitoring versus screening blood pressure measurements in a general population: the Ohasama study. J Hypertens. 2000;18:847-854.

9. Shimada K, Kawamoto A, Matsubayashi K, Nishinaga M, Kimura S, Ozawa T. Diurnal blood pressure variations and silent cerebrovascular damage in elderly patients with hypertension. J Hypertens. 1992;10:875-878.

10. O'Sullivan M, Duggan J, Lyons S, Thornton J, Lee M, O'Brien E. Hypertensive target-organ damage in the very elderly. Hypertension. 2003;42:130-135.

11. Sierra C, de la Sierra A, Mercader J, Gomez-Angelats E, Urbano-Marquez A, Coca A. Silent cerebral white matter lesions in middle-aged essential hypertensive patients. J Hypertens. 2002;20: 519-524.

12. Goldstein IB, Bartzokis G, Hance DB, Shapiro D. Relationship between blood pressure and subcortical lesions in healthy elderly people. Stroke. 1998;29:765-772.

13. Sander D, Winbeck K, klingelhofer J, Conrad B. Extent of cerebral white matter lesions is related to changes of circadian blood pressure rhythmicity. Arch Neurol. 2000;57:1302-1307.

14. Schwartz GL, Bailey KR, Mosley T, Knopman DS, Jack CR, Canzanello VJ, Turner ST. Association of ambulatory blood pressure with ischemic brain injury. Hypertension. 2007;49:1228-1234.

15. van Boxtel MP, Henskens LH, Kroon AA, Hofman PA, Gronenschild EH, Jolles J, de Leeuw PW. Ambulatory blood pressure, asymptomatic cerebrovascular damage and cognitive function in essential hypertension. J Hum Hypertens. 2006;20:5-13.

16. Kukla C, Sander D, Schwarze J, Wittich I, klingelhofer J. Changes of circadian blood pressure patterns are associated with the occurence of lacunar infarction. Arch Neurol. 1998;55:683-688.

17. Watanabe N, Imai Y, Nagai K, Tsuji I, Satoh H, Sakuma M, Sakuma H, Kato J, Onodera-Kikuchi N, Yamada M, Abe F, Hisamichi S, Abe K. Nocturnal blood pressure and silent cerebrovascular lesions in elderly Japanese. Stroke. 1996;27:1319-1327.

18. Kario K, Matsuo T, Kobayashi H, Imiya M, Matsuo M, Shimada K. Nocturnal fall of blood pressure and silent cerebrovascular damage in elderly hypertensive patients. Hypertension. 1996;27: 130-135.

19. Chamorro A, Pujol J, Saiz A, Vila N, Vilanova JC, Alday M, Blanc R. Periventricular white matter lucencies in patients with lacunar stroke. A marker of too high or too low blood pressure? Arch Neurol. 1997;54:1284-1288.

20. Yamamoto Y, Akiguchi I, Oiwa K, Hayashi M, Kimura J. Adverse effect of nighttime blood pressure on the outcome of lacunar infarct patients. Stroke. 1998;29:570-576. 
21. Yamamoto Y, Akiguchi I, Oiwa K, Hayashi M, Ohara T, Ozasa K. The relationship between 24-hour blood pressure readings, subcortical ischemic lesions and vascular dementia. Cerebrovasc Dis. 2005;19:301-308.

22. Chamorro A, Saiz A, Vila N, Ascaso C, Blanc R, Alday M, Pujol J. Contribution of arterial blood pressure to the clinical expression of lacunar infarction. Stroke. 1996;27:388-392.

23. Bamford J, Sandercock P, Jones L, Warlow C. The natural history of lacunar infarction: the Oxfordshire community stroke project. Stroke. 1987;18:545-551.

24. Rouhl RPW, van Oostenbrugge RJ, Knottnerus ILH, Staals J, Lodder J. Virchow-Robin spaces relate to cerebral small vessel disease severity. J Neurol. 2008;255:692-696.

25. Fazekas F, Chawluk JB, Alavi A, Hurtig HI, Zimmerman RA. MR signal abnormalities at $1.5 \mathrm{~T}$ in Alzheimer's dementia and normal aging. AJR. 1987;149:351-356.

26. Henskens LH, van Oostenbrugge RJ, Kroon AA, de Leeuw PW, Lodder J. Brain microbleeds are associated with ambulatory blood pressure levels in a hypertensive population. Hypertension. 2008;51:62-68.

27. Boiten J, Lodder J, Kessels F. Two clinically distinct lacunar infarct entities? A hypothesis. Stroke. 1993;24:652-656.

28. Wardlaw JM. What causes lacunar stroke? JNNP. 2005;76:617-619.

29. Lammie GA. Hypertensive cerebral small vessel disease and stroke. Brain Pathol. 2002;12: 358-370.

30. Yamamoto Y, Akiguchi I, Oiwa K, Hayashi M, Imai K. Twenty-four-hour blood pressure changes in the course of lacunar disease. Cerebrovasc Dis. 2001;11:100-106.

31. Morris MC, Scherr PA, Hebert LE, Bennett DA, Wilson RS, Glynn RJ, Evans DA. Association between blood pressure and cognitive function in a biracial community population of older persons. Neuroepidemiology. 2002;21:123-130.

32. Bohannon AD, Fillenbaum GG, Pieper CF, Hanlon JT, Blazer DG. Relationship of race/ethnicity and blood pressure to change in cognitive function. J Am Geriatr Soc. 2002;50:424-429.

33. Dufouil C, Chalmers J, Coskun O, Besancon V, Bousser MG, Guillon P, MacMahon S, Mazoyer B, Neal B, Woodward M, Tzourio-Mazoyer N, Tzourio C. Effects of blood pressure lowering on cerebral white matter hyperintensities in patients with stroke. Circulation. 2005;112:1644-1650.

34. Birns J, Markus H, Kalra L. Blood pressure reduction for vascular risk. Is there a price to be paid? Stroke. 2005;36:1308-1313.

35. Parati G, Staessen JA. Day-night blood pressure variations: mechanisms, reproducibility and clinical relevance. J Hypertens. 2007;25:2377-2380.

36. Henskens LH, Kroon AA, van Oostenbrugge RJ, Haest RJ, Lodder J, de Leeuw PW. Different classifications of nocturnal blood pressure dipping affect the prevalence of dippers and nondippers and the relation with target-organ damage. J Hypertens. 2008;26:691-698.

37. van Straaten ECW, Fazekas F, Rostrup E, Scheltens P, Schmidt R, Pantoni L, Inzitari D, Waldemar G, Erkinjuntti T, Mantyla R, Wahlund LO, Barkhof F. Impact of white matter hyperintensities scoring method on correlations with clinical data. The LADIS study. Stroke. 2006;37:836-840.

38. Kapeller P, Barber R, Vermeulen R, Ader H, Freidl W, Almkvist O, Moretti M, Del Ser T, Vaghfeldt P, Enziger C, Barkhof F, Scheltens P, Inzitari D, Erkinjuntti T, Schmidt R, Fazekas F. Visual rating of age-related white matter changes on magnetic resonance imaging: scale comparison, interrater agreement, and correlations with quantitative measurements. Stroke. 2003;34:441-445. 



\section{Chapter}

\section{Brain microbleeds relate to higher ambulatory blood pressure levels in first-ever lacunar stroke patients}

J Staals

RJ van Oostenbrugge

ILH Knottnerus

RPW Rouhl

LHG Henskens

J Lodder

Stroke 2009;40:3264-3268 


\section{Abstract}

\section{Background}

Hypertension is an important risk factor for brain microbleeds (BMBs) in lacunar stroke patients. However, beyond the qualitative label "hypertension", little is known about the association with ambulatory blood pressure (BP) levels.

\section{Methods}

In 123 first-ever lacunar stroke patients we performed 24-hour ambulatory BP monitoring after the acute stroke-phase. We counted BMBs on T2*-weighted gradient-echo MR images. Because a different etiology for BMBs according to location has been suggested, we distinguished between BMBs in deep and lobar location.

\section{Results}

BMBs were seen in 36 (29.3\%) patients. After adjusting for age, sex, number of antihypertensive drugs, asymptomatic lacunar infarcts and white matter lesions, we found 24-hour, day and night systolic and diastolic BP levels to be significantly associated with the presence and number of BMBs (odds ratios 1.6-2.3 per standard deviation increase in BP). Distinguishing between different locations, various BP characteristics were significantly associated with the presence of deep (or combined deep and lobar) BMBs, but not with purely lobar BMBs.

\section{Conclusion}

Our results underline the role of a high 24-hour BP load as an important risk factor for BMBs. The association of BP levels with deep but not purely lobar BMBs is in line with the idea that different vasculopathies might be involved. Deep BMBs may be a particular marker of BP-related small vessel disease, but longitudinal and larger studies are now warranted to substantiate these findings. 


\section{Introduction}

Brain microbleeds (BMBs) are frequently seen on T2*-weighted gradient-echo (GE) MR images in lacunar stroke patients. ${ }^{1,2}$ They relate to recurrent stroke and cognitive dysfunction. ${ }^{2-4}$ Hypertension and age are the most important risk factors for BMBs.2,5,6 Instead of using the qualitative label of "hypertension", ambulatory blood pressure monitoring (ABPM) allows the quantitative exploration of blood pressure (BP). Additionally, ABPM gives information about circadian BP characteristics. Ambulatory BP is a stronger predictor of hypertension-related organ damage, including brain damage, than single office measurements. ${ }^{7,8}$ In spite of this, data about the association between ambulatory BP and BMBs are limited. Only one study reported a relationship between high ambulatory BP levels and BMBs in a stroke-free hypertensive population. ${ }^{9}$

We explored the relationship between ambulatory BP characteristics and BMBs in 123 first-ever lacunar stroke patients. We further distinguished between BMBs in deep and lobar brain locations, because some suggest that the etiology of BMBs differs according to their location, with mainly BMBs in deep locations resulting from hypertension-related small vessel disease (SVD). ${ }^{6}$

\section{Methods}

\section{Patients}

We prospectively recruited patients who presented with a first-ever lacunar stroke at Maastricht University Medical Centre and Orbis Medical Centre Sittard, the Netherlands. Lacunar stroke was defined as an acute stroke syndrome with a recent, small, deep infarct on imaging (mostly CT, or MRI when available) compatible with the clinical findings. If no symptomatic lesion was visible, we used established criteria of specific clinical lacunar syndromes. ${ }^{10}$ As we aimed to study patients who most likely had their stroke from local SVD, patients with a potential cardioembolic source or ultrasonographically defined carotid artery stenosis $>50 \%$ were not eligible for inclusion. With informed consent the patients participated in a lacunar stroke research project, which has been approved of by the local Medical Ethical Committee. All included patients underwent MRI, which showed a symptomatic lacunar infarct, defined as a T2-weighted hyperintense, sharply marginated subcortical small lesion of $<20 \mathrm{~mm}$ in diameter compatible with the clinical findings, or no definite recent lesion. Several vascular risk factors were documented: age, sex, diabetes mellitus, current smoking and total cholesterol level $>5 \mathrm{mmol} / \mathrm{l}$. We defined hypertension at time of presentation with stroke as known hypertension from medical history (treated or not) or at least 2 BP recordings $>140 / 90 \mathrm{mmHg}$ before stroke. 


\section{MRI scoring}

MR images (1,5-T MRI scanner, Philips, the Netherlands) were obtained as soon as possible and at least within six months after stroke. Besides standard axial T2weighted fast spin echo and fluid attenuated inversion recovery (FLAIR), we obtained a T2*-weighted GE sequence (TR shortest; TE 23 ms; flip angle $15^{\circ}$; inplane resolution $0.9 \times 0.9 \mathrm{~mm}$; field of view $230 \mathrm{~mm}$; matrix $512 \times 512$; slice thickness $5 \mathrm{~mm}$ and $0.5 \mathrm{~mm}$ interslice gap). With knowledge of the clinical syndrome but blinded to other patient characteristics, two experienced vascular neurologists assessed the scans by consensus. The inter-observer agreement for presence of BMBs, determined prior to this study, was substantial ( $\mathrm{k}=0.68) .{ }^{9} \mathrm{BMBs}$ were defined as punctate hypointense lesions on GE-images with a diameter $<10 \mathrm{~mm}$. We distinguished between lobar (cortex and white matter), deep (basal ganglia, thalamus and internal, external or extreme capsule) and infratentorial (cerebellum, brainstem) BMBs. Symmetric hypointensities in the globi pallidi, likely to represent calcification, and sulcal flow voids from cortical vessels were disregarded. Asymptomatic lacunar infarcts were defined as hyperintense lesions on T2-images with corresponding hypointense lesions with a hyperintense rim on FLAIR, diameter of $<20 \mathrm{~mm}$ and not compatible with clinical findings. Extensive white matter lesions were defined according to Fazekas' classification as T2-weighted (early) confluent deep white matter hyperintensities and/or irregular periventricular hyperintensities extending into the deep white matter. ${ }^{11}$

\section{BP measurements}

ABPM (using Mobil O Graph equipment, IEM GbmH, Stolberg, Germany) was performed after the acute stroke phase, between one and six months post-stroke. Measurements over a 24-hour period were obtained every 15 minutes during day (07.00-23.00) and every 30 minutes during night (23.00-7.00). Patients continued their prescribed medication and we registered the use of antihypertensive drugs. Patients kept a record of retiring and rising times. We determined day and night periods by excluding a 2-hour transition period around the reported rising and retiring times. ${ }^{9}$ Valid recordings required a minimum of 15 daytime and 8 nighttime measurements. ${ }^{12}$ We calculated mean 24-hour, day and night systolic (SBP), diastolic (DBP) and pulse pressure (PP). Relative nocturnal dipping (SBP dipping) was calculated as: (day SBP-night SBP)/day SBP *100\%.

\section{Statistical analysis}

Analyses were performed using SPSS 15.0. Data are presented as N (\%), as mean tstandard deviation (SD) for parametric data, or as median (range) for 
nonparametric data. Differences between groups were determined using $\chi^{2}$ test, t-test or Mann-Whitney test, where appropriate. We assessed the relationship between the various BP characteristics and BMBs by ordinal regression analyses (classifying the number of BMBs as 0,1 or $>1$ ) or binary logistic regression analyses (presence $(-/+)$ of BMBs in different locations), adjusted for age, sex, and the number of antihypertensive drugs in use by each patient (model 1). We additionally adjusted for the presence of asymptomatic lacunar infarcts and white matter lesions (model 2). Finally we performed some exploratory analyses in which we adjusted for cardiovascular risk factors (diabetes mellitus, hypercholesterolemia, current smoking) by adding them one for one separately to the model. Odds ratios (OR) are given with 95\% confidence interval (Cl). Statistical significance was considered at $p<0.05$.

\section{Results}

\section{Patient recruitment}

Of 243 eligible first-ever lacunar stroke patients who presented between June 2003 and January 2008 at Maastricht, 112 patients decided not to participate and 34 were excluded because of inadequate MRI or ABPM data, leaving 97 included patients. There were more males among the included than the remaining patients ( 64.2 vs. $47.3 \%$ male, $p=0.01$ ), whereas age did not differ significantly. Between September 2004 and April 2007 we recruited 26 patients from Sittard, which totals 123 patients. Patients from Maastricht were older than those from Sittard (67.0 \pm 10.9 vs. $55.8 \pm 10.1$ years, $p<0.001$ ), had higher SBPs (24-hour SBP 141 \pm 17 vs. $129 \pm 12 \mathrm{mmHg}, p<0.001$ ) and PPs (24-hour PP $59 \pm 11$ vs. $50 \pm 7 \mathrm{mmHg}$, $p<0.001)$ and had more often white matter lesions (43.3 vs. $19.2 \%, p=0.03$ ) and microbleeds (32.0 vs. $19.2 \%, p=0.21$ ). In 24 of 123 patients (19.5\%), MRI did not show a symptomatic lacunar infarct.

\section{Patient characteristics}

Microbleeds were present in 36 (29.3\%) patients (Table 7.1). Twenty-five (20.3\%) patients had one $\mathrm{BMB}$, and 11 patients $(8.9 \%)$ had two or more (maximum 19 BMBs). Hypertension was more frequent in patients with BMBs, but the difference was not statistically significant (OR 1.59, $\mathrm{p}=0.28$ ). 
Table 7.1 Patient characteristics and MRI findings.

\begin{tabular}{lcccc}
\hline Patient characteristics & All $(\mathrm{n}=123)$ & BMBs $-(\mathrm{n}=87)$ & BMBs + $(\mathrm{n}=36)$ & $\mathrm{p}$-value \\
\hline Age (years) & $64.6 \pm 11.7$ & $63.7 \pm 12.1$ & $66.9 \pm 10.3$ & 0.16 \\
Male sex & $75(61.0 \%)$ & $55(63.2 \%)$ & $20(55.6 \%)$ & 0.43 \\
Diabetes mellitus & $17(13.8 \%)$ & $11(12.6 \%)$ & $6(16.7 \%)$ & 0.56 \\
Current smoking & $49(39.8 \%)$ & $36(41.4 \%)$ & $13(36.1 \%)$ & 0.59 \\
Cholesterol $>5$ mmol/I & $100(81.3 \%)$ & $70(80.4 \%)$ & $30(83.3 \%)$ & 0.90 \\
Hypertension & $80(65.0 \%)$ & $54(62.1 \%)$ & $26(72.2 \%)$ & 0.28 \\
Use of antihypertensive drugs & $80(65.0 \%)$ & $55(63.2 \%)$ & $25(69.4 \%)$ & 0.51 \\
Diuretics & $25(20.3 \%)$ & $16(18.4 \%)$ & $9(25.0 \%)$ & 0.41 \\
Beta-blockers & $35(28.5 \%)$ & $24(27.6 \%)$ & $11(30.6 \%)$ & 0.74 \\
Calcium channel blockers & $15(12.2 \%)$ & $8(9.2 \%)$ & $7(19.4 \%)$ & 0.11 \\
ACE inhibitors & $27(22.0 \%)$ & $19(21.8 \%)$ & $8(22.2 \%)$ & 0.96 \\
Angiotensin receptor blockers & $33(26.8 \%)$ & $24(27.6 \%)$ & $9(25.0 \%)$ & 0.77 \\
Alpha-blockers & $1(0.81 \%)$ & $1(1.1 \%)$ & $0(0.0 \%)$ & 0.46 \\
Number of drugs & $1(0-5)$ & $1(0-5)$ & $1(0-4)$ & $<0.001$ \\
Asymptomatic lacunar infarcts & $77(62.6 \%)$ & $45(51.7 \%)$ & $32(88.9 \%)$ & 0.001 \\
Extensive white matter lesions & $47(38.2 \%)$ & $25(28.7 \%)$ & $22(61.1 \%)$ & \\
\hline
\end{tabular}

Data are missing for current smoking $(n=1)$ and cholesterol $(n=2)$

\section{BP characteristics}

Table 7.2 shows the association between the various BP characteristics and the presence and number of BMBs. Higher SBPs and DBPs were significantly associated with BMBs, after adjustment for age, sex and number of antihypertensive drugs, and additionally for asymptomatic lacunar infarcts and extensive white matter lesions. Adjusting for diabetes mellitus, hypercholesterolemia or smoking did not change results substantially and no center effect was seen (data not shown). Systolic nocturnal dipping and PP had no significant relationship with presence and number of BMBs.

\section{Different locations of BMBs}

Eleven (8.9\%) patients had only lobar BMBs (median number of BMBs 1 (range 1-9)). BP levels in these patients were slightly higher than in those without any BMBs, but associations did not reach statistical significance (Table 7.3). Seventeen (13.8\%) patients had only deep BMBs (median 1 (1-2)). With exception of night SBP $(p=0.061)$, higher SBPs and DBPs were significantly associated with presence of deep BMBs, after adjustment for age, sex, number of antihypertensive drugs, asymptomatic lacunar infarcts and extensive white matter lesions. Seven (5.7\%) patients had combined (both deep and lobar) BMBs (median 3 (2-19)), and 1 $(0.8 \%)$ patient had a cerebellar located BMB. ORs on associations between SBP and DBP levels and presence of combined BMBs varied from 1.93 to 2.90, but only reached statistical significance for 24-hour and day DBP. Systolic nocturnal dipping and PP had no significant relationship with presence of BMBs in any location (data not shown). 
Table 7.2 Ambulatory BP characteristics in relation to presence and number of BMBs.

\begin{tabular}{lccccc}
\hline $\begin{array}{l}\text { Mean BP } \\
\mathrm{mmHg}\end{array}$ & $\begin{array}{c}\text { BMB 0 } \\
(\mathrm{n}=87)\end{array}$ & $\begin{array}{c}\text { BMB 1 } \\
(\mathrm{n}=25)\end{array}$ & $\begin{array}{c}\text { BMB }>1 \\
(\mathrm{n}=11)\end{array}$ & $\begin{array}{c}\text { Model 1 } \\
\text { OR }(95 \% \mathrm{Cl})\end{array}$ & $\begin{array}{c}\text { Model 2 } \\
\text { OR }(95 \% \mathrm{Cl})\end{array}$ \\
\hline $\begin{array}{l}24 \text {-hour } \\
\text { SBP }\end{array}$ & $136 \pm 16$ & $144 \pm 16$ & $148 \pm 22$ & $1.80(1.20-2.74) \dagger$ & $1.93(1.22-3.03) \dagger$ \\
DBP & $81 \pm 11$ & $84 \pm 9$ & $91 \pm 14$ & $2.59(1.62-4.15) \dagger$ & $2.34(1.43-3.88) \dagger$ \\
PP & $56 \pm 11$ & $59 \pm 12$ & $57 \pm 9$ & $1.14(0.75-1.73)$ & $1.31(0.82-2.07)$ \\
Day & & & & & \\
SBP & $141 \pm 16$ & $149 \pm 17$ & $152 \pm 25$ & $1.86(1.23-2.82) \dagger$ & $2.00(1.25-3.13) \dagger$ \\
DBP & $83 \pm 11$ & $87 \pm 9$ & $94 \pm 16$ & $2.65(1.65-4.22) \ddagger$ & $2.33(1.41-3.79) \dagger$ \\
PP & $57 \pm 11$ & $61 \pm 12$ & $58 \pm 10$ & $1.14(0.75-1.72)$ & $1.35(0.85-2.15)$ \\
Night & & & & & \\
SBP & $122 \pm 18$ & $130 \pm 19$ & $134 \pm 17$ & $1.58(1.06-2.36)^{*}$ & $1.61(1.02-2.50)^{*}$ \\
DBP & $71 \pm 11$ & $76 \pm 10$ & $80 \pm 11$ & $2.21(1.41-3.47) \dagger$ & $2.09(1.26-3.43) \dagger$ \\
PP & $52 \pm 12$ & $54 \pm 12$ & $54 \pm 9$ & $1.07(0.71-1.63)$ & $1.14(0.71-1.78)$ \\
SBP dipping (\%) & $13 \pm 8$ & $13 \pm 10$ & $11 \pm 8$ & $0.98(0.65-1.49)$ & $1.07(0.69-1.65)$ \\
\hline
\end{tabular}

Results of ordinal regression analyses presented as OR with 1 SD increase in the relevant $\mathrm{BP}(95 \% \mathrm{Cl})$. The SD of SBP / DBP / PP are 17 / 11 / $11 \mathrm{mmHg}$ for the 24-hour period, 17 / 12 / $11 \mathrm{mmHg}$ for the day period, and $18 / 11 / 12 \mathrm{mmHg}$ for the night period; the SD of dipping is $9 \%$. SBP dipping is defined as (day SBP-night SBP)/day SBP*100\%. Model 1: adjusted for age, sex and number of antihypertensive drugs; Model 2: additionally adjusted for asymptomatic lacunar infarcts and extensive white matter lesions. * $p<0.05 ; \dagger p<0.01 ; \ddagger p<0.001$

Table 7.3 Ambulatory BP characteristics in relation to presence of BMBs in different locations.

\begin{tabular}{|c|c|c|c|c|}
\hline $\begin{array}{l}\text { Mean BP } \\
\mathrm{mmHg}\end{array}$ & & $\begin{array}{c}\text { BMBs + } \\
\text { only deep }(n=17)\end{array}$ & $\begin{array}{c}\text { Model } 1 \\
\text { OR }(95 \% \mathrm{Cl})\end{array}$ & $\begin{array}{c}\text { Model } 2 \\
\text { OR }(95 \% \mathrm{Cl})\end{array}$ \\
\hline \multirow[t]{2}{*}{ 24-hour } & SBP & $147 \pm 17$ & $1.99(1.12-3.53)^{*}$ & $1.96(1.05-3.70)^{*}$ \\
\hline & DBP & $86 \pm 10$ & $2.21(1.16-4.20)^{*}$ & $2.05(1.02-4.04)^{*}$ \\
\hline \multirow[t]{2}{*}{ Day } & SBP & $152 \pm 18$ & $2.00(1.15-3.55)^{*}$ & $2.00(1.07-3.73)^{*}$ \\
\hline & DBP & $89 \pm 11$ & $2.12(1.14-3.97)^{*}$ & $1.97(1.01-3.81)^{*}$ \\
\hline \multirow[t]{4}{*}{ Night } & SBP & $133 \pm 14$ & $1.97(1.08-3.51)^{*}$ & $1.86(0.96-3.57)$ \\
\hline & DBP & $77 \pm 8$ & $2.32(1.21-4.42)^{*}$ & $2.19(1.08-4.42)^{*}$ \\
\hline & & BMBs + & Model 1 & Model 2 \\
\hline & & only lobar $(n=11)$ & OR $(95 \% \mathrm{Cl})$ & OR $(95 \% \mathrm{Cl})$ \\
\hline \multirow[t]{2}{*}{ 24-hour } & SBP & $139 \pm 17$ & $1.16(0.58-2.31)$ & $1.40(0.58-3.42)$ \\
\hline & DBP & $84 \pm 11$ & $1.87(0.85-4.12)$ & $2.00(0.80-5.06)$ \\
\hline \multirow[t]{2}{*}{ Day } & SBP & $144 \pm 17$ & $1.27(0.63-2.57)$ & $1.60(0.63-3.91)$ \\
\hline & DBP & $87 \pm 10$ & $1.95(0.89-4.23)$ & $1.99(0.82-4.90)$ \\
\hline \multirow[t]{4}{*}{ Night } & SBP & $126 \pm 23$ & $1.12(0.58-2.16)$ & $1.27(0.56-2.90)$ \\
\hline & DBP & $76 \pm 13$ & $1.76(0.86-3.57)$ & $1.84(0.78-4.34)$ \\
\hline & & BMBs + & Model 1 & Model 2 \\
\hline & & Combined $(n=7)$ & OR $(95 \% \mathrm{Cl})$ & OR (95\% Cl) \\
\hline \multirow[t]{2}{*}{ 24-hour } & SBP & $151 \pm 23$ & $2.44(0.98-5.95)$ & $2.56(0.84-7.68)$ \\
\hline & DBP & $92 \pm 15$ & $3.47(1.33-9.10)^{*}$ & $2.90(1.05-7.80)$ * \\
\hline \multirow[t]{2}{*}{ Day } & SBP & $153 \pm 26$ & $2.25(0.97-5.28)$ & $2.29(0.97-6.57)$ \\
\hline & DBP & $95 \pm 16$ & $3.02(1.27-7.31)^{*}$ & $2.59(1.00-6.68)$ * \\
\hline \multirow[t]{2}{*}{ Night } & SBP & $136 \pm 19$ & $1.90(0.79-4.60)$ & $1.93(0.61-6.01)$ \\
\hline & DBP & $80 \pm 12$ & $2.46(0.95-6.35)$ & $2.09(0.72-6.12)$ \\
\hline
\end{tabular}

Results of binary logistic regression analyses presented as OR with 1 SD increase in the relevant BP $(95 \% \mathrm{Cl})$. We used the SDs as in Table 7.2. Models were obtained as in Table 7.2. * $p<0.05$ 


\section{Discussion}

In this study in 123 first-ever lacunar stroke patients the presence and number of BMBs was significantly associated with higher ambulatory day and night SBP and DBP levels, independent of age, sex and use of antihypertensive medication. Even after additional adjustment for silent lacunar infarcts and white matter lesions, BP levels remained independent predictors for BMBs.

We found a microbleed prevalence of $29.3 \%$, which is lower than the reported 46 $62 \%$ in some other studies. ${ }^{13,14}$ However, lacunar stroke patients in these studies were older, and recurrent strokes were included as well, which both might have biased towards a higher BMBs rate. ${ }^{2,15}$ Studies in first-ever lacunar stroke patients reported a prevalence of $23-26 \%$, similar to our percentage. ${ }^{15,16}$

A systematic review reported an association between hypertension and BMBs in adults with cerebrovascular disease with an overall OR of $2.3 .^{2}$ We found a nonsignificant OR of 1.6. However, we documented hypertension by history-taking at the time of presentation with stroke, which might have missed undiagnosed cases. Instead of using the arbitrarily defined and qualitative label of hypertension, generally based on few office measurements, we performed ABPM which gives a better presentation of real BP. Our results comply with a recent study in a strokefree hypertensive population, in which also day and night ambulatory BP levels predicted the presence of BMBs. ${ }^{9}$

As in other studies, BMBs were strongly associated to the presence of silent lacunar infarcts and white matter lesions, which implies that they are probably all caused by a similar small vessel pathology.2,5,6 After adjusting for coexistent lacunar infarcts and white matter lesions, the associations between ambulatory BP levels and BMBs remained statistically significant, which suggests that BP is a stronger risk factor for the occurrence of BMBs than for the other BP-related signs of SVD. In CADASIL, a monogenetic cause of SVD, it was also found that office SBP level relates to the presence of BMBs, independently of the extent of lacunar infarcts and white matter lesions. ${ }^{17}$

Dysfunction of the blood-brain barrier has been suggested as a main initial pathogenetic feature in SVD. ${ }^{18}$ The blood-brain barrier depends on endothelial integrity, which could be disrupted by BP-related hemodynamic factors. Our findings emphasize the importance of both day and night BP, that is, an increased 24-hour mean BP-load. Although increased pulsatile stress is considered to be one cause of small vessel wall damage, brachial PP was not related to BMBs in our study. However, central PP or carotid flow augmentation would be a better measure. ${ }^{19}$ The phenomenon of reduced nocturnal dipping has also been related to the degree of hypertensive end-organ damage. ${ }^{20} \mathrm{We}$ found no association between the degree of nocturnal dipping and BMBs. However, there is no consensus on how to define nocturnal dipping, its reproducibility is poor, and its clinical relevance above 24-hour BP level is controversial.20,21 
Pathology studies showed that BMBs consist of hemosiderin deposits from blood that presumably leaked from small blood vessels that are affected by lipohyalinosis in most subjects. ${ }^{22-24}$ In some cases with mainly lobar BMBs, evidence of amyloid angiopathy was found. ${ }^{24}$ These data, though limited, suggest that deep and lobar BMBs represent different underlying pathologies, analogous to symptomatic intracerebral hemorrhage. Evidence from clinical studies supports this concept. Deep and lobar BMBs were found to associate with the presence of a symptomatic hemorrhage in the corresponding area. ${ }^{25}$ The APOE $\varepsilon 4$ genotype, which is related to amyloid angiopathy, was found to be associated with lobar but not deep BMBs. ${ }^{6}$ Hypertension and office SBP were more strongly related to deep than lobar BMBs, suggesting that mainly deep BMBs are a marker of BP-related cerebral SVD. ${ }^{5,6}$ In line with these data, we observed that associations with ambulatory BP levels were stronger for deep than lobar BMBs. However, high BP does not rule out amyloid angiopathy and the vasculopathies may co-exist. Furthermore, subgroups in our study were small which withholds us from drawing firm conclusions.

Our study has several limitations. Firstly, it is cross-sectional. Results of ABPM represent the actual BP level without accounting for BP level in the past. We cannot exclude the possibility that BP level changes after stroke or has been influenced by silent cerebral damage. Follow-up studies are needed to confirm a causal relation between BP levels and (progression of) BMBs. Secondly, more than half of the patients were taking antihypertensive drugs during ABPM, which might have mitigated mean BP levels. We adjusted for the use of antihypertensive drugs, but not for the duration of use. However, our approach may have led to an underestimation rather than an overestimation of the strength of the association between BP and BMBs. Thirdly, detection of BMBs strongly depends on MRI characteristics and the detection criteria used. ${ }^{1}$ This may limit comparability with other studies. Fourtly, we were unable to identify a symptomatic lacunar lesion on MRI in $19.5 \%$ of our patients. This may relate to short (but at least $>24$ hours) duration of symptoms in some cases, but also to the rather long (up to six months) MRI delay in some other cases, blurring the distinction between recent and possible concomitant asymptomatic lesions. However, we feel that this did not lead to unrightfully included patients as they obviously had a clinical lacunar syndrome. Finally, our sample size was rather small, and most patients with BMBs had only one BMB. Larger series are needed to confirm our findings concerning BMBs in different locations, and to facilitate stronger analysis of number in addition to presence of BMBs.

In summary, our results underline the role of a high 24-hour BP load as important risk factor for BMBs in lacunar stroke patients. The association between BP and deep but not lobar BMBs is in line with the idea that different vasculopathies might be involved. Deep BMBs may be a particular marker of BP-related SVD. Longitudinal and larger studies are now warranted to substantiate these findings. 


\section{References}

1. Greenberg SM, Vernooij MW, Cordonnier C, Viswanathan A, Salman RA, Warach S, Launer LJ, van Buchem MA, Breteler MMB. Cerebral microbleeds: a guide to detection and interpretation. Lancet Neurol. 2009;8:165-174.

2. Cordonnier C, Salman RA, Wardlaw J. Spontaneous brain microbleeds: systematic review, subgroup analyses and standards for study design and reporting. Brain. 2007;130:1988-2003.

3. Werring DJ, Frazer DW, Coward L, Losseff NA, Watt H, Cipolotti L, Brown MM, Jager HR. Cognitive dysfunction in patients with cerebral microbleeds on T2*-weighted gradient-echo MRI. Brain. 2004;127:2265-2275.

4. Imaizumi T, Horita Y, Hashimoto Y, Niwa J. Dotlike hemosiderin spots on T2*-weighted magnetic resonance imaging as a predictor of stroke recurrence: a prospective study. J Neurosurg. 2004; 101:915-920.

5. van Es ACGM, van der Grond J, de Craen AJM, Admiraal-Behloul F, Blauw GJ, van Buchem MA. Risk factors for cerebral microbleeds in the elderly. Cerebrovasc Dis. 2008;26:397-403.

6. Vernooij MW, van der Lugt A, Ikram MA, Wielopolski PA, Niessen WJ, Hofman A, Krestin GP, Breteler MM. Prevalence and risk factors of cerebral microbleeds: the Rotterdam Scan Study. Neurology. 2008;70:1208-1214.

7. Shimada K, Kawamoto A, Matsubayashi K, Ozawa T. Silent cerebrovascular disease in the elderly, correlation with ambulatory pressure. Hypertension. 1990;16:692-699.

8. Ohkubo T, Hozawa A, Nagai K, Kikuya M, Tsuji I, Ito S, Satoh H, Hisamichi S, Imai Y. Prediction of stroke by ambulatory blood pressure monitoring versus screening blood pressure measurements in a general population: the Ohasama study. J Hypertens. 2000;18:847-854.

9. Henskens LH, van Oostenbrugge RJ, Kroon AA, de Leeuw PW, Lodder J. Brain microbleeds are associated with ambulatory blood pressure levels in a hypertensive population. Hypertension. 2008;51:62-68.

10. Bamford J, Sandercock P, Jones L, Warlow C. The natural history of lacunar infarction: the Oxfordshire community stroke project. Stroke. 1987;18:545-551.

11. Fazekas F, Chawluk JB, Alavi A, Hurtig HI, Zimmerman RA. MR signal abnormalities at $1.5 \mathrm{~T}$ in Alzheimer's dementia and normal aging. AJR. 1987;149:351-356.

12. O'Brien E, Coats A, Owens P, Petrie J, Padfield PL, Littler WA, de Swiet M, Mee F. Use and interpretation of ambulatory blood pressure monitoring: recommendations of the British Hypertension Society. BMJ. 2000;320:1128-1134.

13. Schonewille WJ, Singer MB, Atlas SW, Tuhrim S. The prevalence of microhemorrhage on gradientecho magnetic resonance imaging in acute lacunar infarction. J Stroke Cerebrovasc Dis. 2005; 14:141-144.

14. Kato H, Izumiyama M, Izumiyama K, Takahashi A, Itoyama Y. Silent cerebral microbleeds on T2* weighted MRI: correlation with stroke subtype, stroke recurrence and leukoaraiosis. Stroke. 2002;33:1536-1540.

15. Naka H, Nomura E, Wakabayashi S, Kajikawa H, Kohriyama T, Mimori Y, Nakamura S, Matsumoto M. Frequency of asymptomatic microbleeds on T2*-weighted MR images of patients with recurrent stroke: association with combination of stroke subtypes and leukoaraiosis. AJNR Am J Neuroradiol. 2004;25:714-719.

16. Wardlaw JM, Lewis SC, Keir SL, Dennis MS, Shenkin S. Cerebral microbleeds are associated with lacunar stroke defined clinically and radiologically, independently of white matter lesions. Stroke. 2006;37:2633-2636.

17. Viswanathan A, Guichard J-P, Gschwendtner A, Buffon F, Cumurcuic R, Boutron C, Vicaut E, Holtmannspotter M, Pachai C, Bousser MG, Dichgans M, Chabriat H. Blood pressure and haemoglobin A1c are associated with microhaemorrhage in CADASIL: a two-centre cohort study. Brain. 2006;129:2375-2383.

18. Wardlaw JM. What causes lacunar stroke? JNNP. 2005;76:617-619.

19. Hirata K, Yaginuma T, O'Rourke MF, Kawakami M. Age-related changes in carotid artery flow and pressure pulses: possible implications for cerebral microvascular disease. Stroke. 2006;37: 2552-2556. 
20. Parati G, Staessen JA. Day-night blood pressure variations: mechanisms, reproducibility and clinical relevance. J Hypertens. 2007;25:2377-2380.

21. Henskens LH, Kroon AA, van Oostenbrugge RJ, Haest RJ, Lodder J, de Leeuw PW. Different classifications of nocturnal blood pressure dipping affect the prevalence of dippers and nondippers and the relation with target-organ damage. J Hypertens. 2008;26:691-698.

22. Tatsumi S, Shinohara M, Yamamoto T. Direct comparison of microbleeds with postmortem MR images. Cerebrovasc Dis. 2008;26:142-146.

23. Tanaka A, Ueno Y, Nakayama Y, Takano K, Takebayashi S. Small chronic hemorrhages and ischemic lesions in association with spontaneous intracerebral hematomas. Stroke. 1999;30: 1637-1642.

24. Fazekas F, Kleinert R, Roob G, Kleinert G, Kapeller P, Schmidt R, Hartung H-P. Histopathologic analysis of foci of signal loss on gradient-echo T2*-weighted MR images in patients with spontaneous intracerebral hemorrhage: evidence of microangiopathy-related microbleeds. AJNR Am J Neuroradiol. 1999;20:637-642.

25. Lee SH, Bae HJ, Kwon SJ, Kim H, Kim YH, Yoon BW, Roh JK. Cerebral microbleeds are regionally associated with intracerebral hemorrhage. Neurology. 2004;62:72-76. 



\section{Chapter 8}

\section{General discussion}


Chapter 8 


\section{Introduction}

About a quarter of all ischemic strokes is a lacunar stroke, and, contrary to general notion, it should not be considered a benign stroke type. We demonstrated that short-term ${ }^{1}$ as well as long-term prognosis (chapter 2) is not better in lacunar stroke than in atherothrombotic stroke. The only difference in prognosis is a lower early case fatality rate in lacunar stroke. However, and quite undeservedly, lacunar (small vessel) stroke has gained far less attention in stroke research than atherothrombotic (large vessel) stroke, and knowledge of its pathogenetic process still contains many gaps.

Lacunar stroke can be subtyped according to the presence or absence of concomitant "silent" signs of small vessel disease: asymptomatic lacunar infarcts, white matter lesions and brain microbleeds. The prevalence of these lesions in lacunar stroke patients is substantial: in the patient group that was included in our research, asymptomatic lacunar lesions were present in about 63\%, extensive white matter lesions in $38 \%$ and brain microbleeds in $29 \%$, while only $23 \%$ was free of any of these lesions. The term "silent" should be disputed. Although these lesions in general do not present with acute neurological symptoms, they can be accompanied by cognitive decline, depict a worse prognosis on functional outcome, and a higher risk of recurrent stroke.2-5 Furthermore, we showed a worse long-term prognosis on mortality in lacunar stroke patients when asymptomatic lacunar infarcts or white matter lesions are present (chapter 2).

The aforementioned differences in clinical consequences validate the distinction of lacunar stroke subtypes: those with and those without concomitant signs of small vessel disease. In this thesis we described several studies that explored differences between lacunar stroke patients with and without these signs. The main topics were the SELDI-TOF-MS approach to study protein expression profiles in serum, haptoglobin phenotypes and 24-hour ambulatory blood pressure characteristics. I will address these three topics and discuss the implications of our findings for future research. Finally I will discuss the clinical and potential therapeutical consequences.

\section{SELDI-TOF-MS}

Up to recently, research in cerebral small vessel disease focused mainly on proteins that are known to be involved in vascular pathogenesis. Research topics are often deducted from the scientific work on large vessel atherosclerotic disease or stroke in general. Unique factors in small vessel disease may go unnoticed in this way. Instead of studying individual proteins we used Surface-Enhanced Laser Desorption / Ionization Time-of-Flight Mass Spectrometry (SELDI-TOF-MS), a new approach to explore the expression profile of the total proteome (chapter 3). 
Unbiased by current ideas about pathogenesis, we compared protein profiles of lacunar stroke patients with and without concomitant lesions and found differences in several proteins, one of which could be identified as $\alpha$-chain of haptoglobin.

Although it seemed a very promising technique, the limitations of the SELDI-TOFMS technique have become clear now. One of the most limiting factors at this moment is that the technique only detects highly abundant proteins (i.e. not below the $\mathrm{mg} / \mathrm{l}$ level). Cellular proteins will not be detected, and many general plasma proteins that are present in a low concentration will go undetected too. Furthermore, it is still unclear whether cerebral small vessel disease is restricted to the brain, or is part of a more generalised small vessel disease. It is doubtful whether differences in the expression of proteins that are involved in a process that takes place at a restricted cerebral small vessel level would be traced in standard venous blood samples. However, there are indications that cerebral small vessel disease is part of a systemic arteriopathy (or more correctly: endotheliopathy) with symptoms most pronounced in the brain, possibly due to the unique characteristics and vulnerability of the blood-brain barrier or other features of the cerebral small perforating arteries. ${ }^{6}$ Impairment of systemic endothelial function as measured by flow-mediated dilatation in the forearm has been associated with lacunar stroke. ${ }^{7}$ Signs of cerebral small vessel disease were found to parallel signs of other small vessel pathologies, such as retinal small artery disease. ${ }^{8}$ Small vessel disease in the kidney, characterized by glomerular endothelium dysfunction and measured by decreased glomerular filtration rate, was found to be related to cerebral deep white matter volume and asymptomatic lacunar infarcts. ${ }^{9}$ Assuming that cerebral small vessel disease is part of a systemic small vessel arteriopathy, does SELDI-TOF-MS still have any value in lacunar research? Are there any abundant general plasma proteins that still go unnoticed in vascular pathogenesis? Although it is possible, it seems quite unlikely, and this restricts further appliance of SELDI-TOF-MS in small vessel research at this time. However, when new developments will improve the technique in future, the SELDITOF-MS approach may still prove valuable.

When applying SELDI-TOF-MS again, careful selection of the study groups in which protein differences at systemic level are to be expected, is needed. Protein profiles of lacunar stroke patients with and without concomitant silent small vessel lesions can be compared, assuming that the presence of those lesions points to a systemic small vessel endotheliopathy, while a single symptomatic lacunar infarct results from micro-atheromatosis which may parallel systemic atherosclerosis. Another possibility is comparing protein profiles of lacunar and atherothrombotic strokes. One should not expect any results from comparing protein profiles of patients with different types of silent lesions, e.g. those with microbleeds vs. those with asymptomatic lacunar infarcts. Although it is an interesting question why some patients develop microbleeds while others show multiple lacunar lesions, this 
probably involves differences at local level mainly, such as differences in vessel structure or in the vulnerability of the vessels and the involved brain areas.

The finding of a protein difference does not imply that the protein is causally involved in pathogenesis, as differences may also be the result of the disease. In our case, the protein difference pointed to a genetic difference.

\section{Haptoglobin phenotypes}

Subsequent to the results of the SELDI-TOF-MS study, we explored the role of haptoglobin phenotypes in cerebral small vessel disease. Haptoglobin phenotypes are determined by a genetic polymorphism. We found the Hp1 allele and Hp1-1 phenotype to be associated with lacunar stroke and deep subcortical white matter lesions (chapter 4 and 5), whereas Hp2-2 phenotype has been associated with extra-cerebral large vessel disease in other studies. This suggests a different role for haptoglobin phenotypes in large and small vessel disease, possibly depending on functional differences in antioxidant and endothelial repair properties.

Genetic research in lacunar stroke is emerging. Family studies suggest a genetic component in the risk of lacunar stroke. ${ }^{10,11}$ One of our recent studies in lacunar stroke patients shows a high genetic relative risk of stroke in first-degree relatives, also indicating substantial genetic involvement. ${ }^{12}$ The genetic influence is expected to be polygenic with each involved polymorphism conferring only a modest increase in risk. Many polymorphisms in a variety of candidate genes that could be involved in the pathogenesis of vascular disease have been explored. However, results of these studies were conflicting. ${ }^{13}$ The main limitations are the sample size, often too small to detect modest associations, and the heterogeneity in lacunar stroke definition. Collaboration with multiple centres (in the same ethnic and ancestral population!) and consent on how to define lacunar stroke (and its subtypes with or without concomitant lesions) on clinical and neuro-imaging grounds, are needed.

Candidate polymorphisms are chosen upon their influence on the structure, function or amount of the involved protein product that could play a role in the pathogenesis of vascular disease. In our case, knowledge about the functions of haptoglobin phenotypes, especially in angiogenesis and endothelial repair, is quite limited and needs further research. We recently showed that Hp1-1 likely impairs the activity of endothelial progenitor cells. ${ }^{14}$

As our knowledge about pathogenesis grows, new candidate genes emerge. For example, we recently showed an association between cerebral white matter lesions and low vitamin B12 levels in lacunar stroke patients, which has also been shown in a non-stroke population. ${ }^{15,16}$ It indicates a role for vitamin B12 in the pathogenesis of blood-brain barrier dysfunction and small vessel disease. Polymorphisms that influence the transport and intracellular availability of vitamin $\mathrm{B} 12$ are currently considered to be explored. 
An important limitation of the candidate gene approach is that it lacks the potential to discover new stroke risk genes. A daring new strategy is genome wide screening. Analogous to the SELDI-TOF-MS approach, this assumes no a priori hypothesis regarding polymorphisms of interest. It has recently been performed in a large cohort study of incident stroke, which showed two previously unsuspected singlenucleotide polymorphisms to be associated with ischemic stroke. ${ }^{17}$ However, strokes were not subtyped. If performed in a well-subtyped homogeneous cohort of lacunar stroke patients it might give more and/or other results. Another strategy is to perform a genome wide linkage analysis in affected sib-pairs, instead of a casecontrol design. This overcomes the problems with selection of an adequately matched control group, although the collection of a large number of affected sibpairs may be quite tantalizing. Ultimately, identification of new genetic factors in small vessel disease may lead to better understanding of the pathogenetic processes, whereas better understanding of pathogenesis will guide to new candidate genes.

\section{4-hour blood pressure characteristics}

We explored the association between several 24-hour ambulatory blood pressure characteristics and the presence of concomitant "silent" signs of small vessel disease in lacunar stroke patients (chapter 6 and 7). The results point at an important role of high 24-hour (both day and night) blood pressure load as risk factor for asymptomatic lacunar infarcts and microbleeds (especially those in deep brain areas). Blood pressure may relate to white matter lesions in a more complex way, as we did not find a definite association here. We found no association between nocturnal dipping and any of the "silent" lesions.

Our studies were cross-sectional. To conclude on causal relationships, we should confirm our results in a longitudinal study. Few longitudinal studies with ABPM have been performed in lacunar stroke patients. ${ }^{18-20}$ These suffer from small patient numbers, a very divergent follow-up period within the study cohort, only baseline ABPM without follow-up measurement, or no neuro-imaging follow-up data. Currently, we are performing a two-year follow-up, including ABPM and MRI, to study the progression of silent lesions in relation to blood pressure characteristics. A longitudinal study could probably also shed more light on the complex relationship between blood pressure and white matter lesions. It seems unlikely that blood pressure doesn't have any relation to white matter lesions in lacunar stroke patients, as in non-stroke patients an association has been shown repeatedly. Our study population was relatively high aged (mean 63 years old). Other factors that were not corrected for, for example vitamin B12 deficiency, may become more important at this age. However, an association between blood 
pressure and white matter lesions has been confirmed in elderly non-stroke populations. ${ }^{21}$

A link in the complex association between blood pressure and white matter damage could be impairment of cerebral autoregulation. Autoregulation maintains cerebral blood flow within certain limits, thus protecting the brain against hyperperfusion in case of high blood pressure, and against hypoperfusion in case of low blood pressure. Autoregulation is a function of the endothelial and media layer of the small vessel wall. However, considering a study that combines 24-hour ABPM and autoregulation data, several problems could be encountered: there are several different techniques that measure different elements of the autoregulation function, such as static and dynamic tests. Furthermore, patients may use medications that can alter endothelial function and thus influences autoregulation, such as statins and inhibitors of the renin-angiotensin system. These factors should be accounted for.

Asymptomatic lacunar infarcts, white matter lesions and brain microbleeds should be considered separately in future studies. Although lacunes, white matter lesions and microbleeds all result from diseased small vessels, and they often co-exist, they do not show complete concordance, and occur in different vascular territories: basal ganglia supplied by deep perforating arteries and white matter supplied by long medullary arteries. Due to differences in vessel structure, in the vulnerability of the vessels and the involved brain areas, and in the role of genetic factors, risk factors and their combined actions, there are differences in the pathogenetic processes.

In future studies, we should even go further in separating small vessel lesions: as discussed in our ABPM study in microbleeds (chapter 7 ), there are indications that the pathogenesis of brain microbleeds in deep locations is different from lobar locations. Analogous to symptomatic intracerebral bleeding, it is thought that deep brain microbleeds are generally caused by blood pressure-related cerebral small vessel disease, whereas lobar brain microbleeds are caused by amyloid angiopathy. ${ }^{22}$ There are also arguments to distinguish deep subcortical white matter lesions from periventricular white matter lesions. While the deep subcortical white matter is supplied solely by medullary arteries, the periventricular white matter is thought to be a borderzone between ventriculopetal medullary arteries and ventriculofugal branches of the deep perforating arteries. ${ }^{23}$ Although not everyone is sharing this view, differences between deep and periventricular white matter lesions are found concerning genetic predisposition ${ }^{24}$, vascular risk factors ${ }^{25}$, clinical consequences in terms of cognitive impairment ${ }^{26}$ and progression rate $^{27}$. We found haptoglobin phenotype to be associated with the extent of deep but not periventricular white matter lesions (chapter 5). 


\section{Clinical and therapeutical consequences}

As the pathogenetic mechanisms differ between small and large vessel stroke, it cannot merely be assumed that acute stroke treatments and secondary preventive measures will be equally effective in these different stroke types. However, until now we make little difference in the therapeutical approach of lacunar and large vessel stroke. For example, the benefit of thrombolysis appears to be similar in lacunar and nonlacunar strokes. ${ }^{28}$ Although the effect of carotid surgery seems lower in lacunar stroke patients, stroke subtype is generally not considered in guidelines on decision for surgery. There is no evidence for different effects of antiplatelet drugs, antihypertensive drugs, or statins. However, future trials should definitely distinguish between stroke subtypes, as differences in pathogenetic processes imply that there may be a need for different therapeutical approaches. As this also holds true for the different "silent" signs of cerebral small vessel disease, these should also be distinguished in future trials.

What are the implications of the present results as described in this thesis for the treatment of small vessel disease? At the moment, knowledge of the haptoglobin phenotype does not have any therapeutical consequences. In the future, evaluation of haptoglobin phenotype and other genetic polymorphisms could provide a small vessel or large vessel risk profile, which then might lead to different therapeutical and preventive strategies. Genetic factors may relate to the degree of treatment efficacy, and knowledge of genetic factors may guide treatment options and prognostic statements. The finding of new genetic risk factors may also provide new therapeutic targets. Results from our haptoglobin phenotyping studies, vitamin B12 study 16 and EPC-studies ${ }^{14}$ add to other studies ${ }^{29,30}$ that point at an important role for blood-brain barrier impairment in the pathogenesis of small vessel disease. Protection of the blood-brain barrier has become a new therapeutical target.

It seems to be appropriate to treat high blood pressure in lacunar stroke patients, especially when there are concomitant asymptomatic lacunar lesions and brain microbleeds, but possibly we should be more careful in the presence of extensive white matter lesions. In some of these patients aggressive blood pressure lowering might promote hypoperfusion and white matter damage. Depending on other factors such as autoregulation, variability of the blood pressure, presence of orthostatic hypotension, and the duration of history with hypertension, some lacunar stroke patients might benefit from higher blood pressure levels. However, at the moment there is no direct and substantial evidence for this.

"Silent" lesions are not only seen in lacunar stroke patients, but are often a coincident finding in non-stroke patients. They entail a risk for future lacunar stroke, other vascular complications and cognitive decline. Although it seems reasonable to start antiplatelet drugs, statins or antihypertensive medication to prevent further damage, we actually do not know whether this has significant and cost-efficient effect. Trials are needed. 
More attention should be paid to the presence of brain microbleeds on neuroimaging. It might have consequences for thrombolytic or antithrombotic therapy. Brain microbleeds might increase the risk of symptomatic bleeding following thrombolysis in acute stroke, and thus could be considered a relative contraindication. However, although a minor increase in bleeding risk cannot be excluded, there is no evidence that this risk would exceed the benefit of thrombolysis. ${ }^{31}$ Another important issue is whether the presence of brain microbleeds increases the risk of intracerebral hemorrhage in persons using anticoagulant or antiplatelet therapy. There is conflicting evidence about the association between antithrombotic therapy and the presence of brain microbleeds, whereas studies on the risk of symptomatic bleeding are lacking. ${ }^{2,32}$ Besides aiming at understanding the pathogenetic processes in small vessel disease, we should also aim our studies at clinical consequences, such as cognitive dysfunction and parkinsonism. Currently we are performing a study in lacunar stroke patients to explore the relation between several risk factors and clinical consequences in terms of cognitive function.

The general aim of the present thesis was to try to further dissolve the underlying processes that lead to different forms of cerebral small vessel disease. We applied a new approach with SELDI-TOF-MS, found a role for haptoglobin phenotypes, and found differences in the association of 24-hour blood pressure characteristics with the presence of several different signs of cerebral small vessel disease.

Dissolving the underlying pathogenetic processes of cerebral small vessel disease will be very complicated, as the different "silent" lesions are not mutually exclusive and often overlap. Now we should go beyond the view that small vessel disease is one disease entity, and the different lesions should be viewed separately in future research.

No lumping anymore, but splitting. 


\section{References}

1. de Jong G, van Raak L, Kessels F, Lodder J. Stroke subtype and mortality: a follow-up study in 998 patients with a first cerebral infarct. J Clin Epidemiol. 2003;56:262-268.

2. Cordonnier C, Salman RA, Wardlaw J. Spontaneous brain microbleeds: systematic review, subgroup analyses and standards for study design and reporting. Brain. 2007;130:1988-2003.

3. Werring DJ, Frazer DW, Coward L, Losseff NA, Watt H, Cipolotti L, Brown MM, Jager HR. Cognitive dysfunction in patients with cerebral microbleeds on T2*-weighted gradient-echo MRI. Brain. 2004;127:2265-2275.

4. de Jong G, Kessels F, Lodder J. Two types of lacunar infarcts, further arguments from a study on prognosis. Stroke. 2002;33:2072-2076.

5. Prins ND, van Dijk EJ, den Heijer T, Vermeer SE, Jolles J, Koudstaal PJ, Hofman A, Breteler MMB. Cerebral small-vessel disease and decline in information processing speed, executive function and memory. Brain. 2005;128:2034-2041.

6. Markus HS. Genes, endothelial function and cerebral small vessel disease in man. Exp Physiol. 2007;93:121-127.

7. Pretnar-Oblak J, Sabovic M, Pogacnik T, Sebestjen M, Zaletel M. Flow-mediated dilatation and intima-media thickness in patients with lacunar infarctions. Acta Neurol Scand. 2006;113: 273-277.

8. Kwa VIH, van der Sande JJ, Stam J, Tijmes N, Vrooland JL. Retinal arterial changes correlate with cerebral small-vessel disease. Neurology. 2002;59:1536-1540.

9. Ikram MA, Vernooij MW, Hofman A, Niessen WJ, van der Lugt A, Breteler MMB. Kidney function is related to cerebral small vessel disease. Stroke. 2008;39:55-61.

10. Jerrard-Dunne P, Cloud G, Hassan A, Markus HS. Evaluating the genetic component in ischemic stroke subtypes. A family history study. Stroke. 2003;34:1364-1369.

11. Jood K, Ladenvall C, Rosengren A, Blomstrand C, Jern C. Family history in ischemic stroke before 70 years of age. The Sahlgrenska Academy Study on ischemic stroke. Stroke. 2005;36: $1383-1387$.

12. Knottnerus ILH, Gielen M, Rouhl RPW, Staals J, Lodder J, Vlietinck RF, van Oostenbrugge RJ. Genetic relative risk in patients with first-ever symptomatic lacunar stroke. Cerebrovasc Dis. 2009;27:S54.

13. Debette S, Seshadri S. Genetics of atherothrombotic and lacunar stroke. Circ Cardiovasc Genet. 2009;2:191-198.

14. Rouhl RPW, van Oostenbrugge RJ, Damoiseaux JGMC, Debrus-Palmans LL, Theunissen ROMFIH, Knottnerus ILH, Staals JEA, Delanghe JR, Cohen Tervaert JW, Lodder J. Haptoglobin phenotype may alter endothelial progenitor cell cluster formation in cerebral small vessel disease. Curr Neurovasc Res. 2009;6:32-41.

15. de Lau LM, Smith AD, Refsum H, Johnston C, Breteler MM. Plasma vitamin B12 status and cerebral white-matter lesions. J Neurol Neurosurg Psychiatry. 2009;80:149-157.

16. Pieters B, Staals J, Knottnerus I, Rouhl R, Menheere P, Kessels A, Lodder J. Periventricular white matter lucencies relate to low vitamin B12 levels in patients with small vessel stroke. Stroke. 2009;40:1623-1626.

17. Ikram MA, Seshadri S, Bis J, Fornage M, DeStefano AL, Aulchenko YS, et al. Genomewide association studies of stroke. N Eng J Med. 2009;360:1718-1728.

18. Yamamoto Y, Akiguchi I, Oiwa K, Hayashi M, Kimura J. Adverse effect of nighttime blood pressure on the outcome of lacunar infarct patients. Stroke. 1998;29:570-576.

19. Yamamoto Y, Akiguchi I, Oiwa K, Hayashi M, Imai K. Twenty-four-hour blood pressure changes in the course of lacunar disease. Cerebrovasc Dis. 2001;11:100-106.

20. Yamamoto Y, Akiguchi I, Oiwa K, Hayashi M, Kasai T, Ozasa K. Twenty-four-hour blood pressure and MRI as predictive factors for different outcomes in patients with lacunar infarct. Stroke. 2002;33:297-305.

21. O'Sullivan M, Duggan J, Lyons S, Thornton J, Lee M, O'Brien E. Hypertensive target-organ damage in the very elderly. Hypertension. 2003;42:130-135. 
22. Vernooij MW, van der Lugt A, Ikram MA, Wielopolski PA, Niessen WJ, Hofman A, Krestin GP, Breteler MM. Prevalence and risk factors of cerebral microbleeds: the Rotterdam Scan Study. Neurology. 2008;70:1208-1214.

23. Donnan G, Norrving B, Bamford J, Bogousslavsky J. Subcortical stroke. New York: Oxford University Press; 2002.

24. Henskens LH, Kroon AA, van Boxtel MP, Hofman PA, de Leeuw PW. Associations of the angiotensin II type 1 receptor $\mathrm{A} 1166 \mathrm{C}$ and the endothelial nitric oxide synthase G894T gene polymorphisms with silent subcortical white matter lesions in essential hypertension. Stroke. 2005;36:18691873.

25. Lazarus R, Prettyman R, Cherryman G. White matter lesions on magnetic resonance imaging and their relationship with vascular risk factors in memory clinic attenders. Int J Geriatr Psychiatry. 2005;20:274-279.

26. Delano-Wood L, Abeles N, Sacco JM, Wierenga CE, Horne NR, Bozoki A. Regional white matter pathology in mild cognitive impairment. Stroke. 2008;39:794-799.

27. Gouw AA, van der Flier WM, Fazekas F, van Straaten ECW, Pantoni L, Poggesi A, Inzitari D, Erkinjuntti T, Wahlund LO, Waldemar G, Schmidt R, Scheltens P, Barkhof F. Progression of white matter hyperintensities and incidence of new lacunes over a 3-year period. Stroke. 2008;39: 1414-1420.

28. Norrving B. Lacunar infarcts: no black holes in the brain are benign. Pract Neurol. 2008;8: 222-228.

29. Farrall AJ, Wardlaw JM. Blood-brain barrier: ageing and microvascular disease - systematic review and meta-analysis. Neurobiol Aging. 2009;30:337-352.

30. Wardlaw JM, Doubal F, Armitage P, Chappell F, Carpenter T, Maniega SM, Farrall A, Sudlow C, Dennis M, Dhillon B. Lacunar stroke is associated with diffuse blood-brain barrier dysfunction. Ann Neurol. 2009;65:194-202.

31. Fiehler J, Albers GW, Boulanger JM, Derex L, Gass A, Hjort N, Kim JS, Liebeskind DS, NeumannHaefelin T, Pedraza S, Rother J, Rothwell P, Rovira A, Schellinger PD, Trenkler J. Bleeding risk analysis in stroke imaging before thrombolysis (BRASIL): pooled analysis of T2*-weighted magnetic resonance imaging data from 570 patients. Stroke. 2007;38:2738-2744.

32. Vernooij MW, Haag MD, van der Lugt A, Hofman A, Krestin GP, Stricker BH, Breteler MM. Use of antithrombotic drugs and the presence of cerebral microbleeds: the Rotterdam Scan Study. Arch Neurol. 2009;66:714-720. 



\section{Chapter}

\section{Summary / Samenvatting}


Chapter 9 


\section{Summary}

Lacunar stroke accounts for about $25 \%$ of all ischemic strokes. It can be identified by rather specific clinical manifestations, the so-called lacunar stroke syndromes. It is usually caused by occlusion of a single small deep perforating artery or one of its branches, leading to infarction. On neuro-imaging it is represented by a small lacunar lesion, located deep in the brain or in the brain stem.

Lacunar stroke can be subtyped according to the presence or absence of additional "silent" lesions : asymptomatic lacunar infarcts, white matter lesions and brain microbleeds. Asymptomatic lacunar infarcts are small, deeply located infarcts that are not accompanied by acute neurological stroke symptoms. White matter lesions (or leukoaraiosis) are diffuse ischemic lesions in the deep or periventricular cerebral white matter. Brain microbleeds represent asymptomatic small old hemorrhages.

Knowledge about the underlying pathogenetic processes that lead to these different forms of cerebral small vessel disease is limited. To further dissolve the underlying pathogenetic processes we explored differences between lacunar stroke patients with and without these additional "silent" lesions.

Although lacunar stroke is generally considered a rather "benign" stroke, data on long-term prognosis are scarce. Most mortality studies are characterized by short follow-up time, small patient groups, and absence of a nonlacunar stroke group for comparison. Furthermore, long-term mortality data on lacunar stroke with or without concomitant "silent" lesions are lacking. In chapter 2 we described a longterm mortality study in 782 first-ever cerebral infarct patients. We determined survival status after a median of 15.0 years in 333 atherothrombotic, 184 cardioembolic and 265 lacunar strokes. Lacunar stroke showed a lower 30-day case fatality rate than atherothrombotic and cardioembolic stroke. However, at the end of follow-up mortality in lacunar stroke was not significantly different from atherothrombotic stroke. Corrected for age, sex, diabetes mellitus, ischemic heart disease and hypertension, lacunar stroke showed better survival than cardioembolic stroke, but not than atherothrombotic stroke (Cox regression analysis).

Then we distinguished between lacunar stroke patients with or without asymptomatic lacunar infarcts on CT. The lacunar type without asymptomatic lesions showed a significantly better long-term survival, whereas the other type did not differ from atherothrombotic and cardioembolic stroke (Cox regression analysis). Distinguishing between lacunar stroke patients with or without leukoaraiosis gave similar results.

Firstly, this study showed that lacunar stroke cannot merely be considered a "benign" stroke type. Only in patients with a single lacunar lesion, unlike in those with additional "silent" lacunar lesions or leukoaraiosis, long-term survival is better 
than in atherothrombotic stroke. Secondly, the difference in long-term mortality between lacunar stroke patients with or without "silent" lesions is in line with former findings of differences in vascular risk factor profile, in functional outcome, in recurrent stroke and in short-term mortality. These differences validate the distinction of lacunar stroke subtypes in our further research.

Up to recently, research in cerebral small vessel disease focused mainly on individual proteins that are already known to be involved in vascular pathogenesis. Research topics are often deducted from the scientific work on large vessel atherosclerotic disease or stroke in general. Unique factors in small vessel disease may go unnoticed in this way. In chapter 3 we described how we applied SurfaceEnhanced Laser Desorption / Ionization Time-of-Flight Mass Spectrometry (SELDITOF-MS), a new approach to explore the expression profile of the total proteome. We compared serum protein profiles using SELDI-TOF-MS in eight lacunar stroke patients with and eight patients without concomitant "silent" lesions on MRI. A 16 $\mathrm{kDa}$ protein, identified as alpha-2-chain of haptoglobin, was found to be overrepresented in lacunar stroke patients without concomitant "silent" lesions compared to those with such lesions.

As a polymorphism with two alleles, $\mathrm{Hp} 1$ and $\mathrm{Hp} 2$, determines the presence of alpha-1 and/or alpha-2-chains in the haptoglobin-molecule, we subsequently performed haptoglobin phenotypic analysis. We found a higher Hp2 allele frequency in the lacunar stroke patients without concomitant "silent" lesions (0.438) than in those with such lesions $(0.188)$, concluding that the overrepresentation of the alpha-2-chain in lacunar stroke patients without concomitant "silent" lesions related to a higher $\mathrm{Hp} 2$ allele frequency.

A further remarkably finding was that the $\mathrm{Hp} 2$ allele frequency in both lacunar stroke groups differed significantly from the expected allele frequency $(0.600)$ derived from a general population reference group.

We showed that using SELDI-TOF-MS it is possible to detect differences in protein expression between two lacunar stroke subtypes. Our findings led to a new idea about a genetic contribution in the etiology of cerebral small vessel disease: haptoglobin phenotype.

\section{Haptoglobin phenotype}

Due to the existence of two coding alleles, $\mathrm{Hp} 1$ and $\mathrm{Hp} 2$, three haptoglobin protein phenotypes with functional differences occur: Hp1-1, Hp2-1 and Hp2-2. The Hp2-2 phenotype has been associated with extracerebral large vessel disease. However, haptoglobin phenotypes have not been studied in cerebral small vessel disease. The results of the SELDI-TOF-MS study (chapter 3 ) led us to the exploration of haptoglobin phenotypes in lacunar stroke, which is described in chapter 4. Using starch gel electrophoresis, we determined haptoglobin phenotypes in 124 lacunar stroke patients and compared these to a large healthy control group. 
Haptoglobin phenotypic distribution differed significantly between lacunar stroke patients and healthy controls ( $\chi^{2}$ analysis, $p=0.032$ ): in lacunar stroke patients the Hp2-2 frequency was lower and the Hp1-1 frequency was higher. Hp1 allele frequency was significantly higher in lacunar stroke patients compared to healthy controls $(0.480$ vs $0.395, p=0.011)$.

The association between the Hp1 allele and lacunar stroke, whereas Hp2-2 phenotype has been associated with extra-cerebral large vessel disease in other studies, suggests a different role for haptoglobin phenotypes in large and small vessel disease. This may depend on functional differences between the phenotypes that may have different importance in various vascular diseases: we discussed possible differences in effect on blood pressure regulation, differences in antioxidant and immunomodulatory capacities, differences in angiogenic effects that may be involved in blood-brain barrier integrity, and differences in the ability to pass the (dysfunctional) blood-brain barrier.

Then, we examined the relationship between haptoglobin phenotypes and "silent" signs of cerebral small vessel disease in hypertensive patients, which is described in chapter 5. Using starch gel electrophoresis, we determined haptoglobin phenotypes in 154 hypertensive patients without symptomatic vascular disease. Asymptomatic lacunar infarcts and volume of deep and periventricular white matter lesions were scored on MRI.

Compared to Hp2-2, phenotype Hp1-1 was associated with larger volumes of deep white matter lesions with an odds ratio of $2.77(95 \% \mathrm{Cl} 1.07-7.10$; ordinal regression analysis with adjustment for age, sex, brain volume, 24-hour mean arterial pressure, duration of hypertension and previous antihypertensive treatment). We found no association between haptoglobin phenotype and periventricular white matter lesions or the presence of asymptomatic lacunar infarcts.

The association between Hp1-1 phenotype and the extent of asymptomatic hypertensive deep white matter damage adds to the former study (chapter 4) in which we showed an association between the $\mathrm{Hp} 1$ allele and symptomatic cerebral small vessel disease (i.e. lacunar stroke). Contrarily, Hp2-2 has been associated with extra-cerebral large vessel disease. We assume that different functional properties of haptoglobin phenotypes play a vasculature-specific role and this may explain the different associations of the haptoglobin phenotype with various vascular diseases. There are indications that the Hp1-1 phenotype relates to lower regenerating power against endothelial injury, which may lead to blood-brain barrier dysfunction, probably an important factor in small vessel disease.

The different results for deep and periventricular white matter lesions add to earlier studies that showed differences regarding genetic factors, vascular risk factors, progression rate and clinical consequences in terms of cognitive impairment. They are indicative of distinct subtypes of white matter lesions, possibly depending on 
differences in vascular supply of the deep and periventricular white matter areas. The role of haptoglobin may differ between these vascular areas.

However, studies on the precise pathogenetic mechanisms of haptoglobin phenotypes in different vascular diseases or in different vascular areas are awaiting.

\section{4-hour blood pressure characteristics}

Hypertension is an important risk factor for stroke in general. In particular, hypertension is considered a strong risk factor for "silent" small vessel lesions. However, hypertension is just a qualitative label, mostly established by a few office blood pressure measurements. Ambulatory blood pressure, easily measured by ambulatory blood pressure monitoring, is a better predictor for blood pressure related end organ damage than office blood pressure, allows exploring blood pressure quantitatively, and gives additional information about 24-hour blood pressure characteristics such as night in addition to day blood pressure and nocturnal dipping.

While associations between ambulatory blood pressure characteristics and asymptomatic lacunar infarcts and white matter lesions have quite extensively been studied in stroke-free (mainly hypertensive) patients, studies in lacunar stroke patients are few. In chapter 6 we studied the relationship between 24-hour ambulatory blood pressure characteristics and asymptomatic lacunar infarcts and white matter lesions in 143 first-ever lacunar stroke patients. Ambulatory blood pressure monitoring over a 24-hour period was performed after the acute stroke phase. We classified the number of asymptomatic lacunar infarcts on MRI in three categories $(0,1-2, \geq 3)$, and we graded the severity of deep and periventricular white matter lesions according to Fazekas scale in four ordinal categories.

Both higher day and night systolic and diastolic ambulatory blood pressure levels were significantly associated with asymptomatic lacunar infarcts (ordinal regression analyses, odds ratios 1.5-1.6 per standard deviation increase in blood pressure, adjusted for age, sex and number of antihypertensive drugs in use by each patient). A high blood pressure during day and night, i.e. a high cumulative 24-hour blood pressure load, probably plays a role in causing dysfunction of the small vessel endothelium, which is considered a main pathogenetic feature in small vessel disease.

None of the blood pressure characteristics was significantly associated with deep or periventricular white matter lesions. We think that blood pressure might play a complex, dual role in white matter lesions: high blood pressure levels may be an initial causal factor in small vessel pathology, by causing endothelial dysfunction. However, once the small arteries are diseased, low blood pressure levels may worsen white matter damage by hypoperfusion. Therefore, depending on the stage of the small vessel damage, similar blood pressure levels may enhance or forestall 
further damage in different patients. This effect may have obscured a clear effect of blood pressure on white matter lesions in our study.

Nocturnal dipping was not found to be related to asymptomatic lacunar infarcts or white matter lesions. However, there is no consensus on how to define nocturnal dipping and its reproducibility is quite poor.

We conclude that future blood pressure controlling studies in lacunar stroke patients should address both day and night blood pressure, and should pay extra attention to the presence of white matter lesions.

Although hypertension is a known risk factor for brain microbleeds, associations between ambulatory blood pressure characteristics and brain microbleeds have not been studied in lacunar stroke patients. We looked for associations between 24-hour ambulatory blood pressure characteristics and brain microbleeds in 123 first-ever lacunar stroke patients (chapter 7). In these patients, ambulatory blood pressure monitoring over a 24-hour period was performed after the acute stroke phase. We counted brain microbleeds on T2*-weighted gradient-echo MR images and classified them in three categories $(0,1, \geq 2)$.

Brain microbleeds were seen in 36 (29.3\%) patients. Both day and night systolic and diastolic ambulatory blood pressure levels were significantly associated with the presence and number of brain microbleeds (ordinal regression analyses, odds ratios 1.6-2.3 per standard deviation increase in blood pressure, adjusted for age, sex, number of antihypertensive drugs, asymptomatic lacunar infarcts and white matter lesions). These results emphasize the importance of an increased 24-hour blood pressure load as an important risk factor for brain microbleeds in lacunar stroke patients.

It is suggested that the etiology of brain microbleeds differs according to their location in the brain, analogous to symptomatic brain hemorrhage: microbleeds in deep locations may result from hypertension-related vasculopathy, while microbleeds in lobar locations may relate to amyloid angiopathy. We thus distinguished between microbleeds in deep brain locations and microbleeds in lobar locations. Various ambulatory blood pressure characteristics were significantly associated with the presence of deep (or combined deep and lobar) brain microbleeds, but not with purely lobar brain microbleeds. Our results support the idea that deep brain microbleeds may be a particular marker of blood pressurerelated small vessel disease. However, the subgroups were small, and longitudinal and larger studies are warranted to substantiate these findings.

In chapter 8 (general discussion) I discussed the implications of our findings for future research. Firstly, further appliance of SELDI-TOF-MS in small vessel research was discussed. One of the most limiting factors of this technique at this moment is that it only detects highly abundant proteins, which restricts the use of SELDI-TOFMS in small vessel research at this time. However, when new developments will 
improve the technique in future, the SELDI-TOF-MS approach may still prove valuable. Secondly, strategies of genetic research in lacunar stroke were discussed. The candidate gene approach, such as our studies on haptoglobin phenotype, genomic wide screening, and linkage analysis in affected sib-pairs were mentioned. Thirdly, I discussed on the clear association between 24-hour ambulatory blood pressure characteristics and the presence of silent lacunar infarcts and brain microbleeds, versus the probably more complex relationship between blood pressure and white matter lesions. The need for longitudinal studies, and the influence of other factors, such as cerebral autoregulation, were mentioned. Fourthly, I gave some views on the clinical and therapeutical consequences of our findings. Finally, I stated that we should go beyond the view that small vessel disease is one disease entity. Besides distinguishing asymptomatic lacunar infarcts, white matter lesions and brain microbleeds, there are also arguments to distinguish deep subcortical from periventricular white matter lesions, and deep from lobar brain microbleeds. As they occur in different vascular territories and show differences in pathogenesis, the different lesions should be splitted in future research. 


\section{Samenvatting}

Ongeveer $25 \%$ van alle ischemische beroertes betreft een lacunaire beroerte. Een lacunaire beroerte kan herkend worden aan specifieke klinische verschijnselen, de zogenaamde lacunaire syndromen. Een lacunaire beroerte wordt meestal veroorzaakt door afsluiting van één van de kleine diepe perforerende hersenvaten, of een zijtak daarvan, hetgeen tot een infarct leidt. Een scan toont een kleine lacunaire laesie diep in het brein of in de hersenstam.

Lacunaire beroertes kunnen onderverdeeld worden naar de aan- of afwezigheid van bijkomende "stille" laesies veroorzaakt door pathologie van de kleine hersenvaten: asymptomatische lacunaire infarcten, witte stoflaesies en microbloedingen. Asymptomatische lacunaire infarcten zijn kleine, diep in het brein gelegen infarcten die niet gepaard gaan met acute neurologische uitvalsverschijnselen. Witte stoflaesies (ook leukoaraiose genoemd) zijn diffuse ischemische laesies in de diepe of periventriculaire witte stof van het brein. Microbloedingen zijn asymptomatische, kleine, oude bloedingen.

Kennis over de onderliggende pathogenetische processen die tot deze verschillende aandoeningen van de kleine hersenvaten leiden, is beperkt. Om de onderliggende pathogenetische processen verder te ontrafelen, onderzochten we verschillen tussen patiënten met een lacunaire beroerte met en zonder deze bijkomende "stille" laesies.

Hoewel lacunaire beroertes over het algemeen als vrij "goedaardige" beroertes beschouwd worden, zijn gegevens over lange termijnprognose beperkt. De meeste mortaliteitsonderzoeken worden gekenmerkt door een korte follow-up tijd, kleine patiëntaantallen, en de afwezigheid van een controlegroep met niet-lacunair infarctpatiënten. Bovendien zijn er geen lange termijn mortaliteitsgegevens over lacunaire beroertes met of zonder bijkomende "stille" laesies.

In hoofdstuk 2 beschreven we een onderzoek naar lange termijnmortaliteit bij 782 patiënten met een eerste beroerte. We bepaalden de overlevingsstatus na een mediaan van 15 jaar bij 333 atherothrombotische beroertes, 184 cardioembolische beroertes, en 265 lacunaire beroertes. De 30-dagen case fatality rate was lager bij lacunaire beroertes dan bij atherothrombotische en cardioembolische beroertes. Aan het einde van de follow-up was de mortaliteit van lacunaire beroertes echter niet lager dan van atherothrombotische beroertes. Gecorrigeerd voor leeftijd, geslacht, diabetes mellitus, coronairlijden en hypertensie, hadden patiënten met lacunaire beroertes een betere overleving dan patiënten met cardioembolische beroertes, maar niet beter dan patiënten met atherothrombotische beroertes (Cox regressie analyse).

Daarna onderzochten we verschillen tussen lacunaire beroertes met en zonder asymptomatische lacunaire infarcten op CT-scan. Het lacunaire type zonder asymptomatische laesies had een significant betere lange termijnoverleving, terwijl 
het andere type niet verschilde van atherothrombotische en cardioembolische beroertes (Cox regressie analyse). Onderverdeling van lacunaire beroertes naar de aan- of afwezigheid van leukoaraiose gaf vergelijkbare resultaten.

Ten eerste toonde dit onderzoek aan dat lacunaire beroertes niet zondermeer als "goedaardig" beschouwd kunnen worden. In vergelijking met atherothrombotische beroertes is de lange termijnoverleving van lacunaire beroertes alleen beter bij patiënten met een enkel lacunair infarct en niet bij de aanwezigheid van "stille" lacunaire infarcten of leukoaraiose. Ten tweede past het verschil in lange termijnmortaliteit tussen lacunaire beroertes met en zonder bijkomende "stille" laesies bij eerdere onderzoeken die verschillen aantoonden in klinische gevolgen (functionele uitkomst, recidief beroertes en korte termijnmortaliteit), en verschillen in vasculair risicoprofiel. Dit valideert het onderscheiden van subtypes van lacunaire beroertes in ons verdere onderzoek.

Tot voor kort was onderzoek naar de aandoening van de kleine hersenvaten vooral gericht op individuele eiwitten waarvan bekend is dat ze betrokken zijn bij de pathogenese van vasculaire aandoeningen. Het onderzoeksonderwerp wordt vaak afgeleid van eerder onderzoek naar atherosclerose van de grote vaten of beroerte in het algemeen. Unieke factoren die een rol spelen in aandoeningen van de kleine hersenvaten kunnen hierdoor onopgemerkt blijven. In hoofdstuk 3 beschreven we de toepassing van Surface-Enhanced Laser Desorption / Ionization Time-of-Flight Mass Spectrometry (SELDI-TOF-MS), een nieuwe manier om het expressieprofiel van het gehele proteoom te onderzoeken. We vergeleken serum eiwitprofielen van acht patiënten met een lacunaire beroerte met, en acht zonder aanwezigheid van bijkomende "stille" laesies op MRI-scan. Bij patiënten zonder bijkomende "stille" laesies vonden we een hogere expressie van een $16 \mathrm{kDa}$ eiwit dan bij patiënten met bijkomende "stille" laesies. Het eiwit werd geïdentificeerd als alpha-2-keten van haptoglobine.

Een polymorfisme met twee allelen, $\mathrm{Hp} 1$ en $\mathrm{Hp} 2$, bepaalt de aanwezigheid van alfa-1 en/of alfa-2-ketens in het haptoglobinemolecuul. Daarom werd vervolgens een haptoglobine fenotype-analyse verricht. $\mathrm{Er}$ werd een hogere $\mathrm{Hp} 2$ allelfrequentie (0.438) gevonden bij de patiënten zonder "stille" laesies dan bij de patiënten met bijkomende laesies (0.188). We concludeerden dat de hogere expressie van de alfa-2-keten in de groep patiënten zonder bijkomende "stille" laesies gerelateerd is aan een hogere $\mathrm{Hp} 2$ allelfrequentie.

Een volgende opvallende bevinding was dat de $\mathrm{Hp} 2$ allelfrequentie in beide groepen patiënten signifcant verschilde van de verwachte allelfrequentie in een referentiegroep uit de algemene bevolking (0.600).

Concluderend hebben we in dit hoofdstuk laten zien dat het met de SELDI-TOF-MS techniek mogelijk is om verschillen in eiwitexpressie aan te tonen tussen twee subtypes van lacunaire beroertes. Onze bevindingen hebben bovendien tot een 
nieuw idee geleid met betrekking tot de genetische bijdrage aan de etiologie van de aandoening van de kleine hersenvaten: het haptoglobine fenotype.

\section{Haptoglobine fenotype}

Twee coderende allelen, $\mathrm{Hp} 1$ en $\mathrm{Hp} 2$, leiden tot het bestaan van drie haptoglobine eiwitfenotypes: Hp1-1, Hp2-1 en Hp2-2. Het Hp2-2 fenotype is geassocieerd met extracerebrale aandoeningen van de grote vaten. In de aandoening van de kleine hersenvaten zijn haptoglobine fenotypes niet onderzocht. De resultaten van het SELDI-TOF-MS onderzoek (hoofdstuk 3) gaven aanleiding tot onderzoek van het haptoglobine fenotype bij lacunaire beroertes, hetgeen in hoofdstuk 4 werd beschreven. Met gelelectroforese werd het haptoglobine fenotype bepaald bij 124 patiënten met een lacunaire beroerte, en deze werden vergeleken met een grote gezonde controlegroep.

De fenotypeverdeling was significant verschillend tussen patiënten met een lacunaire beroerte en gezonde controles $\left(\chi^{2}\right.$ analyse, $\left.p=0.032\right)$ : bij de patiënten met een lacunaire beroerte was de Hp2-2 frequentie lager en de Hp1-1 frequentie hoger. De Hp1 allelfrequentie was derhalve ook significant hoger bij de patiënten met een lacunaire beroerte dan bij de gezonde controles ( 0.480 vs 0.395 , $\mathrm{p}=0.011$ ).

De associatie tussen Hp1 allel en lacunaire beroertes, terwijl Hp2-2 fenotype geassocieerd is met extracerebrale aandoeningen van de grote vaten, suggereert dat haptoglobinefenotypes een verschillende rol spelen in de grote en in de kleine vaten. Mogelijk heeft dit te maken met functionele verschillen tussen de fenotypes, met een verschillend effect op het ontstaan van vasculaire aandoeningen: in het hoofdstuk werden mogelijke verschillen in effect op bloeddrukregulatie besproken, alsmede verschillen in antioxiderende en immuunmodulatoire eigenschappen, verschillen in angiogene effecten die van belang kunnen zijn voor de integriteit van de bloed-hersenbarrière, en verschillen in de mogelijkheid om de (dysfunctionele) bloed-hersenbarrière te passeren.

Daarna onderzochten we in hoofdstuk 5 de relatie tussen het haptoglobine fenotype en "stille" laesies van de kleine hersenvaten bij hypertensieve patiënten. Haptoglobine fenotypes werden met zetmeelgelelectroforese bepaald bij 154 hypertensieve patiënten zonder symptomatisch vaatlijden. Op MRI-scans werden asymptomatische lacunaire infarcten en het volume van diepe en periventriculaire witte stoflaesies bepaald.

In vergelijking met Hp2-2, was fenotype Hp1-1 geassocieerd met grotere volumes van diepe witte stoflaesies, met een odds ratio van 2.77 (95\%betrouwbaarheidsinterval 1.07-7.10; ordinale regressie-analyse met correctie voor leeftijd, geslacht, hersenvolume, 24-uurs mean arterial pressure, duur van de hypertensie en eerdere bloeddrukbehandeling). We vonden geen associatie tussen 
haptoglobine fenotype en periventriculaire witte stoflaesies of asymptomatische lacunaire infarcten.

De associatie tussen fenotype Hp1-1 en de uitgebreidheid van asymptomatische hypertensieve diepe witte stofschade is een aanvulling op het vorige onderzoek (hoofdstuk 4) waarin we een associatie aantoonden tussen $\mathrm{Hp} 1$ allel en symptomatisch lijden van de kleine hersenvaten (ofwel lacunaire beroerte). Daarentegen is Hp2-2 geassocieerd met aandoeningen van de grote vaten buiten het brein. We veronderstellen dat verschillende functionele eigenschappen van de haptoglobine fenotypes een vaatspecifieke rol spelen. Dit zou de verschillende associaties van haptoglobine fenotypes met verschillende vaataandoeningen kunnen verklaren. Er zijn aanwijzingen dat fenotype Hp1-1 gepaard gaat met minder herstelvermogen van endotheelschade, hetgeen kan leiden tot dysfunctie van de bloed-hersenbarrière. Barrièredysfunctie is waarschijnlijk een belangrijke factor in de aandoening van de kleine hersenvaten.

De verschillende resultaten voor diepe en periventriculaire witte stoflaesies past bij eerdere onderzoeken die verschillen in genetische factoren, vasculaire risicofactoren, mate van progressie, en klinische gevolgen in de zin van cognitief (dys)functioneren aantoonden. Deze onderzoeken wijzen op het bestaan van verschillende subtypes van witte stoflaesies, mogelijk samenhangend met verschillen in de bloedtoevoer van de diepe en periventriculaire witte stofgebieden. De rol van haptoglobine zou verschillend kunnen zijn in deze vaatgebieden.

Onderzoek naar de precieze pathogenetische mechanismen van haptoglobine fenotypes in verschillende vaataandoeningen ontbreekt echter nog.

\section{4-uurs bloeddrukkarakteristieken}

Hypertensie is een belangrijke risicofactor voor beroerte in het algemeen, en wordt in het bijzonder beschouwd als een sterke risicofactor voor "stille" laesies van de kleine hersenvaten. Hypertensie is echter slechts een kwalitatief label, meestal vastgesteld met een paar spreekkamermetingen. De ambulante bloeddruk, eenvoudig te meten met een ambulante bloeddrukmeter, is een betere voorspeller voor bloeddrukgerelateerde eindorgaanschade dan de spreekkamerbloeddruk. De ambulante bloeddruk geeft bovendien de mogelijkheid om bloeddruk kwantitatief te onderzoeken en geeft extra informatie over 24-uurs bloeddrukkarakteristieken zoals dag- en nachtwaardes en nachtelijke dipping.

Associaties tussen ambulante bloeddrukkarakteristieken en asymptomatische lacunaire infarcten en witte stoflaesies zijn vrij uitgebreid onderzocht bij (meestal hypertensieve) patiënten zonder doorgemaakte beroerte. Er zijn echter maar weinig onderzoeken gedaan bij patiënten met een lacunaire beroerte. In hoofdstuk 6 onderzochten we de relatie tussen 24-uurs bloeddrukkarakteristieken en asymptomatische lacunaire infarcten en witte stoflaesies bij 143 patiënten met een eerste lacunaire beroerte. Ambulante 24-uurs bloeddrukmetingen werden na 
de acute fase uitgevoerd. Het aantal asymptomatische lacunaire infarcten op MRIscan werd in drie categorieën ingedeeld $(0,1-2, \geq 3)$. De ernst van de diepe en periventriculaire witte stoflaesies werd gescoord volgens de schaal van Fazekas in vier ordinale categorieën.

Zowel een hogere dag- als nacht- systolische en diastolische ambulante bloeddruk was significant geassocieerd met asymptomatische lacunaire infarcten (ordinale regressie analyses, odds ratio's 1.5-1.6 per standaarddeviatie toename in bloeddruk, gecorrigeerd voor leeftijd, geslacht en aantal antihypertensiva dat door elke patiënt werd gebruikt). Een hoge bloeddruk gedurende dag en nacht, dus een hoge cumulatieve 24-uurs bloeddruklast, speelt waarschijnlijk een rol in het veroorzaken van dysfunctie van het endotheel in de kleine bloedvaten. Endotheeldysfunctie wordt als een hoofdkenmerk in de pathogenese van de aandoening van de kleine hersenvaten beschouwd.

Geen enkele bloeddrukkarakteristiek was significant geassocieerd met diepe of periventriculaire witte stoflaesies. We denken dat bloeddruk hier een complexe, dubbele rol speelt: hoge bloeddruk kan een initiële oorzakelijke factor in de pathologie van de kleine vaten zijn, doordat het dysfunctie van het endotheel veroorzaakt. Als de kleine vaten echter eenmaal zijn aangedaan, kan een lage bloeddruk de witte stofschade verergeren, doordat het leidt tot hypoperfusie. Afhankelijk van het stadium van de schade, zouden dezelfde bloeddrukwaardes bij de ene patiënt schade kunnen verergeren, maar bij de andere patiënt verdere schade juist voorkomen. Dit effect zou een duidelijke relatie tussen bloeddruk en witte stoflaesies in ons onderzoek verhuld kunnen hebben.

Nachtelijke dipping was niet gerelateerd aan asymptomatische lacunaire infarcten of witte stoflaesies. Er is echter geen consensus over de definitie van nachtelijke dipping en de reproduceerbaarheid is vrij slecht.

Toekomstige onderzoeken naar bloeddrukbehandeling bij patiënten met een lacunaire beroerte zouden zowel dag- als nachtbloeddruk moeten meenemen, en zouden extra aandacht moeten hebben voor de aanwezigheid van witte stoflaesies.

Hoewel hypertensie een bekende risicofactor voor microbloedingen is, zijn associaties tussen ambulante bloeddrukkarakteristieken en microbloedingen nooit onderzocht bij patiënten met een lacunaire beroerte. Wij onderzochten associaties tussen 24-uurs ambulante bloeddrukkarakteristieken en microbloedingen bij 123 patiënten met een eerste lacunaire beroerte (hoofstuk 7). Ambulante 24-uurs bloeddrukmetingen werden na de acute fase uitgevoerd. Microbloedingen werden geteld op T2*-gewogen gradiënt-echo MR beelden, en ingedeeld in drie categorieën $(0,1, \geq 2)$.

Microbloedingen werden bij 36 (29.3\%) patiënten gezien. Zowel dag- als nachtsystolische en diastolische ambulante bloeddruk waren significant geassocieerd met de aanwezigheid en aantal microbloedingen (ordinale regressie analyses, odds ratio's 1.6-2.3 per standaarddeviatie toename in bloeddruk, gecorrigeerd voor 
leeftijd, geslacht, aantal antihypertensiva, asymptomatische lacunaire infarcten en witte stoflaesies). Deze resultaten benadrukken het belang van een hoge 24-uurs bloeddruklast als belangrijke risicofactor voor microbloedingen bij patiënten met een lacunaire beroerte.

Men suggereert dat de etiologie van microbloedingen verschilt per lokatie in de hersenen, parallel aan symptomatische hersenbloedingen: microbloedingen in diepe lokaties zouden gerelateerd zijn aan een hypertensie-gerelateerde vasculopathie, en microbloedingen in oppervlakkige lobaire lokaties aan amyloid angiopathie. We maakten daarom onderscheid tussen microbloedingen in diepe en in lobaire hersengebieden, en vonden dat verschillende bloeddrukkarakteristieken significant geassocieerd waren met diep (of gecombineerd diep en lobair) gelegen microbloedingen, maar niet met louter lobair gelegen microbloedingen. Deze resultaten ondersteunen het idee dat diep gelegen microbloedingen een specifieke marker zijn van de bloeddrukgerelateerde aandoening van de kleine hersenvaten. De subgroepen waren echter klein, en longitudinale en grotere onderzoeken zijn nodig om deze bevindingen te bevestigen.

In hoofdstuk 8 (algemene discussie) besprak ik de implicaties van onze bevindingen voor toekomstig onderzoek. Ten eerste de verdere toepassing van SELDI-TOF-MS in onderzoek naar de kleine hersenvaten: een van de meest beperkende factoren van deze techniek op dit moment is, dat het alleen eiwitten detecteert die in hoge concentraties aanwezig zijn. Dit beperkt het gebruik van SELDI-TOF-MS in onderzoek naar de kleine hersenvaten. Als nieuwe ontwikkelingen de techniek in de toekomst zullen verbeteren, zal de SELDI-TOF-MS benadering echter nog steeds waardevol kunnen blijken. Ten tweede strategieën van genetisch onderzoek bij lacunaire beroertes: de kandidaatgen-benadering, zoals onze onderzoeken naar het haptoglobine fenotype, alsmede genoomwijde screening en linkage-analyse bij aangedane familieleden, werden besproken. Ten derde de duidelijke associatie tussen 24-uurs ambulante bloeddrukkarakteristieken en de aanwezigheid van asymptomatische lacunaire infarcten en microbloedingen, versus de waarschijnlijk meer complexe relatie tussen bloeddruk en witte stoflaesies. Hierbij noemde ik de noodzaak tot longitudinale onderzoeken, en de invloed van andere factoren zoals cerebrale autoregulatie. Ten vierde mijn ideeën over de klinische en therapeutische gevolgen van onze bevindingen. Tenslotte stelde ik dat we de aandoening van de kleine hersenvaten nu niet langer als één ziekte-entiteit moeten blijven beschouwen. Behalve het onderscheiden van asymptomatische lacunaire infarcten, witte stoflaesies en microbloedingen, zijn er ook argumenten om diepe subcorticale van periventriculaire witte stoflaesies te onderscheiden, en diepe van lobaire microbloedingen. Omdat de verschillende laesies in verschillende vaatgebieden voorkomen en verschillen vertonen in pathogenese, zullen ze in toekomstig onderzoek uitgesplitst moeten worden. 
Dankwoord 


\section{Dankwoord}

Zes jaar lang heb ik aan mijn onderzoek gewerkt, met uiteindelijk dit proefschrift als resultaat. Daarbij heb ik steun gehad van velen. Niet alleen op wetenschappelijk gebied, maar ook daarbuiten, al was het maar door een spontane blijk van interesse.

Enkele personen verdienen een persoonlijk dankwoord.

Prof. dr. J. Lodder, beste Jan. Ik ben blij en trots dat ik de bul uit jouw handen mag ontvangen. Niemand anders zou de eer verdiend hebben om als promotor bij mijn onderzoek te staan. Ik heb in de afgelopen jaren veel van je geleerd. Natuurlijk vooral over het doen van onderzoek, maar ook over "het andere". En af en toe lees ik een vers uit de Dhammapada: "Arise! Watch. Sink not into the world".

Dr. R.J. van Oostenbrugge, beste Robert. Je had (en hebt) het altijd druk, maar wist op de juiste momenten altijd even tijd te maken voor overleg of het nakijken van een manuscript. Je combineert klinische taken en onderzoek, en speelt bovendien een actieve rol in de opleiding van assistenten tot neuroloog. Een voorbeeld! Dank voor je actieve en motiverende houding tijdens mijn opleiding en onderzoek.

Iris Knottnerus en Rob Rouhl. We vormden samen het laci-team en waren ooit van plan om een proefschrift in drie delen uit te geven. Uiteindelijk lopen de tijdspaden dan toch ietwat uiteen, maar zonder jullie was dit proefschrift er zeker niet gekomen. Bedankt dat jullie vandaag als paranimfen naast me staan en succes met het afronden van jullie eigen onderzoek.

Dr. Lisette van Raak en Anne Hilton. Wat een werk hebben jullie verricht om die 782 patiënten na te zoeken. Lisette, ooit schijn je gezegd te hebben dat je al die patiënten tot aan hun overlijden wilde volgen. Dat is je dus bijna gelukt! Ook dank voor de statistiekhulp.

Dr. Judith Bons en Dr. Will Wodzig van de afdeling klinische chemie. "Wij" de klinische input, "jullie" de labtechnische input, en samen werd een mooi resultaat uit het SELDI-TOF-MS onderzoek verkregen. Bedankt voor de samenwerking.

Prof. Joris Delanghe van het Universitair Ziekenhuis Gent. Uw enthousiasme voor haptoglobine fenotypes werkte aanstekelijk.

Dr. Léon Henskens, Dr. Bram Kroon en Prof. dr. Peter de Leeuw van de afdeling interne geneeskunde. Bedankt voor het uitwisselen van ideeën over de ABPMonderzoeken, en het ter beschikking stellen van de Hybrid-gegevens. 
Het neurologie-team van het Orbis Medisch Centrum Sittard/Geleen. Dank voor jullie medewerking om ook in Sittard/Geleen patiënten te includeren.

Al mijn collega's van de neurologie in Maastricht: jullie zijn een geweldige groep. De combinatie opleiding en onderzoek valt soms zwaar. Een plezierige werkomgeving met fijne collega's maakt heel veel goed. Ik hoop dat jullie dit als groep vast weten te houden.

De polimedewerksters. Jullie wisten direct wie je moest bellen als er weer eens een patiënt met een "kastje" voor de balie stond.

Prof. dr. Werner Mess en Ir. Erik Gommer van de afdeling klinische neurofysiologie. Al heb ik nog niet veel met de resultaten van de autoregulatiemetingen gedaan, leerzaam was het wel.

Pap en mam, en Sonja. Jullie hebben dan wel niet direct aan mijn proefschrift bijgedragen (wellicht vinden jullie een groot deel zelfs onbegrijpelijk), jullie waren wel mijn thuisbasis van waaruit ik de wereld ontdekte en mijn kunnen en kennen ontwikkelde. Bedankt voor de onvoorwaardelijke steun en liefde.

Menno. Bij jou blijft Julie gewoon Julie. Die doctor-titel zal daar niets aan veranderen. Gelukkig maar. 
Publications 


\section{Publications}

Staals JEA, Schrander-Stumpel CTRM, Hamers G, Fryns JP. Prenatal diagnosis of trisomy 12 mosaicism: normal development of a 3 years old female child. Genet Couns 2003;14:233-237.

Staals JEA, Visser MOJM, Hulsmans FJH, Luijckx GJR. Een negenjarige jongen met een drietal herseninfarcten ten gevolge van vertebralisdissectie. Tijdschr Neurol Neurochir 2003;104:221-227.

Staals JEA, de Krom MCTFM, van der Geest S. De hete zomer van 2003: hitteberoerte in Maastricht. Ned Tijdschr Geneesk 2004;148:1269-1272.

Staals J, Lodder J. Hypertension and lacunar stroke. Chapter 18 in: Mohler E, Townsend R, eds. Advanced therapy in hypertension and vascular disease. Hamilton: B.C.Decker 2006:152-160.

Cornips EMJ, Staals J, Stavast A, Rijkers K, van Oostenbrugge RJ. Fatal cerebral and cerebellar hemorrhagic infarction after thoracoscopic microdiscectomy. Case report. J Neurosurg Spine 2007;6:276-279.

Staals JEA, Braun KPJ, van Loo-Maurus KEH, Vles JSH. Stenting for coarctation of the aorta precipitating migraine with aura. J Child Neurol 2007;22:321-323.

Staals J, van Raak L, Hilton A, Lodder J. Differences in long-term survival in two lacunar stroke types: a 15-Year follow-up study in 782 cerebral infarct patients. Cerebrovasc Dis 2008;25:26-31.

Staals J, Bons JAP, van Oostenbrugge RJ, Knottnerus ILH, van Dieijen-Visser MP, Bouwman FG, Mariman EC, Delanghe JR, Lodder J, Wodzig WKWH. A SELDI-TOF-MS study in lacunar stroke with subsequent haptoglobin phenotyping. Curr Neurovasc Res 2008;5:93-98.

Rouhl RPW, van Oostenbrugge RJ, Knottnerus ILH, Staals JEA, Lodder J. VirchowRobin spaces relate to cerebral small vessel disease severity. J Neurol 2008;255:692-696.

Staals JEA, Mess WH, Reulen JPH. De neurofysiologische diagnose "albinisme": VEP-asymmetrie. Tijdschr Neurol Neurochir 2008;109:108-112. 
Staals J, Pieters BMA, Knottnerus ILH, Rouhl RPW, van Oostenbrugge RJ, Delanghe JR, Lodder J. Haptoglobin polymorphism and lacunar stroke. Curr Neurovasc Res 2008;5:153-158.

Gommer ED, Staals J, van Ootenbrugge RJ, Lodder J, Mess WH, Reulen JPH. Dynamic cerebral autoregulation and cerebrovascular reactivity: a comparative study in lacunar infarct patients. Physiol Meas 2008;29:1293-1303.

Pieters B, Staals J, Knottnerus I, Rouhl R, Menheere P, Kessels A, Lodder J. Periventricular white matter lucencies relate to low vitamin B12 levels in patients with small vessel stroke. Stroke 2009;40:1623-1626.

Rouhl RPW, van Oostenbrugge RJ, Damoiseaux JGMC, Debrus-Palmans LL, Theunissen ROMFIH, Knottnerus ILH, Staals JEA, Delanghe JR, Cohen Tervaert JW, Lodder J. Haptoglobin phenotype may alter endothelial progenitor cell cluster formation in cerebral small vessel disease. Curr Neurovasc Res 2009;6:32-41.

Staals J, van Oostenbrugge RJ, Knottnerus ILH, Rouhl RPW, Henskens LHG, Lodder $\mathrm{J}$. Brain microbleeds relate to higher ambulatory blood pressure levels in first-ever lacunar stroke patients. Stroke 2009;40:3264-3268.

Staals J, Henskens LHG, Delanghe JR, van Oostenbrugge RJ, Kessels AG, Kroon AA, de Leeuw PW, Lodder J. Haptoglobin phenotype correlates with cerebral deep white matter lesions in hypertensive patients. Submitted. 
Curriculum vitae 


\section{Curriculum vitae}

Juliana Elisabeth Antonia (Julie) Staals was born in Eindhoven, the Netherlands, on January 13th 1977. She grew up in Soerendonk, a little village in the Brabantse Kempen. She attended secondary school (VWO) at Philips van Horne SG in Weert. In 1995 she moved to Maastricht to study medicine at Maastricht University. She graduated in 2001. She started working as a resident at the department of neurology of the Maasland Hospital in Sittard (now Orbis Medical Centre), and in 2002 she switched to the department of neurology at the University Hospital Maastricht (now Maastricht University Medical Centre+). In 2003 she started her training to become a neurologist. In the same year she also started the current research project. In December 2009 she will finish her neurology training and will start working as a neurologist with neurovascular focus at the MUMC+. She lives with her partner Menno in Maastricht.

Juliana Elisabeth Antonia (Julie) Staals werd op 13 januari 1977 geboren in Eindhoven, Nederland. Ze groeide op in Soerendonk, een klein dorp in de Brabantse Kempen. Ze ging naar de middelbare school (VWO, Philips van Horne SG) in Weert. In 1995 verhuisde ze naar Maastricht om geneeskunde te gaan studeren aan de Universiteit Maastricht. Ze slaagde voor deze studie in 2001. Ze begon als arts-assistent op de afdeling neurologie van het Maaslandziekenhuis Sittard (tegenwoordig Orbisch Medisch Centrum) en in 2002 stapte ze over naar het academisch ziekenhuis Maastricht (tegenwoordig Maastricht Universitair Medisch Centrum ${ }^{+}$). In 2003 begon ze aan de opleiding tot neuroloog. In datzelfde jaar startte ze ook met het huidige onderzoeksproject. In december 2009 zal ze de opleiding tot neuroloog voltooien en zal ze gaan werken als neuroloog met neurovasculair aandachtsgebied in het $\mathrm{MUMC}^{+}$. Ze woont met haar partner Menno in Maastricht.

You may contact the author by email / U kunt de auteur per email bereiken : j.staals@mumc.nl 